Portland State University

PDXScholar

7-23-1976

\title{
A Study on the Stabilization of a Floating Platform
}

Waldo Lizcano

Portland State University

Follow this and additional works at: https://pdxscholar.library.pdx.edu/open_access_etds

Part of the Engineering Commons

Let us know how access to this document benefits you.

\section{Recommended Citation}

Lizcano, Waldo, "A Study on the Stabilization of a Floating Platform" (1976). Dissertations and Theses.

Paper 2441.

https://doi.org/10.15760/etd.2438

This Thesis is brought to you for free and open access. It has been accepted for inclusion in Dissertations and Theses by an authorized administrator of PDXScholar. For more information, please contact pdxscholar@pdx.edu. 
AN ABSTRACT OF THE THESIS OF Waldo Iizcano for the Master of Science in Applied Science presented July 23, 1976.

Title: A Study on the Stabilization of a Floating Platform. APPROVED BY MEMBERS OF THE THESIS COMMITTEE:
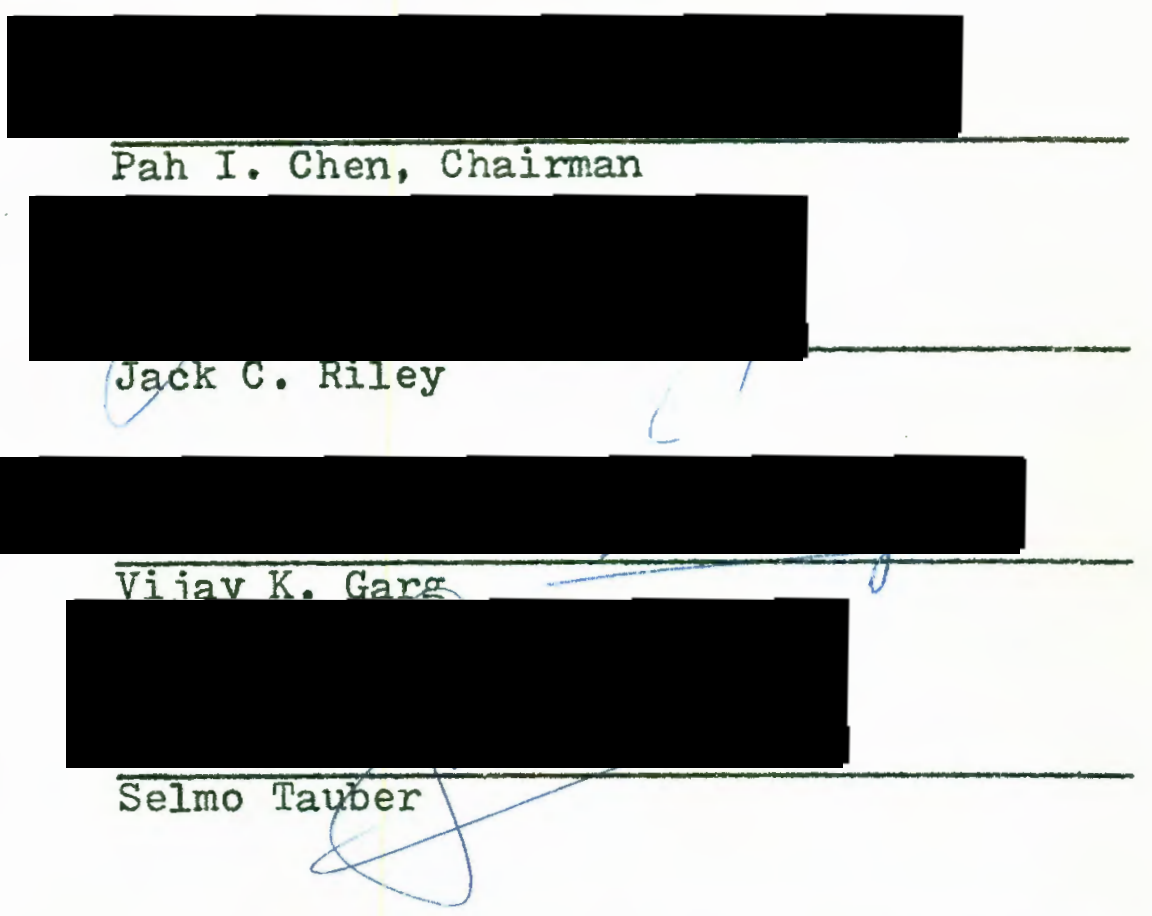

A new technique for controlling the pitching motion of a floating platform is proposed in this study.

The floating platform is assumed to be a simplified model of the columnar type rectangular platform supported by buoyant force from four cylindrical legs. The control arrangement consists of water jet streams immerging horizontally from two points located some distance apart on each 
leg to form a restoring couple. The water jet streams can be shifted to opposite horizontal positions or to the vertical downward positions according to control requirements. They are governed by angle control criterion as well as velocity control criterion. The goal is to attain the platform stability within a desirable range of angles about the equilibrium position.

The mathematical model goverming the motion of the floating platform consists of all pertinent forces along with a control variable. It is a second order nonlinear differential equation having no known exact solution. The state variable technique is employed to solve this equation numerically. The state transition equation is established and reduced to a sampled-data system. Two Fortran computer programs were written for the numerical process involved in the solution of this nonlinear equation.

This theoretical study shows that the platform motion under investigation is controllable by the proposed technique. The study also shows that major concern of this technique is the high energy consumption that would be required to maintain the stability of the structure. 


\title{
A STUDY ON THE STABIIIZATION OF
}

\section{A FLOATING PLATFORM}

by

WAIDO IIZCANO

A thesis submitted in partial fulfillment of the requirements for the degree of

\author{
MASTER OF SCIENCE \\ in \\ APPLIED SCIENCE
}

Portland State University

1976 
TO THE OFFICE OF GRADUATE STUDIES AND RESEARCH:

The members of the committee approve the thesis of Waldo Iizcano presented July 23, 1976.

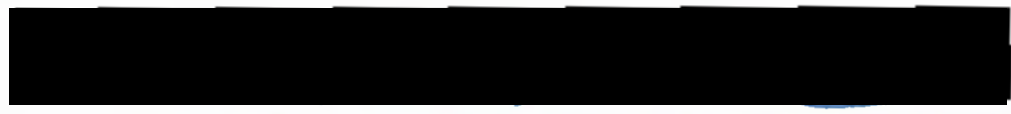

Pah I. Chen, Chairman

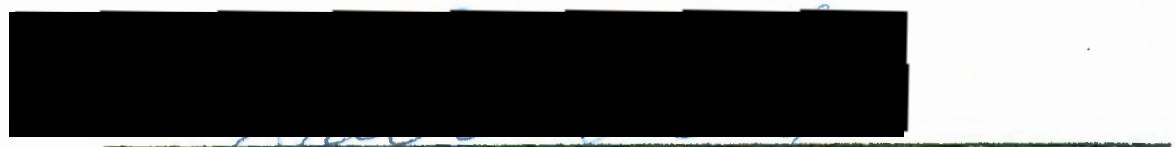

Jack C, Riley

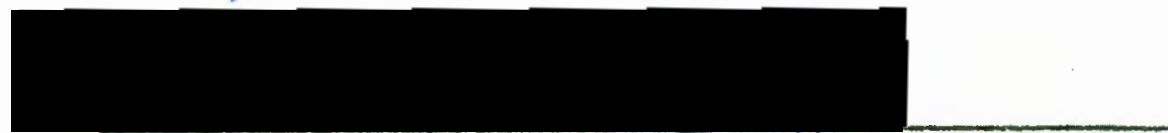

Vijay K. Garg

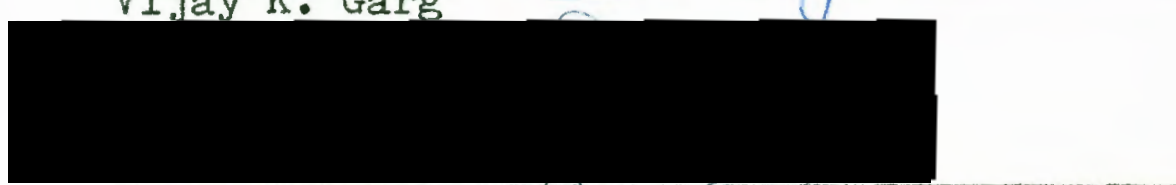

Selmo Tauber

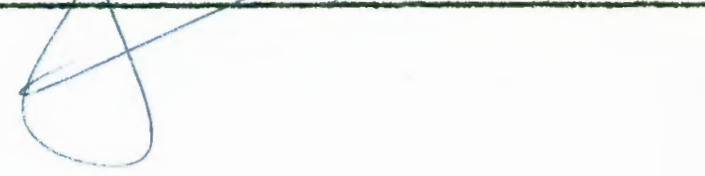

APPROVED :

Fred M. Youngd Heads

Departmen of Drgineering and Applied Science

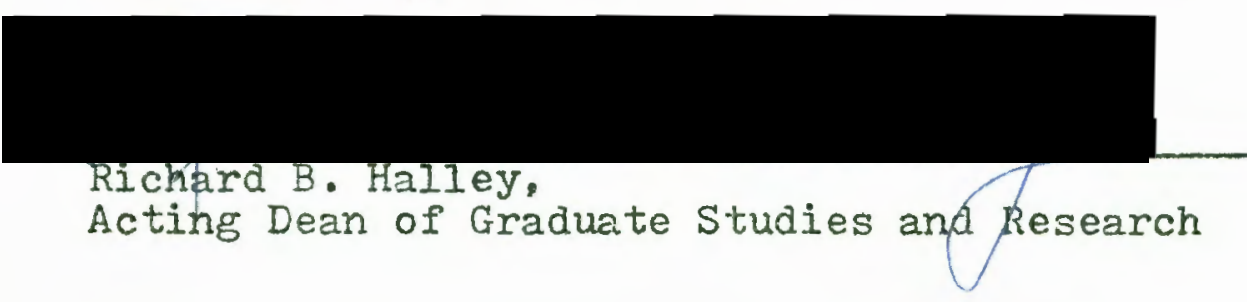




\section{ACKNOWLEDGEMENTS}

I wish to acknowledge the invaluable suggestions received from Dr. Pah I. Chen, Dr. Vijay K. Garg, and Professor Jack C. Riley during the preparation of this thesis.

I am especially indebted to Dr. Chen, my thesis advisor, for his wise advice, patient guidance, and continued encouragement in the development on this study.

I want to express my deepest gratitude to my wife, for her patience, encouragement, and untiring assistance throughout the preparation of this thesis. 
TABLE OF CONTENTS

PAGE

ACKNOWLEDGEWENTS . . . . . . . . . . . iii

LIST OF TABLES . . . . . . . . . . . . . vii

IIST OF FIGURES . . . . . . . . . . . . viii

CHAPTER

I LITERATURE REVIEN . . . . . . . . 1

II MATHEMATICAI MODEI . . . . . . . . 11

Free Body Diagram . . . . . . . 11

Assumptions ......... 13

Drag Moment . . . . . . . 15

Buoyant Moment . . . . . . . 17

In-Iine Moment........ . 19

Equation of Motion....... 22

III CONTROLLED MOTION OF THE PLATFORM . . . 24

Control Noment ........ 24

Control Criteria....... 26

Control Function ........ . 27

A Mathematical Model for the
Controlled Motion . . . . . 27

IV SOLUTION OF THE EQUATION OF MOTION .... 30

State Equations ...... . 30 
CHAPTER

PAGE

Solution of the State Transition

Equation........ 32

V COMPUTER SOLUTION . . . . . . . . . 37

Program "Platform Parameters" . . . 37

Program "Motion" . . . . . . 38

Subroutine Wald

Subroutine Trans

Subprogram Platform

VI ANAIYSIS OF RESUITS . . . . . . . . . 41

Independent Variables . . . . . . 41

Values of the Control Function and the Control Criteria...... 44

Amplitude of the Waves... . . . 48

Weight and Load of the Platform . . . 55

Platform Length . . . . . . . 58

Leg Length . . . . . . . . . 60

Leg Dianeter. . . . . . . . 61

Control Function ......... . 64

Conclusions and Recommendations . . 64

BIBLIOGRAPHY . . . . . . . . . . . . . . 69 APPENDIX

A OSCIULATORY GRAVITY WAVES . . . . . . 72

Wave Description . . . . . . . 72

Water Particle Description... . . 75

B STRUCTURAI MOMENT OF INERTIA . . . . . . . 77

Center of Gravity . . . . . . . 77 
Moment of inertia ......... 79

C NOMENCIATURE ............... 81

Symbols in the Text ......... 81

Symbols in the Computer Programs. . . 85

D FIOW CHARTS . . . . . . . . . . . 92

E COMPUTER PROGRAMS AND PRINTOUT . . . . . 109 


\section{IIST OF TABIES}

TABIE

PAGE

I Characteristics of the Structures . . . 43

II Moments of Inertia of the Structures . . . 44

II Coefficients of the Equation of Motion for

Different Structure Characteristics . 45

IV Wave Characteristics for Different

Wave Amplitudes . . . . . . . 46

V Coefficients of the Equation of Motion

for Different Wave Amplitudes . . . . 47

VI Characteristics of the Control

Requirements for Different Wave

Amplitudes . . . . . . . . . 54

VII Control Requirements for Different

Structure Characteristics . . . . 57

VIII Buoyancy Requirements for Different

Structure Characteristics . . . . 67 


\section{IIST OF FIGURES}

FIGURE

PAGE

1 Platform Free Body Diagram . . . . . . 12

2 Rotational Motion of a Leg . . . . . . 15

3 Parameters Involved in the Calculation

of the In-line Moment . . . . . 20

4 Control Moment of the Jet Streams . . . 25

5 Discrete Method of Calculation . . . . 32

6 Platform Motion with and without Control

(Wave Amplitude = $10 \mathrm{Ft}$ )..... 49

7 Platform Motion with and without Control

(Wave Amplitude = $20 \mathrm{Ft}$ ). . . . . 50

8 Platform Motion with and without Control

(Wave Amplitude = $30 \mathrm{Ft}$ )..... 51

9 Platform Motion with and without Control

(Wave Amplitude $=50 \mathrm{Ft}$ ) . . . . . 52

10 Platform Response for Different Values of

Weight and Load . . . . . . . 56

11 Platform Response for Different Values of

Platform Length . . . . . . . . 59

12 Platform Response for Different Values of

Leg Length . . . . . . . . . 62 
13 Pliuform Response for Different Values of Leg Diameter ... . . . . . 63

14 Control Position for Structure 1.... 65

15 Simple Oscillatory Wave Motion..... 73

16 Water Particle Motion Description . . . 76

17 Characteristics of the structure . . . 78

18 Flow Chart for the Program Platform

Parameters . . . . . . . . 92

19 Flow Chart for the Program Motion .... 97

20 Flow Chart for the Subroutine Wald . . . 99

21 Flow Chart for the Subroutine Trans .. 100

22 Flow Chart for the Subprogram Platform. . 103 
CHAPTER I

\section{IITERATURE REVIEW}

The first design of a floating platform can be traced back to 1924 when Armstrong $(1)^{1}$ received a patent on a Seadrome design for a landing field. However, his Seadrome was never built. Today, many offshore structures have been built and most of them are used in offshore oil drilling operations. Offshore structures are classified as fixed or. floating platforms. The fixed ocean platform extends from the ocean bottom to a deck above the water. Canted piles are driven through the hollow legs into the bottom sediment to secure the structure in place. The floating platform utilizes the buoyant force of the submerged portion to support the structure and its payload.

Bader (2), 1970, classifies ocean platform configurations as buoys, bottom mounted (supported) or semi-submersible, ship-shaped, jack-up, or fixed. The SPAR (Seagoing Platform for Acoustic Research) is a buoy 16 feet in diameter, 355 feet in length, and it has 12 watertight compartments for ballast and buoyancy tanks. The Fords design buoy (Altemate 2) was a development of a Naval Research labora-

1 Numbers in parentheses designate References at the end of the thesis. 
tory concept for a floating stable platform. The basic scheme was a 300 feet tower having a Iarge diameter doughnut shaped cylinder (toroid) for a base, which submerged 250 feet for testing 400 ton devices suspended to 6,000 foot depths. The buoys had low motion in severe seas but were limited in deck areas. Bedore (4) in 1972, added a new type of floating platform which he called the columnar type. Both the columnar and semi-submersible types have a low water plane area to minimize motion response to the waves. The shape of the underwater volume constitutes the principal difference between these two types. The columnar type has most of the underwater volume in the form of 3 to 100 spheroids and vertical tubes arranged in a circular or rectangular patterm, while the semi-submersible type has most of the underwater volume in the form of two to four horizontal hulls (tubes) oriented in one direction. Generally, although the semi-submersible platform has much lower drag than a columnar platform, it does have slightly greater motion response to waves. The project Mohole drilling platform was a semi-submersible one intended to provide a stable floating platform for drilling a hole through the crust of the earth in the ocean off Hawail. The Fords Alternate $7 \mathrm{~A}$ was also a semi-submersible platform designed to handle very large acoustic devices suspended from the platform by long cables. Both designs consisted of a pair of parallel underwater cylindrical hulls which supported a deck by 
means of vertical stability columns. The ship-shaped floating platforms range from a simple barge, a catamaran, to a circular hull shape. The ship Glomar Challenger was specially designed to carry out a National Science Foundation deep-sea drilling project where operation in the Atlantic and Pacific Oceans were accomplished in water depth of 3,000 to 20,000 feet.

In order to design the offshore structures and analize their motion, the forces acting on submerged piles and bodies have been a subject of investigation over the last thirty years. Morison et al, in 1950 (25) and in 1954 (26), investigated the force exerted by unbroken surface waves on cylinders and found that it was made up of two components, namely:

(1) drag force, $f_{D}$, proportional to the square of the velocity, and

(2) virtual mass force, $f_{I}$, or inertia force, proportional to the horizontal component of the accelerative force exerted on the mass of water displaced by the pile.

This force is known as the in-line force, and it is expressible by the well-known Morison's equation:

$$
F(t)=f_{D}+f_{I}
$$

where,

$$
f_{D}=0.5 c_{d}(2 R) \rho|U| U
$$

and 


$$
f_{I}=0.25 \pi \rho c_{m}(2 R)^{2} \mathrm{dU} / \mathrm{dt}
$$

Symbols contained in these equations are described as folIow:

$$
\begin{aligned}
F(t)^{2}= & \text { horizontal component of the total force (in-line } \\
& \text { foree) per unit length of cylinder, } \\
C_{d}= & \text { drag coefficient, } \\
C_{m}= & \text { inertia coefficient, } \\
P \quad= & \text { density of the water, } \\
2 R \quad= & \text { diameter of the pile, } \\
U \quad= & \text { horizontal component of the flow velocity at the }
\end{aligned}
$$

$\mathrm{dU} / \mathrm{dt}=$ horizontal component of the local acceleration of water particles at the cylinder.

One of the Morison's conclusions is that the theoretical value of 2.0 for $C_{m}$ seems adequate but more work needs to be done to correlate $\mathrm{C}_{\mathrm{d}}$ over the range of variables included in the analysis. Weigel et al, in 1957 (36), studied the wave forces at an exposed location near Davenport, California. They reported large lateral vibrations in their test pile until the pile was restrained at the lower end. In 1958, Keulegan and Carpenter (20) investigated the lift force as a dependent variable according to a dimensionless number $U_{m} T /(2 R)$, known as the Keulegan-Carpenter number or period parameter. The variable $U_{m}$ is the maximum horizontal

2 Symbols are explained as they first appear and also in Appendix C. 
component of flow velocity at the pile and $T$ is the wave period. The iift force acts on a vertical pile in the horizontal plane, its direction is normal to that of the wave propagation. Bidde in 1971 (6), investigated the ratio of the lift forces to the longitudinal forces and found that the magnitude of the lift force could not be neglected. Since in his experimental investigations the lift force reached 60 per cent of the Iongitudinal force. He also found the Keulegan-Carpenter number appeared to be a useful parameter to predict the ratio of the lift forces to the Iongitudinal forces.

Seulegan and Carpenter (20) also made one of the most systematic evaluations of the Fourier-averaged drag and inertia coefficients through measurements on submerged horizontal cylinders and plates in the node of a standing wave based on theoretically derived values for water particle velocities and accelerations. Sarpkaya in 1975 (31), measured the in-line and transverse forces on cylinders immersed in a fluid oscillating strictly sinusoidally. The drag and inertia coefficients that he found followed in essence those obtained by Keulegan and Carpenter. He also found both coefficients correlated reasonably well with the Keulegan-Carpenter number and that they did not have any correlation with the Reynolds number. The most important and previously little explored finding of Sarpkaya's investigation was that the transverse force acting on a cylinder 
was as large or larger than the in-line force.

In considering the iydrodymamic forces on an offshore structure, Burke (9), considered a modified form of the Morison equation that accounts for the relative motion of the structure and the water simultaneously. The equation related horizontal force per unit length on a vertical cylinder to horizontal fIuid and structure velocities and accelerations. The following is the modified equation used by Burke :

$$
\begin{aligned}
F(t)= & c_{d} \rho(2 R)|U-\dot{x}|(U-\dot{x}) / 2+\rho \pi(2 R)^{2}\left[c_{m} \dot{U}-\right. \\
& \left.\left(c_{m}-1\right) \ddot{x}\right]
\end{aligned}
$$

where, $\dot{U}$ is the water acceleration, $\dot{X}$ is the cylinder velocity, and $\ddot{X}$ is the cylinder acceleration. In solving his mathematical model the continuum forces in an exact model of an offshore structure were approximated by a number of discrete forces. In 1976, Hong and Brooks (17) analyzed the dynamic behavior and design of offshore caissons representing the hydrodymamic forces on the structure by the modified form of the Morison equation given by Equation (1-4). Because their empirical data showed a tremendous scatter in the calculated values for the inertia and drag coefficients, Hong and Brooks emphasized the difficulty for selecting proper values for these coefficients. In general, the inertia coefficient varies from 1.35 in a severe sea state to 2.0 at lower sea states and the drag coefficient varies 
similarly from 0.5 to 1.2 . A conservative response was predicted by ising values of 2.0 for the inertia coefficient and 0.7 for the drag coefficient.

In his analysis of wave forces on vertical cylinders, Johnson (18) claimed that the inertial forces become predominating when the cylinder diameter and the water depth are increasing. He started his study from the Morison equation and after certain simplifications as well as experimental investigations he found that there was a good agreement between the predicted and the measured forces when the forces were predominantly inertial. He also developed some analytical expressions for the maximu horizontal force and the distance at which the equation is valid. In the study of wave forces on submerged bodies, Garrison and Chow (13) stated that as the size of the object, in comparison to the incident wavelength, increases, scattering occurs and the Morison equation becomes invalid. They also stated that in the case of large submerged objects the simplified theory becomes invalid and a more basic approach such as the diffraction theory must be considered.

In 1975, Giannotti (14) classified the wave force action on a floating platform as a combined effect of quasistatic and dynamic loads. The former corresponded to a relatively low frequency wave induced load and the latter was considered as an equally critical type of load that results from hydrodynamic impacts occurring mainly at the bottom of 
the structure. This phenomenon is commonly known as slamming and the resulting dymamic loads are highly transient. In addition to the impact force acting on the whole platform and the localized action of the impact pressures, there is a vibrational effect associated with the occurrence of a slam. The later is known as whipping and is associated with the high resonant frequency of the Ioad. Following the initial impact this resonance causes a shudder throughout the entire hull.

In order to sense and record the motions of a vessel responding to wave force inputs, Merchant, Sergev, and orr (24) in 1975, developed the Vessel Response Monitoring System (VRMS). The vessel was considered to be a rigid body with six degrees of freedom corresponding to surge, sway, heave, yaw, pitch, and roll. Surge, sway, and heave are the translational motions along the longitudinal axis, the horizontal axis perpendicular to the longitudinal axis, and the vertical axis, respectively. Roll, pitch, and yaw are the associated rotational motions about the axes named above. With wave amplitudes ranging from 1.8 to 2.4 meters and wave frequency in the $0.9 \mathrm{rad} / \mathrm{sec}$ range the maximum pitch and roll angle of a loaded barge were reported to be \pm 6.0 and \pm 7.6 degrees, respectively. The authors claimed that their system and data reduction techniques are applicable to floating platforms in general.

A new technique for controlling the pitching motion 
of a floating structure is proposed in this study. The floating stricture is assumed to be a simplified model of the columnar type (4) rectangular platform supported by the buoyant force from four cylindrical legs. The control arrangement consists of water jet streams immerging horizontally from two points located some distance apart on each leg to form a restoring couple. The water jet streams can be shifted to reverse the couple or directed vertically downward according to control requirements. These choices are governed by angle control criterion as well as velocity control criterion. The goal is to maintain the platform stability within a desirable range of angles about the equilibrium position.

The Morison equation in modified form is used to determine the hydrodynamic forces on the legs of the platform. To simplify the problem the motion of water with respect to the platform legs, and the motion of the platform legs with respect to the water are considered independently. Thus the Morison equation is applied to the motion of water with respect to the platform legs. In the meantime, a drag force as defined by the Euler's number is used to determine the motion of the legs with respect to water. The final equation of motion of the floating structure consisting of all disturbing forces and control forces forms a second order nonlinear differential equation which has no known exact solution. A special method called the state variable tech- 
nique (19) is employed to solve this equation. In this wethod the state transition equation is reduced to a sampled-data system. Two Fortran computer programs are written for the numerical process involved in the solution of the equation of motion. 
CHAPTER II

\section{MATHEMATICAI MODEI}

This chapter contains the formulation of the mathematical model on which the present study is based.

In order to simplify the problem, a rectangular floating platform supported by buoyant forces on four cylindrical legs is considered. The pitch motion is analyzed when the platform is subjected to the action of forces generated by the motion of oscillatory gravity waves. The platform structure formed by the platform and its four supporting legs may rotate freely about an axis through its center of gravity. In this study, the vertical and horizontal forces acting on the platform are reduced to corresponding moments about the axis of rotation. The equation of motion of the platform is finally derived by applying the D'Alembert's dynamic equilibrium principle.

\section{FREE BODY DIAGRAM}

One possible platform configuration is shown in Figure 1 to facilitate the understanding of the mathematical model. This figure shows the moments produced by the vertical and horizontal forces acting on the plane of the motion when the rotating angle $\theta$ is increasing in the indicated 


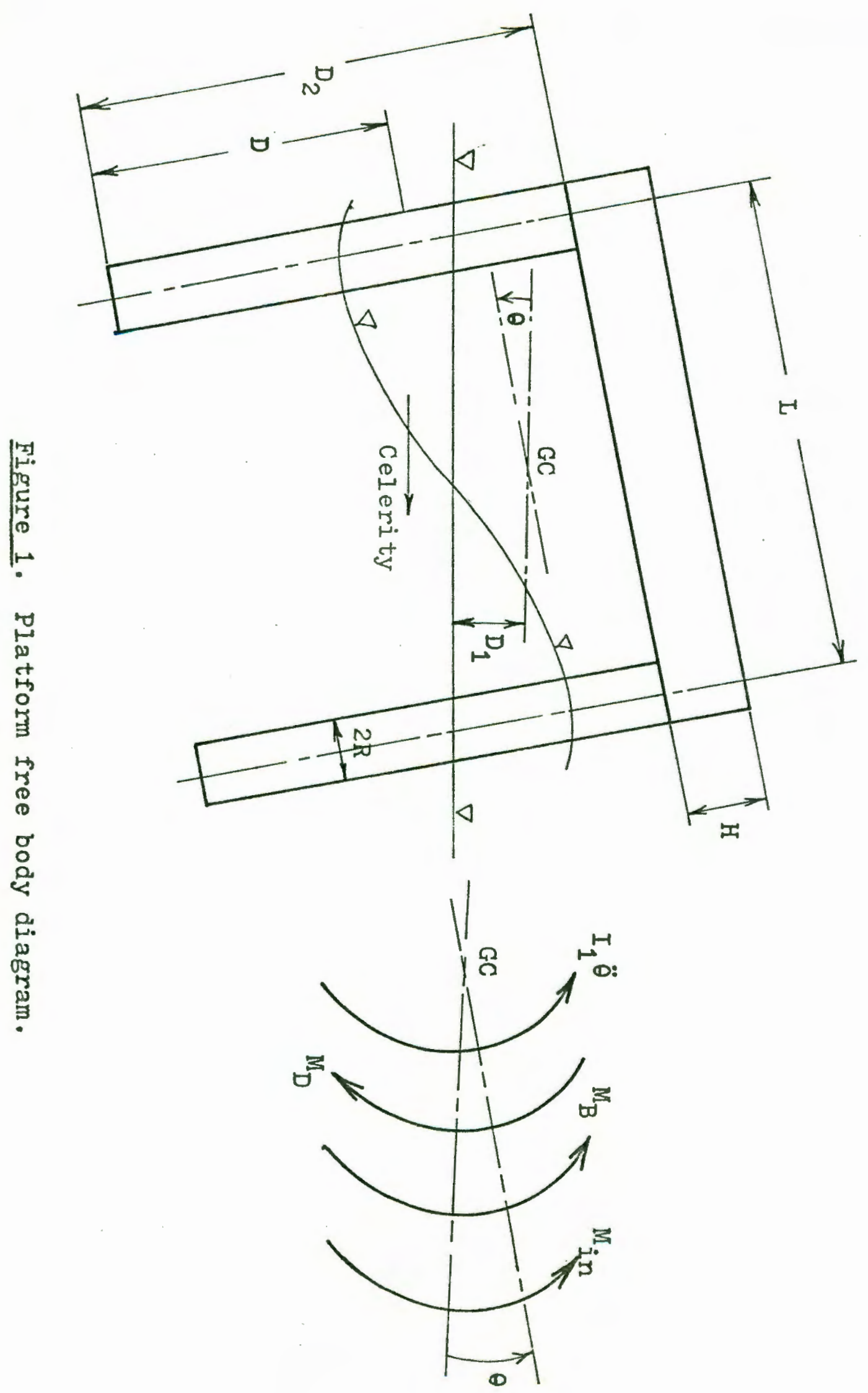


direction. In the following sections, each one of the moments show on Figure 1 will be described, explaired, and derived.

\section{ASSUMPTIONS}

The mathematical model under investigation is based on the following assumptions:

1. The oscillatory gravity waves consist of a simple oscillatory motion (see Appendix A) which can be described by :

$$
Y=A \sin (6.28 X / \lambda-w t)
$$

The origin of the X-axis is on the left leg of the platform. In order to account for the direction from which a wave may approach the legs of the floating platform a phase angle $\varnothing$ is introduced into Equation (2-1). Hence, the positions of the waves with respect to the reference level of the water surface are given by:

$$
Y_{1}=A \sin (-\not-w t)
$$

at the left leg, and by:

$$
\mathrm{Y}_{2}=A \sin (6.28 \mathrm{I} / \lambda-\varnothing-w t)
$$

at the right leg.

2. The displacement angle $\theta$ of the platform is small.

3. The floating platform is simply supported by the buoyant force on its legs. Each leg produces a displacement equivalent to one fourth of the overall weight of the floating structure. Therefore, the displacement of each leg 
is given by:

$$
D_{i}=w_{1} / 4+w_{2}
$$

where, $D_{i}$ is the displacement per leg; $W_{1}$ and $W_{2}$ are the weights of the platform and the leg, respectively.

4. The wave length is large compared with the leg diameter. Therefore, the water surface around the leg is considered to be horizontal.

5. Because of the wave movement the water on each leg will oscillate up and down around the reference level of the water surface at the equilibrium position. Due to this fact and depending on the ratio of the length $I$ of the platform to the wave length $\lambda$ of the oscillatory motion, the forces acting on the platform will make it rotate. This, also known as pitching motion.

6. The axis of the pitching motion goes through the center of gravity of the whole structure.

7. The waves have the same effect and relative position on both the left and right legs of the platform. Thus the problem is reduced to a single rotational degree of freedom.

8. The analysis presented here is also applicable to the rolling motion of the platform on the perpendicular plane with respect to the plane of motion. The extension of this analysis to the rolling motion is limited to the one-dimensional oscillatory motion of the waves on the plane of rotation. 
III. DRAG MOMENT

In order to find the magnitude of the drag moment the water is considered to be stationary and the rotational motion of the legs of the platform is considered to be relative to the water. Each leg is assumed to rotate by an angle $\theta$ about an axis through a point intersected by the center-line of the leg with the plane of the water. The rotational motion of a leg and the parameters involved in the drag moment are shown on Figure 2.
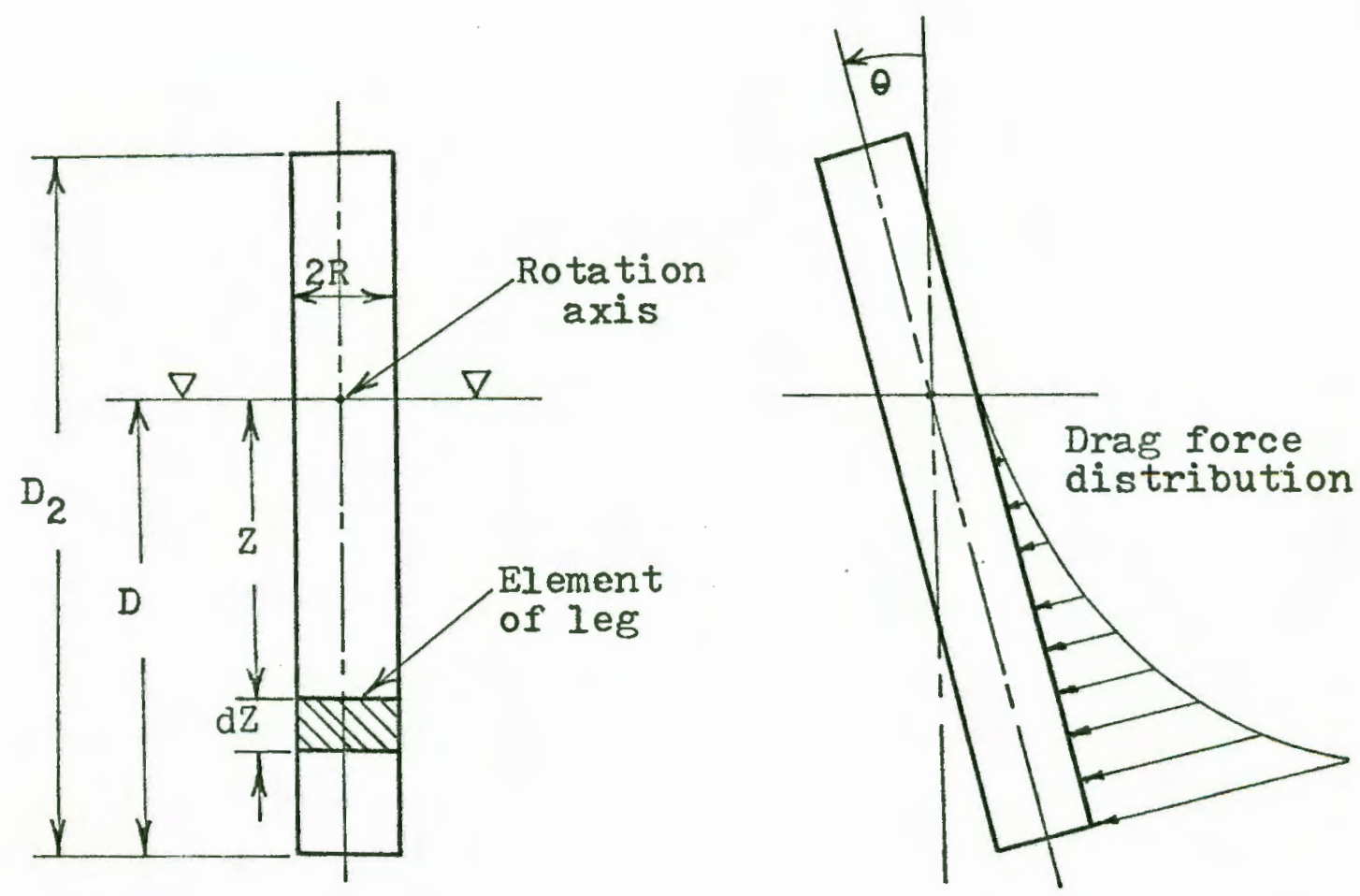

Figure 2. Rotational motion of a leg.

The drag force is found in terms of the dimensionless parameter $C_{D}$ called the Euler's number, the velocity $V_{1}$ of 
the main stream around the leg, the area of the leg $A_{1}$ normal to the direction of flow, and the density of the fluid $p$. In general the drag force is given by:

$$
F_{D}=C_{D} A_{1} \rho v_{1}^{2} / 2
$$

The net effect of this drag force on the rotational motion is a drag moment opposite to the direction of motion. The distribution of the drag force along the leg is shown on Figure 2. In order to find the drag moment about the axis of rotation of the leg, it is necessary to integrate the drag force distribution on each leg.

If the velocity $V_{1}$ in Equation $(2-5)$ is to be substituted by $Z \dot{\theta}$, the drag force on the differential leg element on Figure 2 is given by:

$$
\text { d } F_{D 1}=C_{D}(2 R)(d Z) \rho(Z \dot{\theta})^{2} / 2
$$

where,

$\mathrm{Z}=$ distance from the water reference level to the differential leg element,

$\mathrm{dZ}=$ length of the differential leg element,

$2 \mathrm{R}=\mathrm{leg}$ diameter, and

$\dot{\theta}=$ angular velocity of the leg.

Therefore, from Figure 2 and Equation (2-6) the differential drag moment $d M_{D 1}$ about the axis of rotation is

$$
d M_{D 1}=z\left(d F_{D 1}\right)=C_{D}(2 R) \rho \dot{\theta}^{2} z^{3}(d Z) / 2
$$

Integrating Equation (2-7) between $z$ equal to zero and $z$ equal to the length of the leg submerged in the water, $D$, 
we have

$$
\mathrm{M}_{D 1}=C_{D} \rho D^{4}(2 R) \dot{\theta}^{2} / 8
$$

Since the drag moment is opposite to the motion of the platform, Equation (2-8) can be transformed to

$$
M_{D 1}=C_{D} \rho D^{4}(2 R)|\dot{\theta}| \dot{\theta} / 8
$$

Assuming the drag moment is the same for each leg and its net effect on the motion is equivalent to $4 \mathrm{M}_{D 1}$ acting on the center of gravity of the whole structure, we get

$$
M_{D}=C_{D} P D^{4}(2 R)|\dot{\theta}| \dot{\theta} / 2
$$

Thus, Equation (2-10) gives the value of the drag moment as shown on Figure 1.

\section{BUOYANT MOMENT}

Because of the movement of the water due to the oscillatory gravity waves, the buoyant forces on the platform are given by:

$$
F_{B I}=(\gamma \pi / 4)(2 R)^{2}\left(D+Y_{1}\right)
$$

at each left leg, and

$$
F_{B R}=(\gamma \pi / 4)(2 R)^{2}\left(D+Y_{2}\right)
$$

at each right leg. In the above equations $\gamma$ is the specific weight of water and $Y_{1}$ and $Y_{2}$ are given respectively by Equations $(2-2)$ and $(2-3)$.

Assuming the platform is uniform and its load is uniformly distributed, we find that the gravity center of the 
whole structure is located at a distance equal to $\mathrm{I} / 2$ measured from the center-line of its legs with respect to the plane of motion. Therefore, the buoyant moment about the axis of rotation is given by:

$$
M_{B}=2(\gamma \pi / 4)(2 R)^{2}\left[\left(D+Y_{1}\right)-\left(D+Y_{2}\right)\right] L / 2
$$

The factor 2 is used to indicate two left and two right legs. Simplifying Equation $(2-13)$ we have

$$
M_{B}=(\gamma \pi / 4)(2 R)^{2}\left(Y_{1}-Y_{2}\right) I
$$

Substituting Equations $(2-2)$ and $(2-3)$ into Equation (2-14) we get

$$
\begin{aligned}
\mathrm{M}_{B}= & (\gamma \pi / 4) \mathrm{AL}(2 \mathrm{R})^{2}[\sin (-\not-w t)-\sin (6.28 \mathrm{I} / \\
& \lambda-\not-w t)]
\end{aligned}
$$

Since

$$
\sin A-\sin B=2 \cos \frac{1}{2}(A+B) \sin \frac{1}{2}(A-B)
$$
we obtain

$$
\begin{aligned}
M_{B}= & 2(\gamma \pi / 4) A I(2 R)^{2} \sin (-\pi L / \lambda) \cos (w t+\varnothing \\
& -\pi I / \lambda)
\end{aligned}
$$

Now, by making

$$
K_{2}=(Y \pi / 4) \mathrm{AI}(2 \mathrm{R})^{2}
$$

and replacing Equation (2-18) into Equation (2-17), we get the buoyant moment 


$$
M_{B}=2 K_{2} \sin (-\pi L / \lambda) \cos (w t+\not L-\pi L / \lambda)
$$

The coefficient $K_{2}$ in Equation $(2-19)$ will be called buoyancy coefficient.

\section{IN-LINE MONENT}

The in-line force (after Morison et al, Equations $(1-1),(1-2)$, and $(1-3)$ in Chapter I) should be considered in the equation of motion when unbroken surface waves are exerted on a fixed platform. This consideration is reasonable when the leg movement is relatively small.

Since this study deals with oscillatory gravity waves, the velocity $U$ in Equations $(1-2)$ and $(1-3)$ is given by:

$$
U=V_{x}=A_{2} w \sin (6.28 x / \lambda-\phi-w t)
$$

This is described by Equation $(A-19)$ in Appendix $A$ for waves approaching the platform with a phase angle $\varnothing$. The value $A_{2}$ is given by Equation $(A-15)$ as:

$$
A_{2}=\frac{A \cosh (6.28(D+Y) / \lambda)}{\sinh (6.28 D / \lambda)}
$$

The net effect of the in-line force on the platform may be replaced by an equivalent moment acting on the axis of rotation. This moment due to the in-line force has been referred to as the in-line moment $M_{i n}$ on Figure 1.

Figure 3 shows the general sketch of the variables involved in the calculation of the in-line moment about the axis of interest. The in-line moment is given by : 


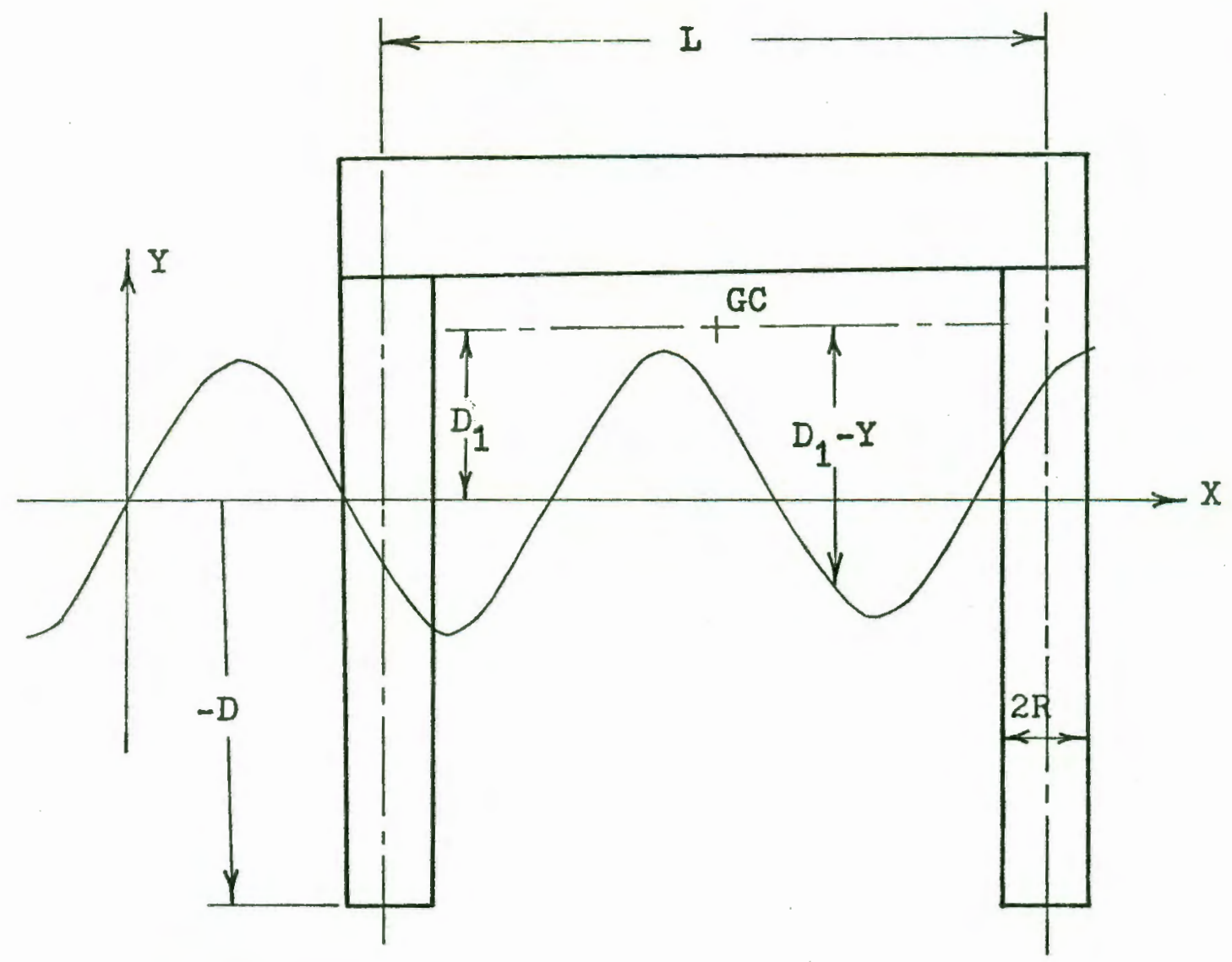

Figure 3: Parameters involved in the calculation of the in-line moment.

$$
\mathrm{M}_{\text {in }}=\mathrm{M}_{i}+\mathrm{M}_{\mathrm{d}}
$$

where, $\mathrm{M}_{i}$ and $\mathrm{M}_{\mathrm{d}}$ are the moments produced by the inertia and drag components of the in-line force, respectively. According to Figure 3 , we have

$$
\begin{aligned}
& M_{i}=\int_{-D}^{Y}\left[\left(D_{1}-Y\right) f_{I}\right] d Y \\
& M_{d}=\int_{-D}^{Y}\left[\left(D_{1}-Y\right) f_{D}\right] d Y
\end{aligned}
$$


Replacing the corresponding values given by Equations $(1-2),(1-3),(2-20)$, and $(2-21)$ into Equations $(2-23)$ and $(2-24)$, we get the following results:

$$
\begin{aligned}
M_{d}= & C_{f D}\left\{\frac{D_{1}}{4} \sinh \frac{4 \pi}{\lambda}(D+Y)+\frac{\pi D_{1}}{\lambda}(D+Y)+\frac{\lambda D}{2 \pi} \cdot\right. \\
& {\left[0.25 \sinh \frac{4 \pi}{\lambda}(D+Y)+2 \pi(D+Y) / \lambda\right]-\left[\frac{\lambda}{2 \pi}\right]^{2} . } \\
& {\left[\frac{\pi}{2 \lambda}(D+Y) \sinh \frac{4 \pi}{\lambda}(D+Y)-0.25 \cosh \frac{4 \pi}{\lambda}(D+Y)\right.} \\
& \left.\left.+\left(\frac{\pi}{\lambda}(D+Y)\right)^{2}+1 / 8\right]\right\}\left|\sin \left(\frac{6.28}{\lambda} X-\varnothing-w t\right)\right| . \\
& \sin \left(\frac{6.28}{\lambda} X-\varnothing-w t\right)
\end{aligned}
$$

where,

$$
C_{f D}=A^{2} C_{d} \rho(2 R) w^{2} /\left[2 \operatorname{Sinh}^{2}(6.28 D / \lambda)\right]
$$

and

$$
\begin{aligned}
M_{i}= & C_{f I}\left\{D_{1} \operatorname{Sinh} \frac{2 \pi}{\lambda}(D+Y)+0.159 \lambda\left[\operatorname{Cosh} \frac{2 \pi}{\lambda}(D+Y)\right.\right. \\
& \left.+1]-Y \operatorname{Sinh} \frac{2 \pi}{\lambda}(D+Y)\right\} \cos \left(\frac{6.28}{\lambda} X-\varnothing-w t\right)
\end{aligned}
$$

in which,

$$
c_{f I}=A c_{m} P(2 R)^{2} w^{2} \lambda /[8 \operatorname{Sinh}(6.28 \mathrm{D} / \lambda)]
$$

The value of the distance $D_{1}$ shown in Figure 3 in- 
volved in Equations $(2-23),(2-24),(2-25)$, and $(2-27)$ depends on the geometric characteristics and the loauing on the platform. For computer solution of Equations $(2-25)$ and $(2-27)$, the value of $D_{1}$ is given by Equation $(B-2)$ in $A p-$ pendix $B$.

\section{EQUATION OF MOTION}

Applying the D'Alembert's dynamic equilibrium principle for the free body diagram as shown on Figure 1, we get

$$
I_{1} \ddot{\theta}+M_{D}=M_{B}+M_{\text {in }}
$$

where, $I_{1}$ is the moment of inertia of the overall structure about the axis of rotation. This moment of inertia is a characteristic representing the structure geometry and its load distribution. For the numerical values needed in the computer solution of Equation (2-29), the moment of inertia $I_{1}$ is calculated according to Equation (B-7) in Appendix B. Substituting Equations $(2-10),(2-19)$, and $(2-21)$ into Equation $(2-29)$ we get

$$
\begin{aligned}
I_{1} \ddot{\theta}+C_{D} \rho D^{4}(2 R)|\dot{\theta}| \dot{\theta} / 2= & 2 K_{2} \sin (-\pi I / \lambda) \cos (w t \\
& -\varnothing-\pi I / \lambda)+M_{i}+M_{d}
\end{aligned}
$$

Let,

$$
c_{1}=C_{D} P D^{4}(2 R) / 2
$$

and substituting which into Equation $(2-30)$ we get 


$$
\begin{aligned}
I_{1} \ddot{\theta}+C_{1}|\dot{\theta}| \dot{\theta}= & 2 K_{2} \sin (-\pi I / \lambda) \cos (w t-\not- \\
& \left.\pi I_{1} / \lambda\right)+M_{i}+M_{d}
\end{aligned}
$$

Thus, Equation $(2-32)$ is the equation of motion of the floating platform under the stated constraints. 
CHAPTER III

CONTROLIED MOTION OF THE PIATFORM

In Chapter II we have considered a mathematical model for the motion of a floating platform under the action of oscillatory gravity waves. From the nature of the analysis, it is understandable that the platform will react according to wave characteristics. In order to maintain stability of the platform, a control function must be added to Equation $(2-32)$.

This chapter deals with the characteristics of the control function and its required criteria. When this control function is included in the equation of motion, a mathematical model for the controlled motion of the platform is obtained.

\section{CONTROL MOMENT}

The equation of motion of the floating platform derived in Chapter II is a result of the summation of moments about the axis of rotation. These moments are produced by the wave action on the platform. Therefore, in order to control the stability of the structure, an additional control moment must be added to counteract the wave action. Figure 4 proposes a simple way that this control mo- 


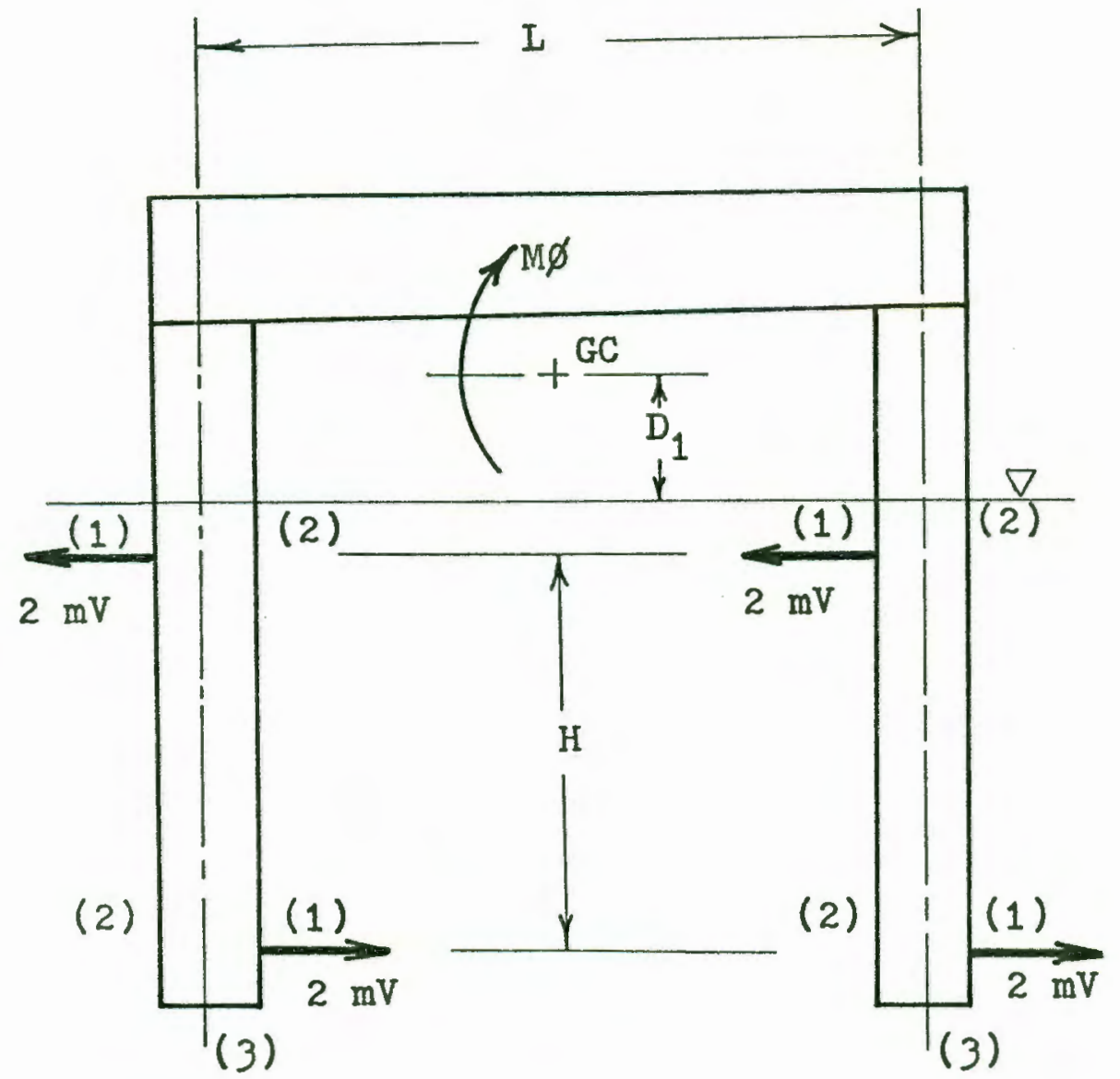

Figure 4. Control moment of the jet streams.

ment may be added to the structure. The control mechanism consists of two identical water jet streams immerging in opposite direction horizontally from each platform leg at a distance $H$ apart to form a couple. The net horizontal momentum of the water streams should be equal to zero in order to avoid lateral forces which may cause a translational motion of the structure.

The magnitude of this control moment is given by $M \not \varnothing=(4 \mathrm{~m}) \mathrm{VH}$ 
where, Mø is the control moment; $m$ is the mass of water per jet stream, and $V$ is the velocity of the jet stream.

For control purposes, it is necessary to assume that the control jet streams on Figure 4 may change direction by shifting from position (1), to (2) or (3), etc. This shifting of the control streams permits the control moment to be applied in either clockwise or counterclockwise directions as needed, or not to be applied if there is no need (that is, to shift to position (3)).

\section{CONTROL CRITERIA}

The permissible range of motion of the structure about the equilibrium position plays an important role in determining the direction of the control moment. If the angle of platform motion is within a permissible limit, the water jet streams will immerge from position (3) for no directional control. This fact implies that a reference value $\theta_{r}$ must me chosen to govern the shifting of the control streams to a corresponding position for stability purposes. This reference value will be called the angle control criterion.

When the angle goes through the reference value $\theta_{r}$ the magnitude of the velocity of the platform movement is also an important variable in controlling the motion of the platform. As assumed above, when the angle is within a certain permissible range of values, no control is needed, 
however, if the velocity at the reference angle is relatively high the next maximum displaceinent of the platform will go beyond the desired values. Due to this, a control of the maximum angular velocity of the platform is needed. In order to fulfill this control requirement, a velocity control criterion $\dot{\theta}_{r}$ will be selected for the maximum permissible value of the platform angular velocity.

In order to express the control criteria mathematically a new variable $\mathrm{N}$ is defined as follows: $\left.\begin{array}{l}N=+1 \text { : the streams immerge at position (1) } \\ N=0 \text { : the streams immerge at position (3) } \\ N=-1 \text { : the streams immerge at position (2) }\end{array}\right\}$

\section{CONTROI FUNCTION}

The control function in essence is a form of digital control function. This function is given by the product of the defined variable $\mathbb{N}$ and the control moment $M \varnothing$. Therefore,

Control function $=N M \varnothing$

IV. A MATHEMATICAL MODEL FOR THE CONTROLIED MOTION

Let us express Equation (2-32) by:

$$
I_{1} \ddot{\theta}+C_{1}|\dot{\theta}| \dot{\theta}=f(t)
$$

where,

$$
\begin{aligned}
f(t)= & 2 K_{2} \sin (-\pi I / \lambda) \cos (w t-\varnothing-\pi L / \lambda)+ \\
& M_{i}+M_{d}
\end{aligned}
$$


Rearranging Equation (3-4) we have

$$
I_{1} \ddot{\theta}=f(t)-C_{1}|\dot{\theta}| \dot{\theta}
$$

From this equation and the control criteria explained in Section II of this chapter, we can deduce that:

1. For $\theta$ values larger than $\theta_{r}$ the acceleration $\ddot{\theta}$ should be negative if the angle is to be kept within a permissible set of values.

2. For $\theta$ values smaller than $-\theta_{r}$ the acceleration $\ddot{\theta}$ should be positive if the angle is to be kept within a permissible set of values.

In order to accomplish the conditions stated above and according to Figures 1 and 3, Equation $(3-6)$ is reduced by $N$ M to give:

$$
I_{1} \ddot{\theta}=f(t)-C_{1}|\dot{\theta}| \dot{\theta}-N M \phi
$$

The values of $N$ are chosen according to the following conditions:

$$
\begin{aligned}
& \text { a. For } \theta \text { larger than } \theta_{r^{\prime}} N=+1 \\
& \text { b. For } \theta \text { smaller than }-\theta_{r^{\prime}} N=-1 \\
& \text { c. For } \theta \text { between }-\theta_{r} \text { and } \theta_{r^{\prime}} N=0
\end{aligned}
$$

Although the conditions stated by Equations (3-7) and (3-8) are necessary for keeping the angle within a prescribed limits, they are not sufficient for control purposes since the magnitude of the velocity should also be controlied as explained previously in section II. Therefore, it is necessary to rely on additional control conditions 
governed by a maximum permissible angular velocity $\dot{\theta}_{r}$. These additiural conditions together with those given by Equation (3-8) are as follows:

$$
\begin{aligned}
& \left.\begin{array}{l}
\text { a. For } \dot{\theta} \text { larger than } \dot{\theta}_{r}, N=+1 \\
\text { b. For } \dot{\theta} \text { smaller than } \dot{\theta}_{r}, N=-1 \\
\text { c. For the absolute value of } \dot{\theta} \text { smaller } \\
\text { than } \dot{\theta}_{r}, N \text { is defined by Equation (3-8) }
\end{array}\right\} \text { (3-9) } \\
& \text { Thus, Equations (3-9) and (3-7) represent the con- } \\
& \text { trolled mathematical model of the floating platform under }
\end{aligned}
$$
investigation. 


\section{CHAPTER IV}

\section{SOLUTION OF THE EQUATION OF MOTION}

The solution of the equation of motion derived in Chapters II and III is developed in this chapter. The state variable approach and the method proposed by Garg and Chen (12) are used for the solution of these equations.

The method is presented in two parts: (1) the definition of a set of state variables for writing the state equations of the controlled motion, and (2) the solution of the state transition equation of the controlled motion as a sampled-data system.

\section{STATE EQUATIONS}

The controlled equation of motion, given by Equation $(3-7)$, may be expressed by:

$$
\ddot{\theta}=f_{1}(t)-C_{2}|\dot{\theta}| \dot{\theta}-N M \phi_{1}
$$

where,

$$
\begin{aligned}
& f_{1}(t)=f(t) / I_{1} \\
& C_{2}=C_{1} / I_{1} \\
& M \phi_{1}=M \phi / I_{1}
\end{aligned}
$$

Equation (4-1) may also be given by: 


$$
\ddot{\theta}=-C_{2}|\dot{\theta}| \dot{\theta}+U(t)
$$

where,

$$
U(t)=f_{1}(t)-N \mathbb{M}_{1}
$$

Equation (4-4) is a function of time which represents the time input or driving function for Equation (4-3).

Let the state variables be defined as

$$
\begin{aligned}
& x_{1}=\theta \\
& x_{2}=\dot{\theta}
\end{aligned}
$$

Substituting the last two equations into Equation (4-3), we have

$$
\dot{\mathrm{x}}_{2}=-\mathrm{c}_{2}\left|\mathrm{x}_{2}\right| \mathrm{x}_{2}+\mathrm{u}(\mathrm{t})
$$

Equations $(4-5 b)$ and $(4-5 c)$ represent the two state equations of the controlled motion. They can be written in matrix form as

$$
\left[\begin{array}{l}
\dot{x}_{1} \\
\dot{x}_{2}
\end{array}\right]=\left[\begin{array}{lc}
0 & 1 \\
0 & -c_{2}\left|x_{2}\right|
\end{array}\right]\left[\begin{array}{l}
x_{1} \\
x_{2}
\end{array}\right]+\left[\begin{array}{c}
0 \\
u(t)
\end{array}\right]
$$

Figure 5 illustrates a discrete method of calculation for simplifying the solution of Equation (4-6). The term $\mathrm{C}_{2}\left|\mathrm{x}_{2}\right|$ of the coefficient matrix is assumed to be a constant for the sampling period $\mathrm{T}_{1}$. Thus, The term $\mathrm{C}_{2}\left|\mathrm{x}_{2}\right|$ in Equation (4-6) becomes a constant throughout the sampling period. Therefore, during a time period between $n T_{1}$ and $(n+1) T_{1}$ a new state variable $\mathrm{X}_{3}$ may be defined as 


$$
x_{3}=c_{2}\left|x_{2}\right|
$$

then,

$$
\dot{\mathrm{X}}_{3}=0 \text { for } \mathrm{nT}_{1} \leqslant t<(n+1) \mathrm{T}_{1}
$$

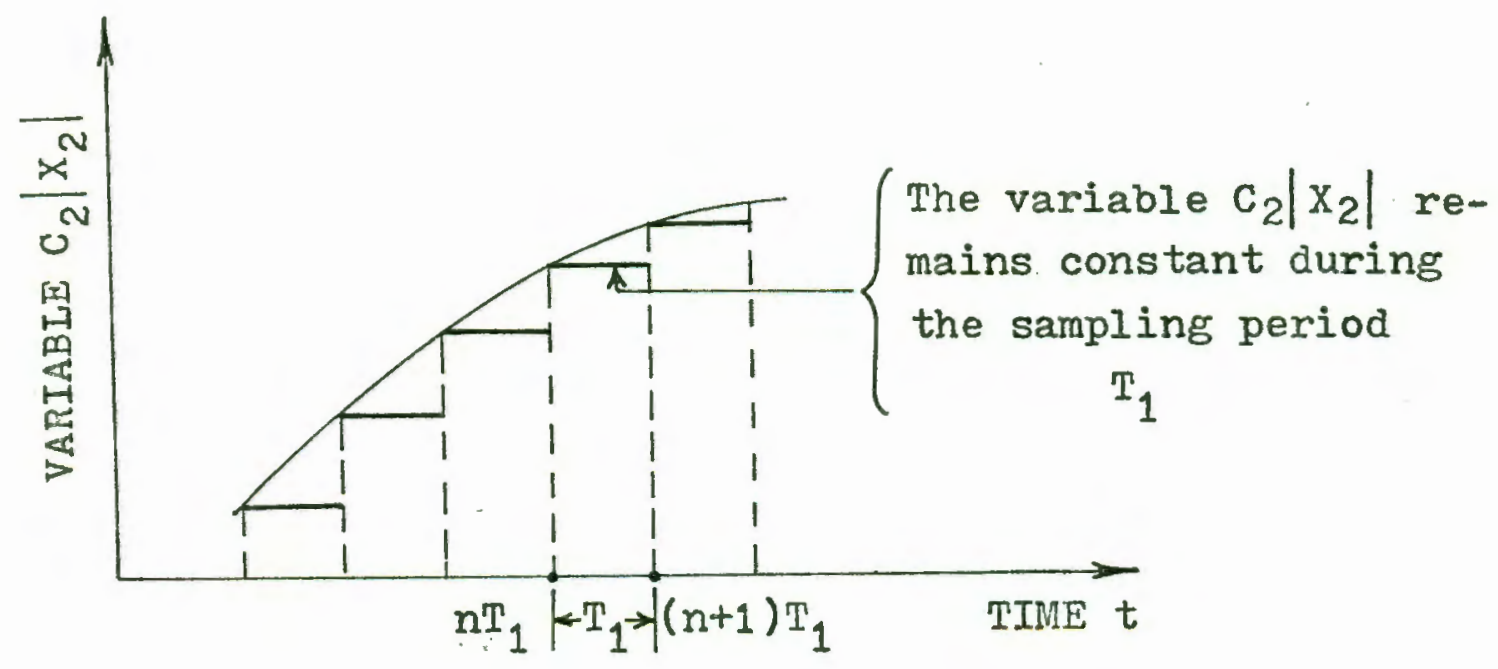

Figure 5. Discrete method of calculation.

Appiying the discrete method of calculation as stated above, the state equations of the controlled motion are given by:

$$
\left[\begin{array}{l}
\dot{x}_{1} \\
\dot{x}_{2} \\
\dot{x}_{3}
\end{array}\right]=\left[\begin{array}{lll}
0 & 1 & 0 \\
0 & 0 & -1 \\
0 & 0 & 0
\end{array}\right]\left[\begin{array}{l}
x_{1} \\
x_{2} \\
x_{3}
\end{array}\right]+\left[\begin{array}{c}
0 \\
u(t) \\
0
\end{array}\right]
$$

II. SOLUTION OF THE STATE TRANSITION EQUATION

The state transition equation for the solution (19) of Equation (4-9) is given by: 


$$
\vec{X}(t)=e^{A t} \vec{X}(0)+\int_{0}^{t} e^{A(t-T)} \vec{U}(T) d T
$$

where,

$$
e^{A t}=I+A t+A^{2} t^{2} / 2 !+A^{3} t^{3} / 3 !+\ldots+A^{m} t^{m} / m !+\ldots
$$

$(4-10 b)$

is the state transition matrix of the controlled motion. The symbol I in Equation (4-10b) represents the identity matrix. Let $t$ in Equation $(4-10 b)$ be equal to the sampling period $T_{1}$, then

$$
e^{A T_{1}}=I+A T_{1}+A^{2} T_{1}^{2} / 2 !+A^{3} T_{1}^{3} / 3 !+\ldots+A^{m_{T} m_{1}} / m !+\ldots
$$

The matrix $A$ in Equations (4-10) and (4-11) is called the coefficient matrix. The Vector $\vec{X}(t)$ is recognized as the state vector.

From the state equations for the problem under consideration, the state vector and the coefficient matrix are given by:

$$
\begin{aligned}
& \vec{x}(t)=\left[\begin{array}{l}
x_{1}(t) \\
x_{2}(t) \\
x_{3}(t)
\end{array}\right] \\
& {[A]=\left[\begin{array}{rrr}
0 & 1 & 0 \\
0 & 0 & -1 \\
0 & 0 & 0
\end{array}\right]}
\end{aligned}
$$


The state transition equation given by Equation (4-10) is useful only whes the initial time is defined to be at $t=0$. For the discrete method of calculation shown on Figure 5 the state transition process is divided into a sequence of transitions and a more flexible initial time must be chosen. Let the initial time be represented by $t_{1}$ and the corresponding initial state by $\vec{x}\left(t_{1}\right)$, and assume that the time input $U(t)$ is applied for $t$ larger than $t_{1}$, then Equation (4-10b) becomes

$$
\vec{X}(t)=e^{A\left(t-t_{1}\right)} \vec{X}\left(t_{1}\right)+\int_{t_{1}}^{t} e^{A(t-\tau)} \vec{U}(\tau) d \tau \quad(4-14)
$$

Let the sampling period $\mathrm{T}_{1}$ be defined by:

$$
\begin{aligned}
& t=(n+1) T_{1} \\
& t_{1}=n T_{1} \\
& t_{1} \leqslant \tau<t
\end{aligned}
$$

and substitution of these into Equation (4-14) yields

$$
\begin{aligned}
\vec{X}(n+1) T_{1}= & e^{A T_{1}} \vec{X}\left(n T_{1}\right)+\int_{n T_{1}}^{(n+1) T_{1}}\left[e^{A\left((n+1) T_{1}-\tau\right)} .\right. \\
& \vec{U}(T)] d T
\end{aligned}
$$

By making the following change of variable:

$$
\begin{aligned}
& \psi=(n+1) T_{1}-\tau \\
& d T=-d \psi
\end{aligned}
$$

and substituting these values into Equation (4-16), we get 


$$
\vec{X}(n+1) T_{1}=e^{A T_{1}} \vec{X}\left(n T_{1}\right)+\int_{T_{1}}^{0} e^{A}(-d \psi) \vec{U}(\tau)
$$

From the discrete method of calculation explained in Section I of this chapter it is permissible to assume that

$$
\vec{U}(\tau)=\vec{U}\left(n T_{1}\right)
$$

and substituting this into Equation $(4-18)$ yields

$$
\vec{X}(n+1) T_{1}=e^{A T_{1}} \vec{X}\left(n T_{1}\right)+\vec{U}\left(n T_{1}\right) \int_{0}^{T_{1}} e^{A \psi} d \psi \quad(4-20)
$$

Finally, by making the series expansion of $\mathrm{e}^{\mathrm{A} \psi}$ according to the definition given by Equation (4-11) and performing the integration between the prescribed limits, we get

$$
\begin{aligned}
\vec{X}(n+1) T_{1}= & e^{A T_{1}} \vec{X}\left(n T_{1}\right)+\left(I T_{1}+A T_{1}^{2} / 2 !+A^{2} T_{1}^{3} / 3 !+\ldots\right. \\
& \left.\ldots+A^{m-1} T_{1}^{m} / m !+\ldots\right) \vec{U}\left(n T_{1}\right)
\end{aligned}
$$

This is the solution of Equation (4-1) with the state variables as defined by Equations $(4-5)$. The state vector at a time equal to $T$ in Equation (4-19) determines the value of $n$ in Equation (4-21). If $T$ is equal to zero, $n$ is equal to zero. Thus, from Equation $(4-21)$ one can find the value of the state vector at a time $\mathrm{T}_{1}$. An accurate solution of Equation (4-1) requires the time interval $T_{1}$ to be small. In general, for any instant of time between $\mathrm{nT}_{1}$ and 
$(n+1) T_{1}$ the state vector $\vec{X}\left(n T_{1}\right)$ and the time input vector $\vec{U}\left(n T_{1}\right)$ are obtainable, and the value oI the state vector for the next instant of time, between $(n+1) T_{1}$ and $(n+2) T_{1}$ is calculable by Equation (4-21).

Thus, the solution of the equation of motion as given by Equation (4-21) has been reduced to a simple iterative process. This computational process may be facilitated by using a digital computer. 


\section{CHAPTER V}

\section{COMPUTER SOLUTION}

Two Fortran programs have been written in order to find the solution for the equation of motion. The programming technique is based on the state variable approach as described in Chapter IV. One of the programs deals with the calculation of the platform variables and parameters which are essential for the solution of the equation of motion. The other is related to the solution of the equation of motion. The flow charts for these programs are given in Appendix D. A list of both programs and sample results of the computer solution are given in Appendix $\mathrm{E}$.

\section{PROGRAM "PLATFORN PARAMETERS"}

This program finds the dependent variables of the platform, the characteristics of the waves to which the platform is exposed, and the power required for handling the water jet streams needed for the control of the platform motion. A flow chart for this program is given in Figure 18 in Appendix $D$.

The print-out of the program contains the values of variables as tabulated in Chapter VI. 


\section{PROGRAM "MOTION"}

This program consists of three parts: (1) the subroutine VAID for finding the in-line moment as explained in Chapter II; (2) the subroutine TRANS for calculating the power series given in Equations (4-11) and (4-21), and (3) the subprogram PLATFORM for performing the numerical calculation required by Equation (4-21). A flow chart of this program is show on Figure 19 in Appendix $D$.

\section{Subroutine WAID}

This subroutine was prepared for the purpose of calculating the drag and inertia components of the in-line moment. The drag and inertia components of the in-line moment are given by Equations $(2-25)$ and $(2-27)$, respectively. The results as presented have been divided by the moment of inertia of the whole structure. A flow chart of this program is given by Figure 20 in Appendix D.

\section{Subroutine TRANS}

The subroutine TRANS was prepared to find the transition matrix PHI, and the integral of the transition matrix THETA. The transition matrix is defined by Equation (4-11) and $i$ ts integral is given by Equations $(4-20)$ and $(4-21)$. A flow chart of this program is shown on Figure 21 in Appen$\operatorname{dix} D$. 


\section{Subprogram PIATFORM}

This program was written to find the value of the state vector $\vec{X}(t)$ as given by Equation (4-21) for the sampling period defined by Equation $(4-15)$. The response of the platform is obtainable by using the iterative process contained in the program. The control criteria as explained in Chapter III has been incorporated in the program.

The program inputs consist of the initial conditions of the platform, the coefficient matrix, and some variables processed by the program PLATFORN PARAMETERS. By using the subroutines TRANS and WAID we are able to find the state vector as defined in Equation $(4-21)$.

The program outputs provide the coefficients of the equation of motion, the initial state vector, the transition matrix, and nine columns whose headings correspond to following descriptions:

TIME

Sampling period in hundredths of a second.

ANGLE Platform angle $\theta$ in radians.

VELOCITY Platform angular velocity $\dot{\theta}$ in radians per second.

DANPEN Value of the nonlinear term, $\mathrm{c}_{2}|\dot{\theta}| \dot{\theta}$, as given by Equation (4-1).

ACCELERATION Angular acceleration $\ddot{\theta}$ in $\mathrm{rad} / \mathrm{sec}^{2}$. WAVE Position of the wave at the left legs of the platform. 
TIME INPUT Value of the time function $f_{1}(t)$ contained in the equation of motion.

INPUT Value of $U(t)$ contained in Equation $(4-4)$.

CONTROL Value of the control variable $\mathrm{N}$ as defined in Chapter III.

The program prints a line for each twenty hundredths $(0.2 \mathrm{sec})$ of a second of TAU increment if the value of $\mathrm{N}$ remains unchanged. But if $\mathrm{N}$ changes between two consecutive iterations, the program prints a line for each change of $\mathrm{N}$. This printing process saves print-out time. A flow chart of this program is shown on Figure 22 in Appendix D. 


\section{CHAPTER VI}

\section{ANALYSIS OF RESULTS}

In this chapter, the response of the platform as a function of several independent variables is presented. Variables which are considered as independent are: the amplitude of the waves, the weight and load of the platform, the platform length, the leg length, and the leg diameter.

The computer results for the solution of the equation of motion are shown in plots to facilitate comparison. Also, the computer results for the program PLATFORM PARAMETERS corresponding to several different values of the independent variables are presented by Tables II through VIII.

\section{INDEPENDENT VARIABLES}

In order to make the study systematically, parameters pertinent to a floating structure have been selected. This structure will be called the reference structure. The magnitude of the independent variables are varied with respect to the original value of the reference structure for each investigation. Based on ten foot wave amplitude, the response of the floating platform due to a certain set of independent variables is analyzed for eight different structures. These structures and their corresponding independent 
variables are as follow

1. Structure 1 and Structure 2 : weight and load of the platform.

2. Structure 3 and Structure 4 : length of the platform.

3. Structure 5 and structure 6 : length of the Ieg.

4. Structure 7 and Structure 8 : diameter of the $1 \mathrm{eg}$.

The dimensions of the structures are given in Table I. The computer output of the moments of inertia and the coefficients in the equation of motion for these structures are tabulated respectively in Table II and Table III.

The responses of the reference structure for wave amplitudes of $10,20,30$, and 50 feet are investigated. The wave characteristics and the corresponding coefficients in the equation of motion are tabulated in Table IV and Table $\mathrm{V}$, respectively. The initial conditions of the controlled response of the platform are characterized by an angle equal to 0.02 radians and an angular velocity equal to zero.

A variation of the independent variables changes the magnitude of the coefficients in the equation of motion. Because of the complexity involved in the expression for the in-1ine moment (Equations $(2-25),(2-26),(2-27)$, and $(2-28))$, the analysis of results will be focused on the effects produced by the moment of inertia, the buoyant moment, and the control moment with respect to the corresponding values of the reference structure. 


\section{TABLE I}

CHARACTERISTICS OF THE STRUCTURES

\begin{tabular}{|c|c|c|c|c|c|c|}
\hline \multicolumn{4}{|c|}{ Platform } & \multicolumn{3}{|c|}{ Leg } \\
\hline $\begin{array}{l}\text { weight } \\
\text { and load } \\
\text { (lb) }\end{array}$ & $\begin{array}{l}\text { length } \\
\text { (ft) }\end{array}$ & $\begin{array}{l}\text { width } \\
(f t)\end{array}$ & $\begin{array}{c}\text { height } \\
\text { (ft) }\end{array}$ & $\begin{array}{l}\text { weight } \\
\text { (Ib) }\end{array}$ & $\begin{array}{l}\text { length } \\
(f t)\end{array}$ & $\begin{array}{c}\text { diameter } \\
(f t)\end{array}$ \\
\hline
\end{tabular}

$\begin{array}{llllllll}\begin{array}{l}\text { Reference } \\ \text { structure }\end{array} & 7 \times 10^{6} & 200 & 150 & 20 & 12 \times 10^{5} & 300 & 15 \\ \text { Structure 1 } & 15 \times 10^{6} & 200 & 150 & 20 & 12 \times 10^{5} & 300 & 15 \\ \text { Structure 2 } & 25 \times 10^{6} & 200 & 150 & 20 & 12 \times 10^{5} & 300 & 15 \\ \text { Structure 3 } & 7 \times 10^{6} & 400 & 150 & 20 & 12 \times 10^{5} & 300 & 15 \\ \text { Structure 4 } & 7 \times 10^{6} & 500 & 150 & 20 & 12 \times 10^{5} & 300 & 15 \\ \text { Structure 5 } & 7 \times 10^{6} & 200 & 150 & 20 & 12 \times 10^{5} & 450 & 15 \\ \text { Structure 6 } & 7 \times 10^{6} & 200 & 150 & 20 & 12 \times 10^{5} & 800 & 15 \\ \text { Structure 7 } & 7 \times 10^{6} & 200 & 150 & 20 & 12 \times 10^{5} & 300 & 20 \\ \text { Structure 8 } & 7 \times 10^{6} & 200 & 150 & 20 & 12 \times 10^{5} & 300 & 25\end{array}$




\section{TABLE II}

MOMENTS OF INERTIA OF THE STRIT,TURES

$$
\begin{gathered}
\text { Moment of } \\
\text { inertia }
\end{gathered}
$$

$$
\left(I b-f t-s e c^{2}\right)
$$

Reference

$$
\text { structure }
$$$$
4.1193 \times 10^{9}
$$

$$
5.5971 \times 10^{9}
$$

Structure 1

$6.9726 \times 10^{9}$

Structure 2

$6.2932 \times 10^{9}$

Structure 3

$7.9237 \times 10^{9}$

Structure 4

$8.1366 \times 10^{9}$

Structure 6

$2.3552 \times 10^{10}$

Structure 7

$4.1193 \times 10^{9}$

Structure 8

$4.1193 \times 10^{9}$

II. VALUES OF THE CONTROL FUNCTION AND THE

\section{CONTROI CRITERIA}

To achieve the stability of the platform, it is necessary to assign values to the control function according to Equations $(3-2)$ and $(3-3)$. Based on several data, the buoyancy coefficient has been found to be a good reference for setting the values of this function. A ratio of the magnitude of the control function $\mathbb{M} \varnothing$ to the buoyancy coefficient $K_{2}$ equal to 4 has been found to be usefull for accomplishing the stability of the floating structure.

In order to keep the stability of the structure with- 
COEFFICIENTS OF THE EQUATION OF MOTION FOR DIFFERENT STRUCTURE CHARACTERISTICS
C1
$\left(1 / \sec ^{2}\right)$
$C F D$
$\left(1 / \sec ^{2}\right)$
CFI
$\left(1 / \sec ^{2}\right)$
CMO
(dimensionless)
$\left(1 / \sec ^{2}\right)$

Reference

structure

$1.4356 \times 10^{1}$

$5 \cdot 5905 \times 10^{-3}$

$7.2452 \times 10^{-10}$

$3.2877 \times 10^{-6}$

Structure 1

$1.0560 \times 10^{1}$

$4.1040 \times 10^{-3}$

$8.2058 \times 10^{-10}$

$4.5235 \times 10^{-6}$

$2.2362 \times 10^{-2}$

Structure 2

8.4810

$3.2940 \times 10^{-3}$

$5.7881 \times 10^{-10}$

$3.6311 \times 10^{-6}$

$1.6410 \times 10^{-2}$

Structure 3

$7.3000 \times 10^{-3}$

$6.4130 \times 10^{-10}$

$4.0232 \times 10^{-6}$

$1.3170 \times 10^{-2}$

Structure 4

$7.2480 \times 10^{-3}$

$5.0934 \times 10^{-10}$

$3.1953 \times 10^{-6}$

$2.9200 \times 10^{-2}$

7.4630

$2.8230 \times 10^{-3}$

$1.5353 \times 10^{-11}$

$5.4746 \times 10^{-6}$

$2.8990 \times 10^{-2}$

Structure 5

$4.7630 \times 10^{1}$

$9.7530 \times 10^{-4}$

$1.6177 \times 10^{-15}$

$3.3031 \times 10^{-9}$

$1.1290 \times 10^{-2}$

Structure 6

$2.0330 \times 10^{2}$

$9.9140 \times 10^{-3}$

$1.3063 \times 10^{-9}$

$1.0927 \times 10^{-5}$

$3.9010 \times 10^{-3}$

Structure ?

$1.9140 \times 10^{1}$

$1.5490 \times 10^{-2}$

$1.6329 \times 10^{-9}$

$1.7073 \times 10^{-5}$

$3.9650 \times 10^{-2}$

$2.3920 \times 10^{1}$

$6.1960 \times 10^{-2}$ 
TABLE IV

WAVE CHARACTERISTICS FOR DIFFERENT WAVE AMPLITUDES

$\begin{array}{ccccccr}\begin{array}{c}\text { Wind } \\ \text { velocity } \\ \text { (mots) }\end{array} & \begin{array}{c}\text { Fetch } \\ \text { (knots*sec) }\end{array} & \begin{array}{c}\text { Period } \\ \text { (sec) }\end{array} & \begin{array}{c}\text { Amplitude } \\ (\mathrm{ft})\end{array} & \begin{array}{c}\text { Wavelength } \\ \text { (ft) }\end{array} & \begin{array}{r}\text { Frequency } \\ \text { (rad/sec) }\end{array} & \begin{array}{r}\text { Celerity } \\ (\mathrm{ft} / \mathrm{sec})\end{array} \\ 30 & 145 & 9.50 & 10 & 462.39 & 0.6611 & 48.65 \\ 55 & 172 & 13.42 & 20 & 922.52 & 0.4681 & 68.73 \\ 60 & 325 & 16.44 & 30 & 1383.78 & 0.3822 & 84.17 \\ 100 & 325 & 21.22 & 50 & 2306.30 & 0.2960 & 108.66\end{array}$


TABLE V

COEFFICIENTS OF THE EQUATION OF MOTION FOR DIFFERENT WAVE AMPIITUDES

Amplitude

(ft)

10

20

30

50
C1

(dimensionless) $\quad\left(1 / \mathrm{sec}^{2}\right)$

$1.4356 \times 10^{1}$

$1.4356 \times 10^{1}$

$1.4356 \times 10^{1}$

$1.4356 \times 10^{1}$
$5.5905 \times 10^{-3}$

$1.1150 \times 10^{-2}$

$1.6730 \times 10^{-2}$

$2.7880 \times 10^{-2}$
CFD

$\left(1 / \sec ^{2}\right)$

$7.2452 \times 10^{-10}$

$3.2081 \times 10^{-10}$

$9.9289 \times 10^{-9}$

$3.1729 \times 10^{-8}$
CFI

$\left(1 / \sec ^{2}\right)$

$3.2877 \times 10^{-6}$

$4.2106 \times 10^{-6}$

$1.3350 \times 10^{-5}$

$8.1803 \times 10^{-5}$
CMO $\left(1 / \sec ^{2}\right)$ $2.2362 \times 10^{-2}$

$4.4610 \times 10^{-2}$

$6.6920 \times 10^{-2}$

$1.1500 \times 10^{-1}$ 
in a permissible range, it is necessary to assign values to the control ciiteria $\theta_{r}$ and $\dot{\theta}_{r}$ as defined in chapter III. In the present study, a value of $\theta_{r}$ equal to 0.02 radians has been selected, and from the experience of several trials a value of $\dot{\theta}_{r}$ equal to 0.05 radians per second has been found to be capable of keeping the platform motion within a permissible range of values.

\section{AMPIITUDE OF THE WAVES}

Pigures 6 through 9 show the response of the refererence structure due to different wave amplitudes. Each figure indicates the position of the wave at the left legs of the platform for the controlled and uncontrolled response of the platform. These figures also show the inprovement of the response when the control function is applied. For example, Figure 6 shows the improvement in the response of the platform when a ratio of the control function to the buoyancy coefficient equal to $\operatorname{six}\left(M \phi / \mathrm{K}_{2}=6\right)$ is used. The characteristics of the control requirements for different wave amplitudes are given in Table VI.

The initial conditions for the uncontrolled response of the platform in Figures 6, 7, and 9 are characterized by an angle equal to 0.20 radians and an angular velocity equal to 0.00 radians per second. For the uncontrolled response of the platform in Figure 8 it is characterized by an angle equal to 0.00 radians and an angular velocity 


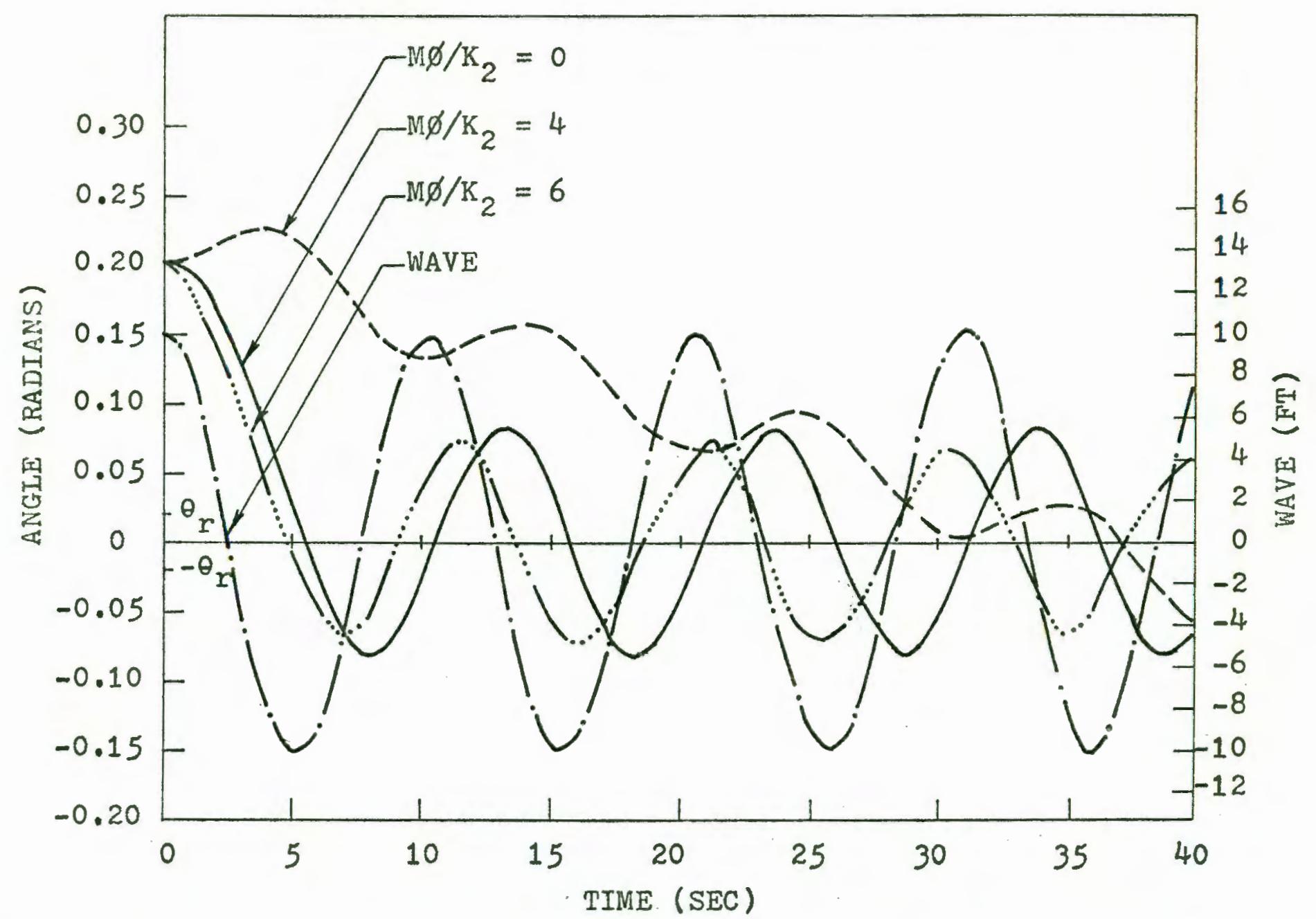

Figure 6. Platform motion with and without control (wave amplitude $=10 \mathrm{Ft}$ ). 


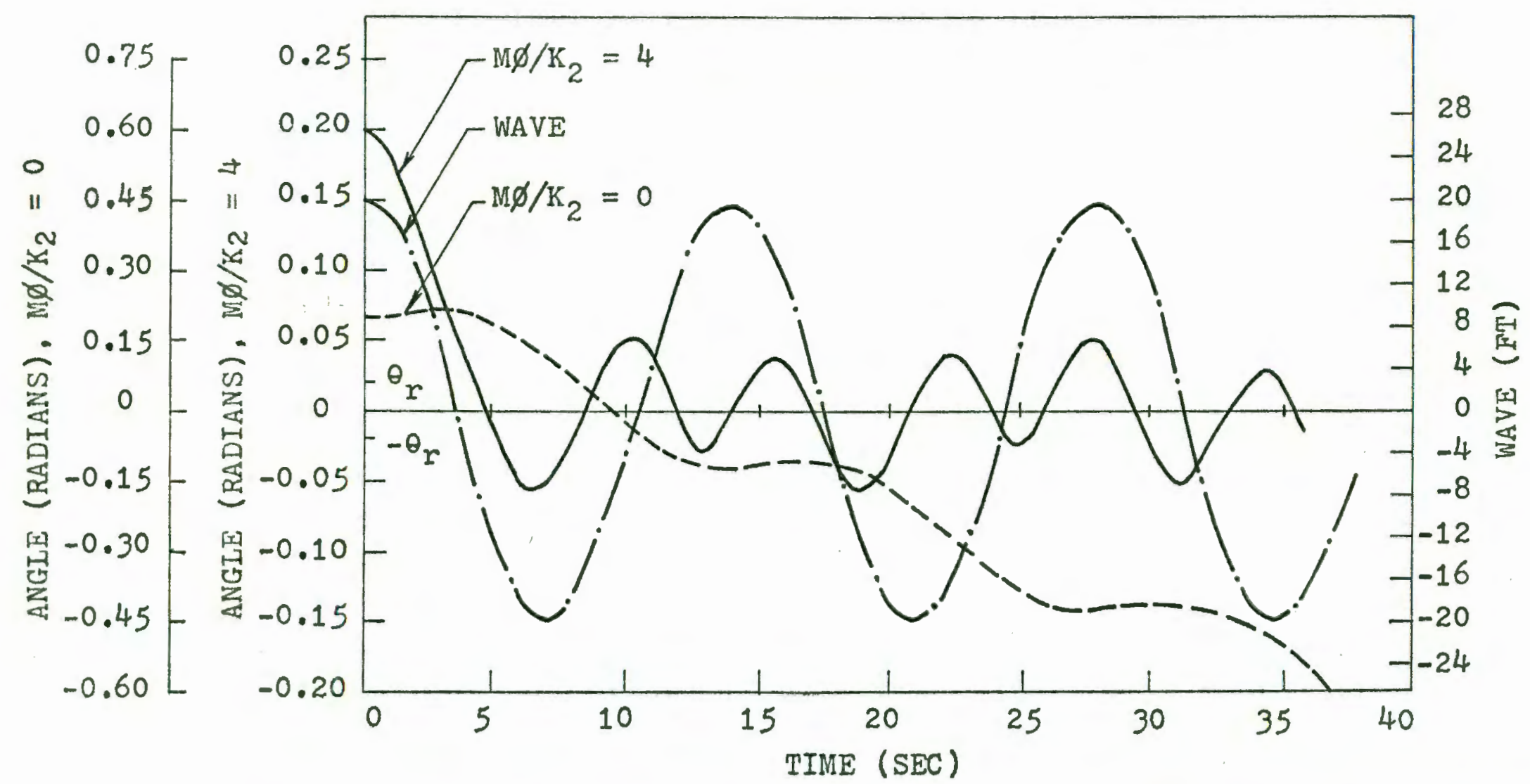

Figure 7. Platform motion with and without control (wave amplitude $=20 \mathrm{Ft}$ ). 


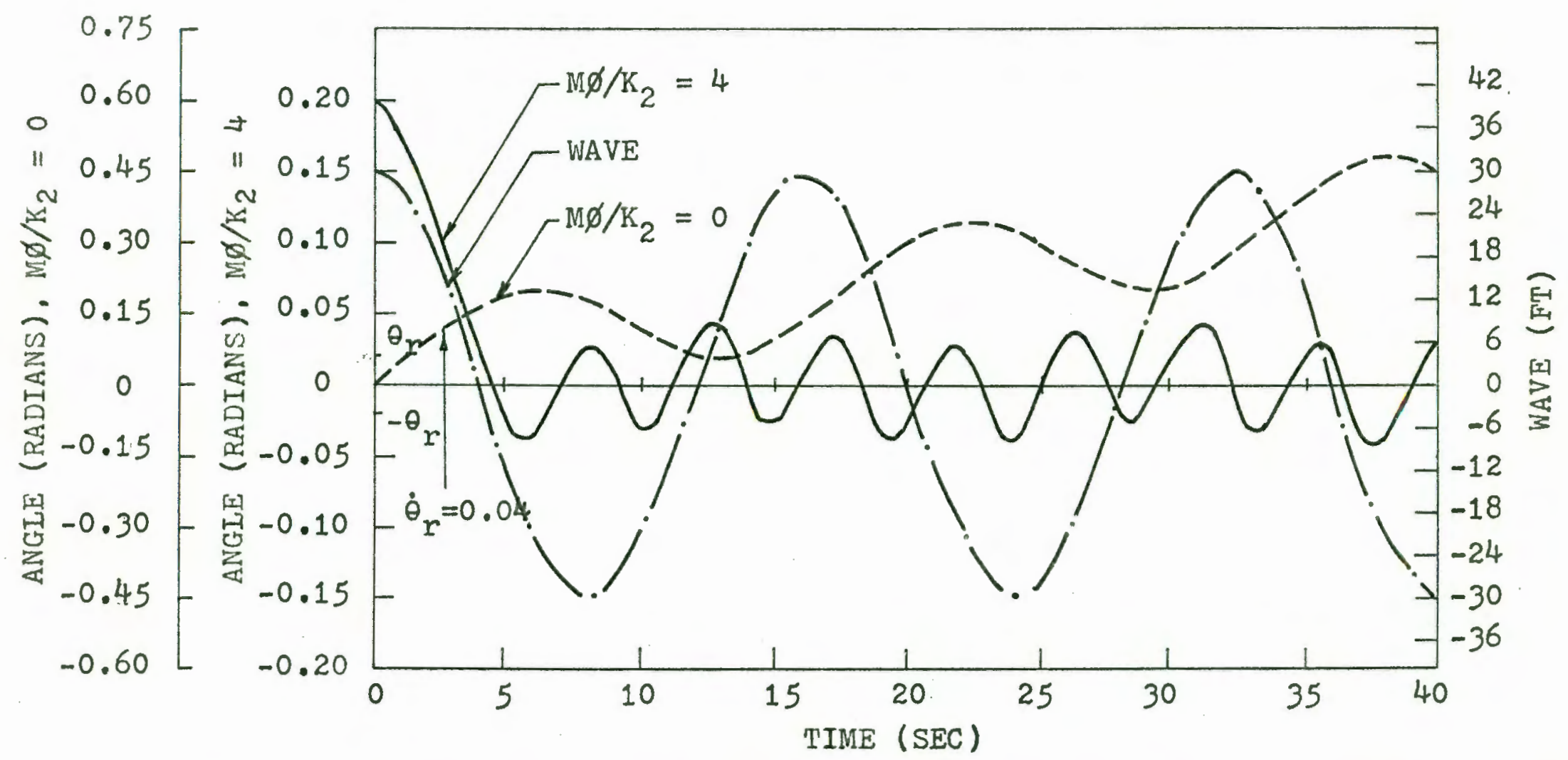

Figure 8. Platform motion with and without control (wave amplitude $=30 \mathrm{Ft}$ ). 


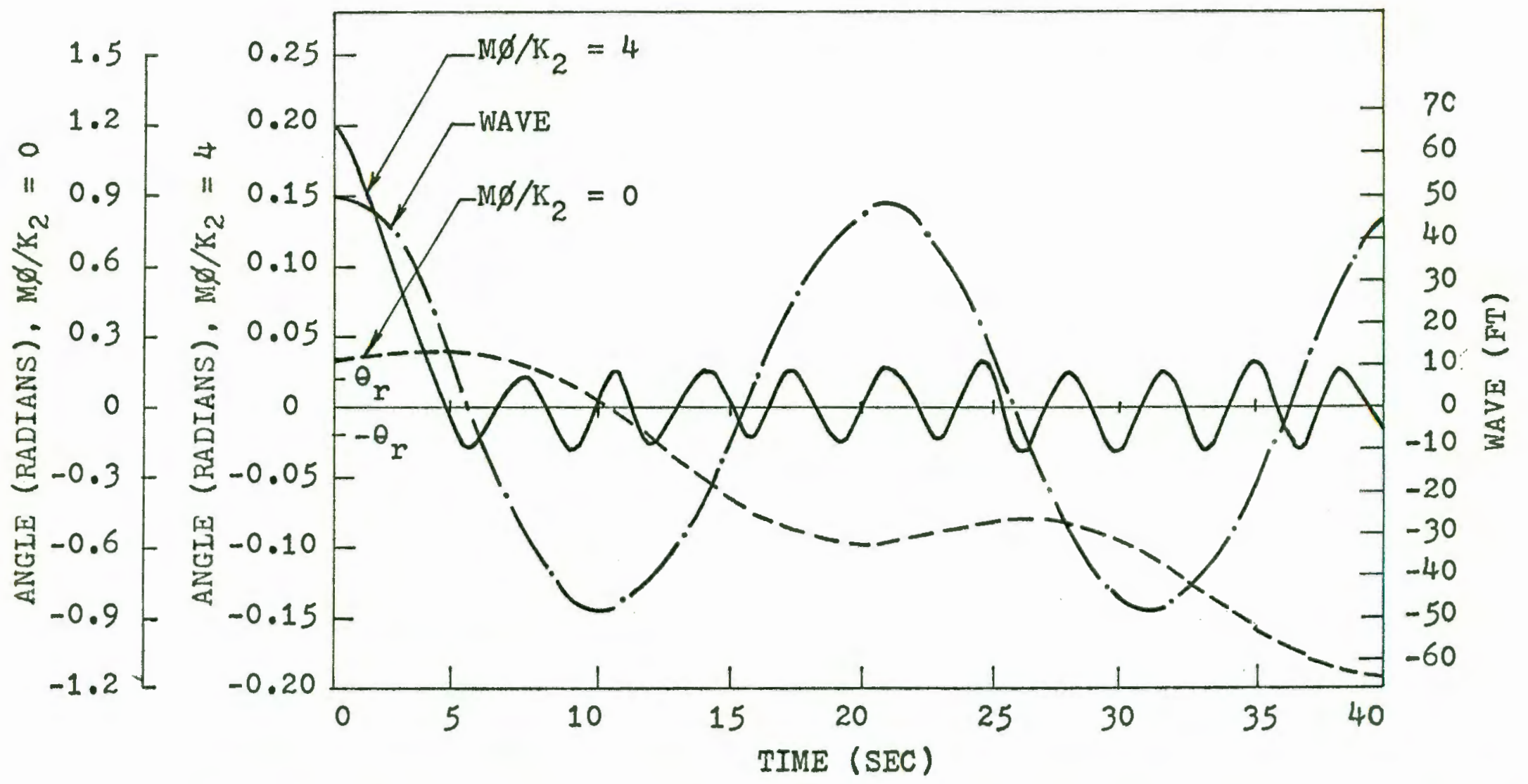

Figure 2. Platform motion with and without control (wave amplitude $=50 \mathrm{Ft}$ ). 
equal to 0.04 radians per second. From the comparison of the uncontrolled response on these figures one can conclude that the response of this type is a function of the initial conditions imposed on the platform.

When the magnitude of the control function is increasing the power requirement for controlling the platform motion becomes larger, and the platform goes from its initial conditions to the most stable position in relatively shorter time. For example, let us interpret from Figure 6, when the wave amplitude equal to 10 feet and $M \varnothing$ equal to $4 \mathrm{~K}_{2}$, it takes 5.47 seconds to accomplish this motion, while for the case of $\mathrm{M} \phi$ equal to $6 \mathrm{~K}_{2}$ it takes $4.94 \mathrm{sec}-$ onds. However the reduction of the time response is limited by the value of $\dot{\theta}_{r}$ of 0.05 radians per second.

The power requirement for controlling the platform motion increases simultaneously with the wave amplitude as indicated by Table VI. As the wave amplitude increases the controlled platform response becomes rather oscillatory. This effect is caused by the relative increase of the control function and the decrease of the ratio of platform length to wave length (the changes of the magnitude of the control function are shown in Table V). The ratio of platform length to wave length decreases due to the increased magnitude of wave length ( as tabulated in Table IV ). The effect of increasing the control function and decreasing the ratio of platform length to wave length is to increase 
TABLE VI

CHARACTERISTICS OF THE CONTROI REQUIREMENTS FOR DIFFERENT WAVE AMPIITUDES

Amplitude
(ft)
10
20
30
50

FLOW
$\left(f t^{3} / \mathrm{sec}\right)$
1521.12
3034.70
4552.10
7586.90

$V F$
$(\mathrm{ft} / \mathrm{sec})$
150
150
150
150

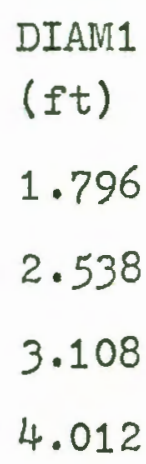

DIAM 2

(ft)

1.270

1.794

2.197

2.837
POWER

( $h p)$

62807.6

125300.0

187950.0

313260.0 
the ratio of the control moment to the buoyant moment. The increase of the ratio of control momert to buoyant moment gives similar results to those given by the increase in the ratio of the control function to the buoyancy coefficient. And, as shown by Figures 7 through 9, the time required for retuming from the initial conditions to the most stable position becomes shorter as described above. Figures 6 through 9 show that as wave amplitude increases the platform response becomes rather oscillatory with respect to the most stable position. This oscillatory response is a result of the increase of the ratio of control moment to buoyant moment. A simultaneous result by the increase of this ratio is that the maximum and minimum oscillations (refer to Figures 6 through 9) become fairly close to the given magnitude of $\theta_{r}$.

In general, for the case of a wave amplitude change, we find that the platform motion is controllable by the water jet streams immerging horizontally from each platform leg as proposed by the present study.

IV. WEIGHT AND IOAD OF THE PLATFORM

Figure 10 illustrates the response of the reference structure according to different weights and loads. It is clear from Table VII, that the power requirement for the control of the platform motion is independent of these changes. By analyzing the coefficients of the equation of 


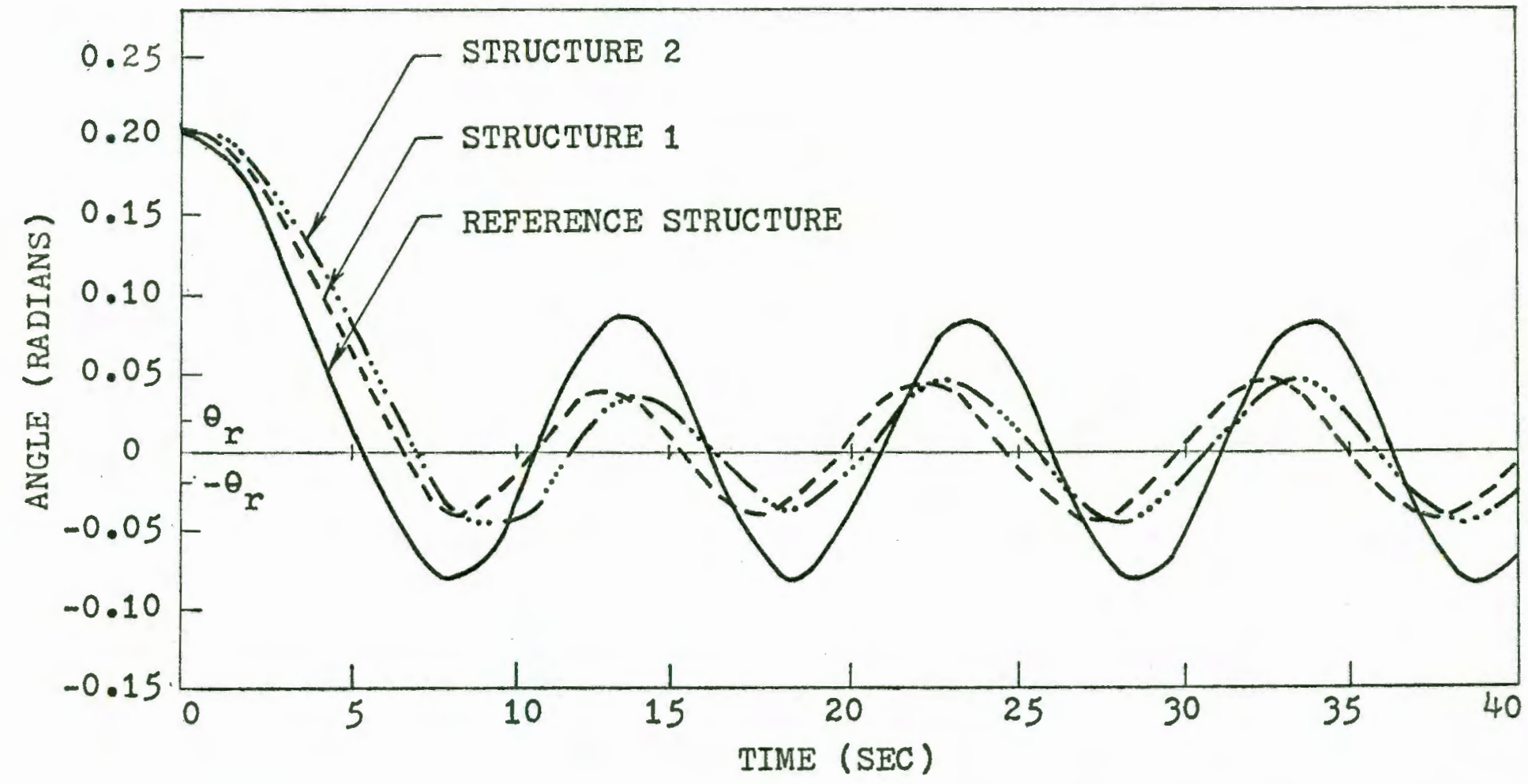

Figure 10. Platform response for different values of weight and load. 
TABLE VII

CONTROI REQUIREMENTS FOR DIFFERENT STRUCTURE CHARACTERISTICS

\begin{tabular}{lccccr} 
FLOW & $\begin{array}{c}\text { VF } \\
\left(f t^{3} / \mathrm{sec}\right)\end{array}$ & $\begin{array}{l}\text { DIAM1 } \\
(\mathrm{ft} / \mathrm{sec})\end{array}$ & $\begin{array}{l}\text { DIAN2 } \\
(\mathrm{ft})\end{array}$ & \multicolumn{1}{c}{$\begin{array}{c}\text { POWER } \\
(\mathrm{hp})\end{array}$} \\
$\begin{array}{l}\text { Reference } \\
\text { structure }\end{array}$ & 1521.12 & 150 & 1.796 & 1.270 & 62807.6 \\
Structure 1 & 1521.12 & 150 & 1.796 & 1.270 & 62807.6 \\
Structure 2 & 1521.12 & 150 & 1.796 & 1.270 & 62807.6 \\
Structure 3 & 3034.70 & 150 & 2.538 & 1.794 & 125300.0 \\
Structure 4 & 3793.40 & 150 & 2.837 & 2.006 & 156630.0 \\
Structure 5 & 867.07 & 150 & 1.356 & 0.959 & 35801.0 \\
Structure 6 & 433.53 & 150 & 0.959 & 0.678 & 17900.0 \\
Structure 7 & 2697.50 & 150 & 2.392 & 1.692 & 111380.0 \\
Structure 8 & 4214.90 & 150 & 2.990 & 2.115 & 174030.0
\end{tabular}


motion, it is understood that the changes under consideration produce only different magnitudes in the moment of inertia of the structure. These effects upon the response of the structure have been summarized in Figure 10.

From a comparison of the platform responses shown in Figure 10, we find that as the structural moment of inertia increases the time for propelling the platform from a given initial condition to the most stable position becomes longer. Figure 10 also indicates that the peaks of the oscillatory response become smaller as the moment of inertia increases. These variations in the response are appreciable as soon as the moment of inertia reaches a certain magnitude.

\section{PIATFORM LENGTH}

Figure 11 shows the response of the reference structure for different values of platform length. A change of the platform length produces variations in the magnitude of the buoyant moment, the control moment, and the moment of inertia. The magnitude of the buoyant moment is a function of the buoyancy coefficient and the ratio of platform length to wave length. The magnitude of the control moment is linearly related to the buoyancy coefficient according to Equation (2-18) along with the control function criteria.

Figure 10 shows that as the moment of inertia increases, the time for propelling the platform from its ini- 


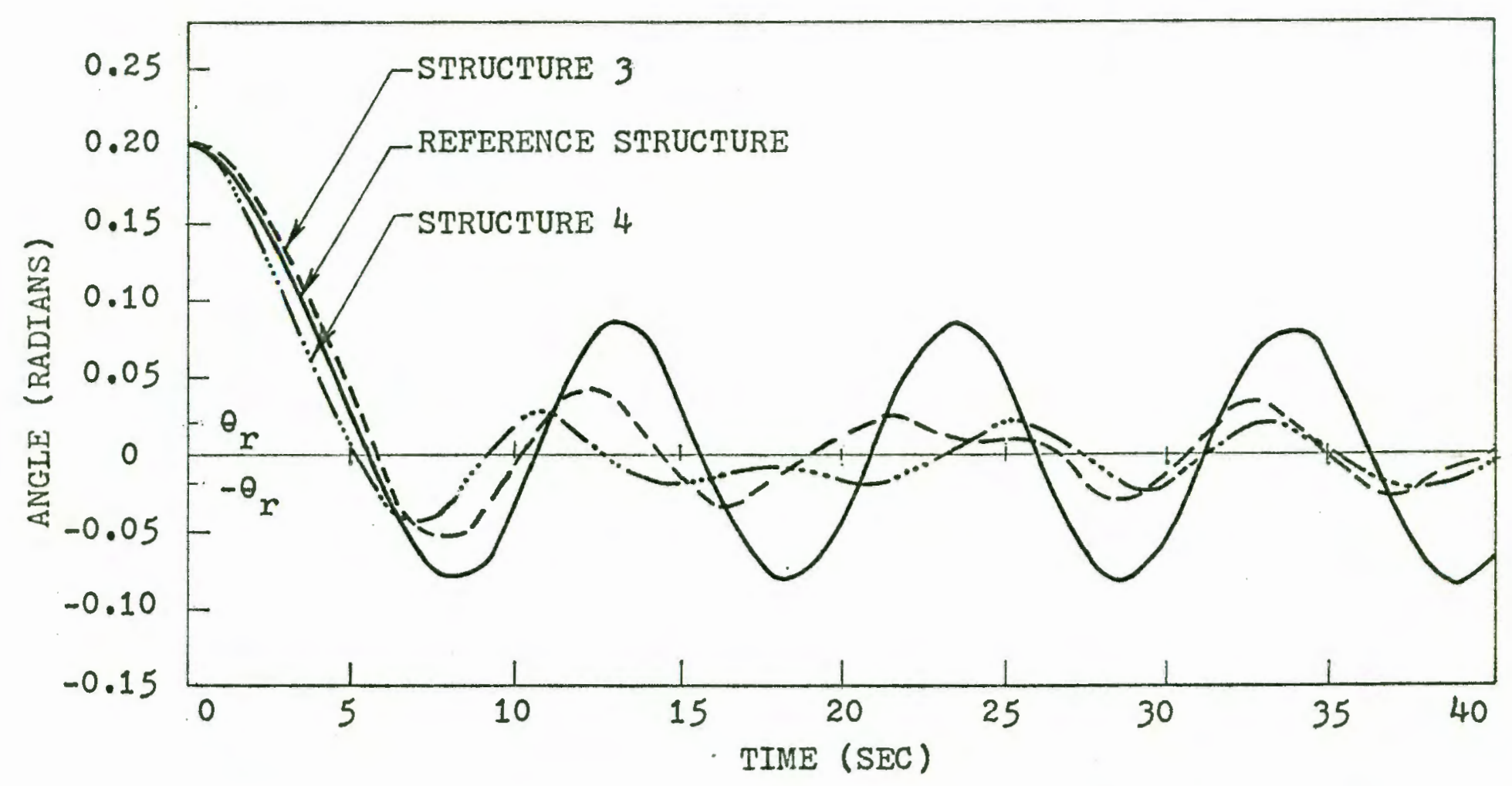

Figure 11. Platform response for different values of platform length, 
tial conditions to the most stable position becomes longer. While Figure 6 shows that as the control moment increases, the time for propelling the platform from its initial conditions to the most stable position becomes shorter. From Figure 11 we can observe that the increase in magnitude of the moment of inertia due to a platform length of 400 feet makes this time longer; whereas the increase in magnitude of the control moment due to a platform length of 500 feet makes this time shorter.

On Figure 11 we can see that the peaks of the oscillatory response are rather close to the given value of $\theta_{r}$. When the magnitude of the angular velocity is smaller than $\dot{\theta}_{r}$ and the angle is between ${ }^{-\theta_{r}}$ and $\theta_{r}$ the platform motion is within the permissible range ( as defined in Chapter III). Thus, from Figure 11 the response of Structure 3 after about 25 seconds is within the range of the permissible motion. The same characteristics are observed for Structure 4 after about 18 seconds.

\section{LEG LENGTH}

From Table I and Table II we realize that the increase of the leg length causes the moment of inertia to become larger. As the leg length of the reference structure is changed, the buoyant and control moments remain constant according to Equation $(2-17)$ along with the control function criterion. As a consequence, coefficients $\mathrm{K}_{2}$ and $\mathrm{M} \varnothing$ in 
the equation of motion become smaller while coefficient $\mathrm{C} 1$ (in Table III) becomes larger. The response of the seference structure for different values of leg length is shown on Figure 12. This figure shows the response of the platform as the moment of inertia becomes larger.

As can be seen from Figure 12, the platform motion is still controllable by the proposed method even though the response is sluggish. However, from Table VII, it can be found that the power requirement for the stability control of these structures is the smallest. Therefore, the time response of Structures 5 and 6 may be improved by using a higher value of control criterion, i.e. the ratio of the control function to the buoyancy coefficient should be larger than 4.

Another characteristics of the response of the reference structure due to different values of leg length is shown by the response of Structure 5 whose motion remains within the range of values between $-\theta_{r}$ and $\theta_{r}$.

\section{LEG DIAMETER}

A change in the leg diameter of the reference structure varies the buoyant coefficient and the power requirement for the stability control. Its effect on the moment of inertia, however, is negligible (see Table II). The response of the reference structure for different sizes of leg diameter is shown on Figure 13. The time for driving 


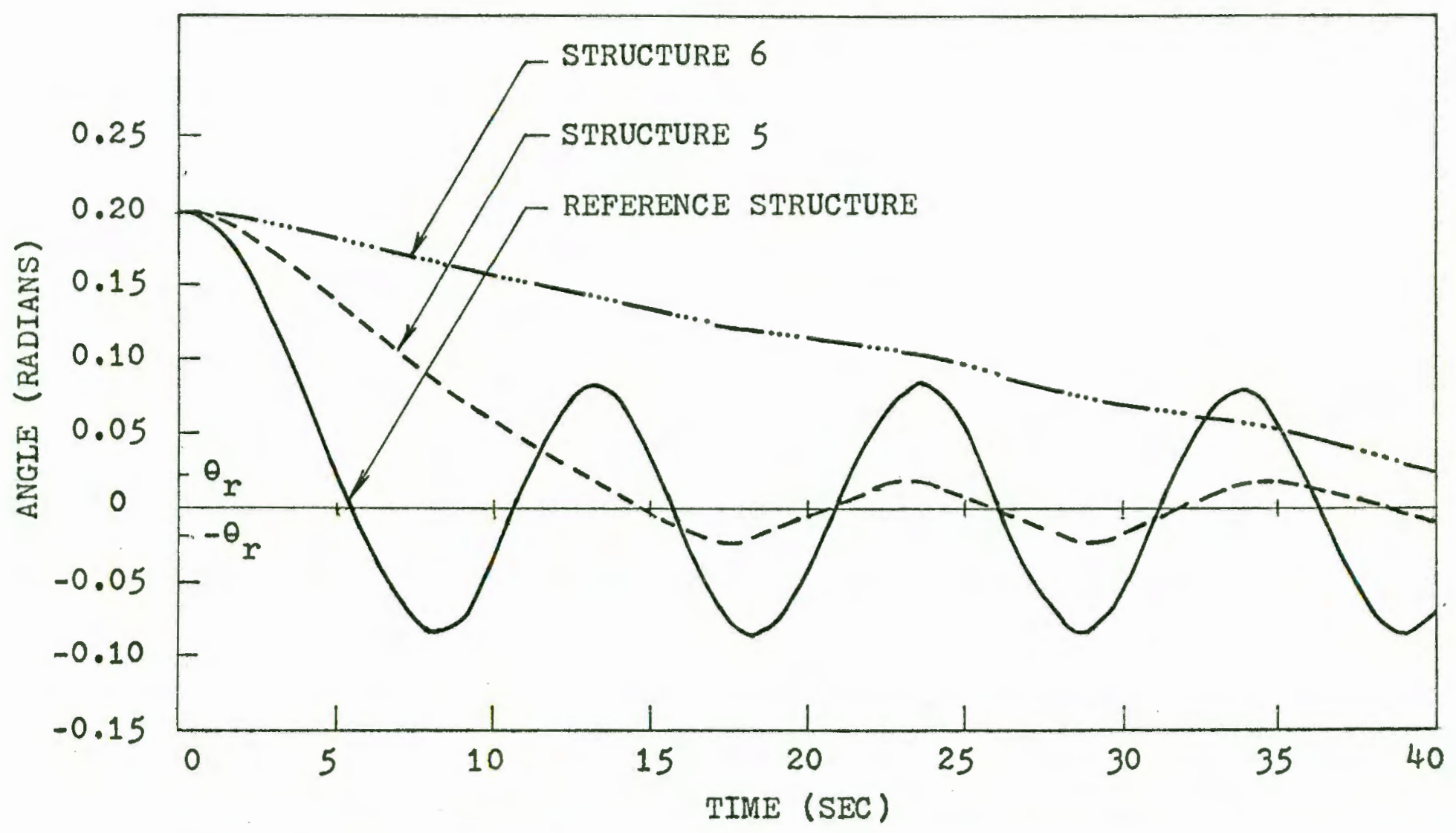

Figure 12. Platform response for different values of leg length. 


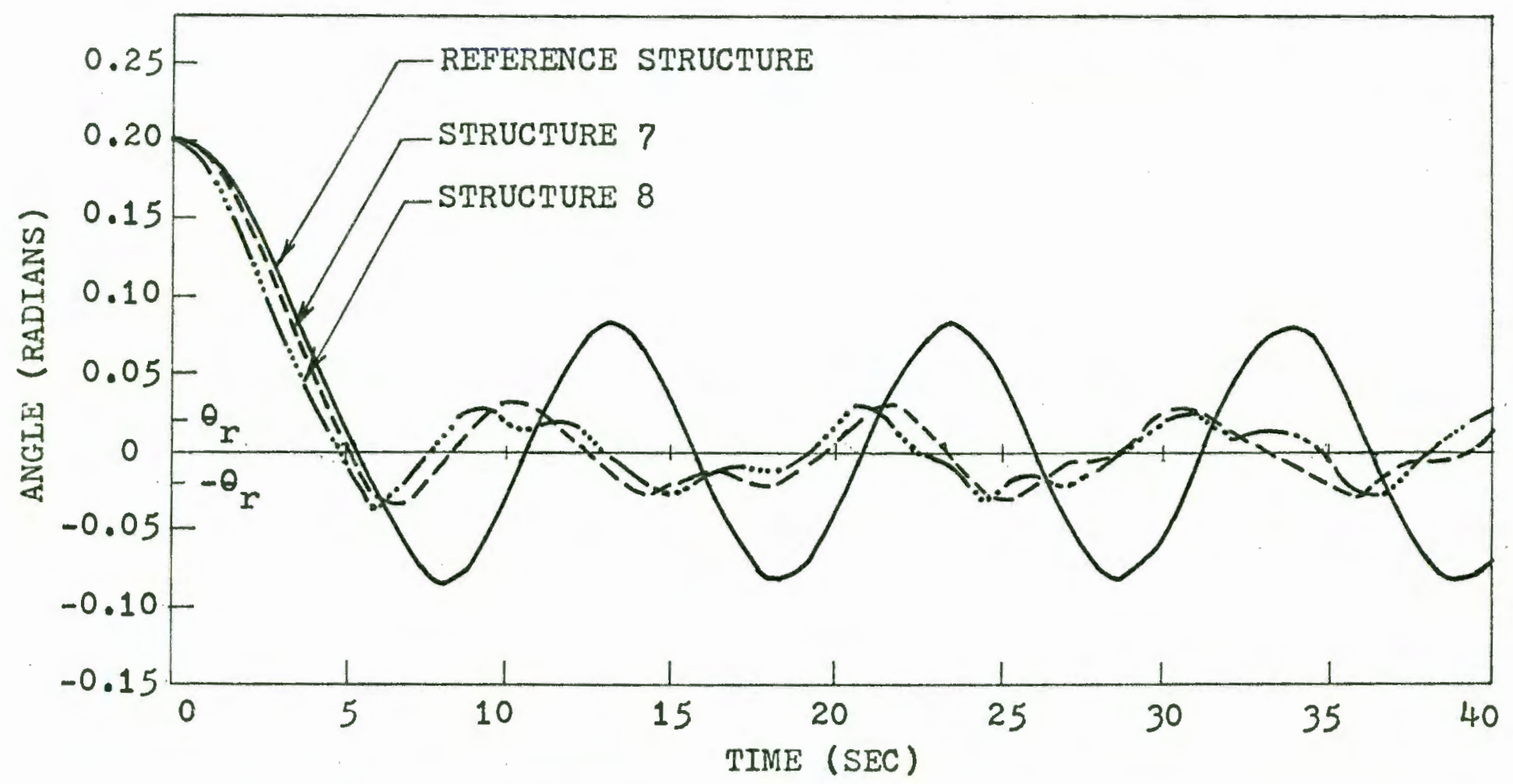

Figure 13. Platform response for different values of leg diameter. 
the platform from its initial condition to the most stable Fosition becomes shorter for Structures 7 and 8 . The decrease in time is a result of the increase in magnitude of the control function (as explained in Section III). The oscillatory responses of Structures 7 and 8 illustrate the characteristics of the controiled motion which refrains the structures from going beyond the permissible range of ${ }^{-\theta}{ }_{r}$ to $\theta_{r}$. From Table VII we can find that structure 8 requires more power than any others for achieving the control purposes.

\section{CONTROI FUNCTION}

The direction of the control moment, given by the value of $\mathrm{N}$ as defined in Chapter III, plays an important role in the stability control. Figure 14 shows the values of $\mathrm{N}$ as a function of time for Structure 1. Other plots for values of $\mathrm{N}$ as a function of time (for the reference structure and Structures 2 through 8 ) are rather unachievable because some Ns change sign within a hundredth of a second.

\section{CONCLUSIONS AND RECOMMENDATIONS}

The platform response as affected by each independent variable has been considered individually. But nothing has been stated about the response of the floating structure due to a combination of independent variables. However, with the computer results of the buoyancy requirements (as 


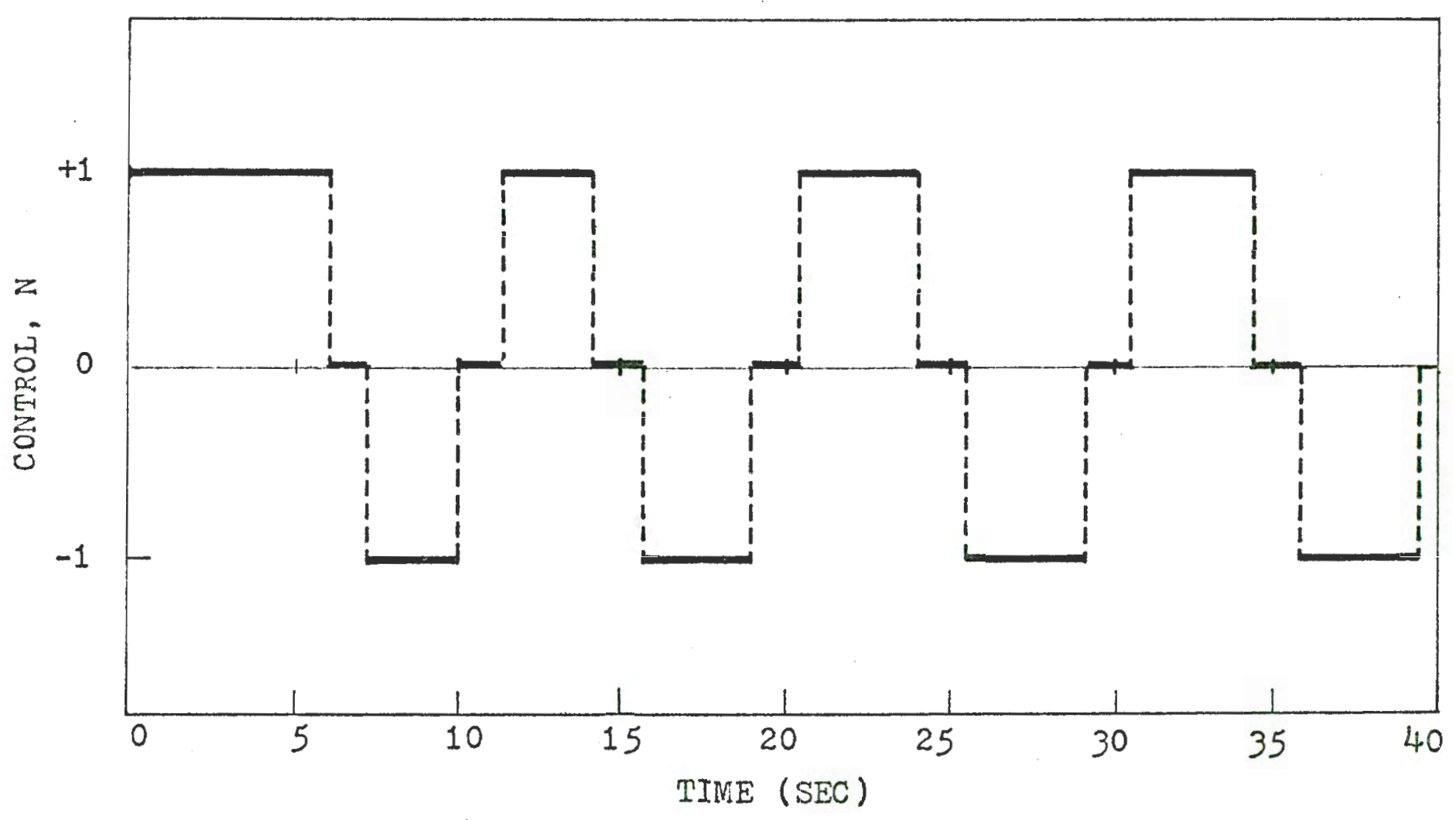

Figure 14. Control position for Structure 1.

$a$ 
tabulated in Table VIII) and the analysis available for the values of inciependent variables in structures 1 through 8 , we can summarize the significant characteristics of the response of the reference structure to the combined effect of two or more independent variables.

Structure 1 requires longer legs in order to meet the buoyancy requirements. The response of the platform (when this requirement is met) will be a combination of the responses given by Structures 1 and 6. As the response of this new structure is slow, a higher value of the ratio of control function to buoyancy coefficient is needed. Therefore, the power consumption will be higher than the values shown in Table VII. Another altemative for meeting the buoyancy requirements of Structure 1 is to increase the diameter of the platform legs as shown in Table VIII for Structures $?$ and 8 . If this solution is selected, the response of the new structure will be a combination of responses as show in Figures 10 and 13. Although the response of this new platform will be controllable with the given value of the ratio of control function to buoyancy coefficient the power requirement will be high as can be seen from Table VII.

As the results in Structures 2 through 8 are compared we are able to find similar conclusions to those stated above. Comparisons like these would enable us to evaluate compromises among a set of goveming independent variables, 
TABLE VIII

BUNYANCY REQUIREMENTS FOR DIFFERENT STRUCTURE CHARACTERISTICS

$$
\begin{array}{ll}
\text { EXBUF } & \text { CWALE } \\
(I b) & (f t)
\end{array}
$$

$\begin{array}{llr}\begin{array}{l}\text { Reference } \\ \text { structure }\end{array} & 0.78388 \times 10^{5} & 256.82 \\ \text { Structure 1 } & 0.20783 \times 10^{7} & 430.94 \\ \text { Structure 2 } & 0.45783 \times 10^{7} & 648.59 \\ \text { Structure 3 } & 0.78388 \times 10^{5} & 256.82 \\ \text { Structure 4 } & 0.78388 \times 10^{5} & 256.82 \\ \text { Structure 5 } & -0.16445 \times 10^{7} & 256.82 \\ \text { Structure 6 } & -0.56648 \times 10^{7} & 256.82 \\ \text { Structure 7 } & -0.21550 \times 10^{7} & 144.46 \\ \text { Structure 8 } & -0.50266 \times 10^{7} & 92.46\end{array}$

the control requirements, and the power consumption. In summary, the theoretical study shows that the floating platform under investigation is controllable by the water jet streams immerging horizontally from each platform leg. These jet streams may also be used for proprelling the platform from one place to another without requiring additional investment. Major economic concerm of the proposed technique is the high power consumption that would be required for the stability of the structure. However, it may be a necessary step in protecting the enormous amount of capital invested in the off-shore installations. Possibilities for further investigations of this 
study are numerous, some examples are:

1. Verification of the mathematical model by an experimental model.

2. Extending the mathematical model for the combined effect from pitch and roll on the platform stability.

3. Investigating the motion of the platform under the action of random waves. 


\section{BIBLIOGRAPHY}

1 Armstrong, E.R., "Armstrong Seadrome", U.S. Patent No, 1, 511,153, October 7, 1924.

2 Bader, J., "Ocean Platform-State of the Art", Offshore Technology Conference Preprints, 1970, Vol. 2, pp. $557-592$.

3 Backbur, J.F., Reethof, G., Shearer, J.I., Fluid Power Control, The M.I.T. Press, Cambridge, Massachusetts, 1960, pp. $591-630$.

4 Bedore, R.I., "Large Floating Platform Technology: a Review", Joumal of Basic Engineering, Trans. ASME, Vol. 94. December 1972, pp. 834-840.

5 Best, I.C., Mclean, W.G., Analytical Mechanics for Engineers, Intemational Textbook Company, Scranton, Penn., 1965.

6 Bidde, D.D., "Laboratory Study of Iift Forces on Circular Piles", Joumal of Waterways, Harbors and Coastal Engineering Division, ASCE, Vol. 97, Wh4, 1971, pp. 595-614.

7 Bretschneider, I., "Hurricane Design-Wave Practices", Trans. ASCE, VoI. 124, 1959, pp. 39-62.

8 Burke, B.G., "A Vessel Motion Instrumentation System", Joumal of Petroleum Technology, September 1966, pp. 1041-1046.

9 Burke, B.G., "A Time Series Model for Dynamic Behavior of Offshore Structures", Society of Petroleum Engineers Journal, April 1972, pp. 156-170.

10 Burke, B.G., "The Analysis of Drilling Motion in a Random Sea", Society of Petroleum Engineers Joumal, December 1972, pp. 341-355.

11 D'Azzo, J.J., Houpis, H., Feedback Control System Analysis and Synthesis, McGraw-Hill Book Company, New York, 1960, pp. 136-143. 
12 Garg, V.K., Chen, P.I., "A Study on Nonlinear Viscous Oscillations", ASME Symposium on Numerical Laboratory Computer Methods in Fid Engineering, 1976.

13 Garrison, C.J., Chow, P.Y., "Wave Forces on Submerged Bodies", Journal of Waterways, Harbors and Coastal Engineering Division, ASCE, Vol. 98, NWW3, August 1972, pp. $375-392$.

14 Giannotti, J.G., "A Dynamic Simulation of Wave Impact loads on Offshore Floating Platforms". ASME paper No. $75-W A / O C E-4$ presented at the Winter Annual Meeting, Houston, Texas, 1975.

15 Harris, C.M., Creede, C.E., Shock and Vibration Handbook, McGraw-Hill, New York, 1961, Vol. III, pp. $46.1-46.20$.

16 Hartkemeier, H.P., Fortran Programming of Electronic Computers, Charles E. Merril Books, Inc., Columbus, ohio, 1956.

17 Hong, S.T., Brooks, J.C., "Dynamic Behavior and Design of Offshore Caissons", Offshore Technology Conference Preprints, 1976, Vol. 2, pp. 363-372.

18 Johnson, E.R., "Horizontal Forces Due to Waves Acting on Large Vertical Cylinders in Deep Water", Joumal of Basic Engineering, Trans. ASME, Vol. 94, December 1972, pp. 862-866.

19 Kuo, B.C., Automatic Control Systems, third edition, Prentice-Hall, Inc.,Englewood Cliffs, New Jersey, 1975, pp. 95-115.

20 Keulegan, G.H., Carpenter, I.H., "Forces on Cylinders and Plates in an Oscillating Fluid", Joumal of Research of the National Bureau of Standards, Vol. 60, May 1958, pp. 423-440.

21 Iamb, Sir Horace, Hydrodynamics, sixth edition, Dover Publications, New York, 1932, pp. 160-170.

22. Lauer, H., Lesnick, N.R., Matson, E.L., Servomechanism Fundamentals, McGraw-Hill, New York, 1960, pp. $366-403$.

23 McCracken, D.D., Fortran with Engineering Applications, John Wiley \& Sons, Inc., New York, 1967. 
24 Merchant, H.C., Sergev, S.S., Orr, W.A., "Development of a Response Monitoring System and Application to a Barge", ASME paper No. 75-NA/OCE-10 presented at the Winter Annual Meeting, Houston, Texas, 1975.

25 Morison, J.R., et al, "The Force Exerted by Surface Waves on Piles", Petroleum Trans. AIME, Vol. 189, 1950, pp. 149-157.

26 Morison, J.R., et aI, "Experimental Study on Forces on Piles", Proceedings of the Fourth Conference of Wave Research, Berkely, Califomia, 1954, pp. 240-247.

27 Morris, H.M., Applied Hydraulics in Engineering, The Ronald Press Company, 1963, pp. $402-435$.

28 Ogata, K., Modem Control Engineering, Prentice Hall, Inc., Englewood Cliffs, N.J., 1970.

29 Organick, E.I., A Fortran IV Primer, Addison-Wesley Publishing Company, Inc., Reading, Massachusetts, 1966.

30 Roberson, J.A., Crowe, C.T., Engineering Fluid Mechanics, Houghton Miffilin Company, Boston, 1975.

31 Sarpkaya, T., "Forces on Cylinders and Spheres in a Sinusoidally Oscillating Fluid", ASHE paper No. 75-APMW27. presented at the Applied Mechanics Western Conference, University of Hawaii, Honolulu, Hawaii, 1975.

32 Shames, H.I., Engineering Mechanics. Dynamics, Prentice-Hall, Inc., Englewood Cliffs, N.J., 1970.

33 Shinners, S.M., Control System Design, John Wiley \& Sons, New York, 1954.

34 Streeter, V.I., Fluid Mechanics, fifth edition, McGraw-Hill Company, New York, 1971.

35 Thorson, W.T., Theory of Vibrations with Applications, Prentice-Hall, Inc.. Englewood Cliffs, N.J., 1972.

36 Weigel, R.I., Beebe, K.E., Moon, J., "Ocean Wave Forces on Circular Cylindrical Piles", Journal of the Hydraulics Division, ASCE, Vol. 83, April 1957, pp. 1199.1 1199.36 . 
APPENDIX A

\section{OSCILIATORY GRAVITY WAVES}

The present study deals with the effect of oscillatory gravity waves on floating platforms. Oscillatory gravity waves are those in which the water particles do not actualIy travel with the waves, but tend to oscillate about a mean position as the wave passes. These waves are characterized by a depth of water greater than one-half the wave length.

\section{WAVE DESCRIPTION}

Consider a simple oscillatory wave motion as shown on Figure 15 where $\lambda, A$, and $D$ represent the wave length, amplitude and depth of flow, respectively. If the origin of coordinates is taken at one of the nodes at a time $t=0$, and the wave is assumed to move in simple harmonic motion, then the equation on the water surface is given by:

$$
Y=A \sin (2 \pi x / \lambda-w t)
$$

where,

$Y=$ position of the water surface,

$A=$ amplitude of the oscillatory motion,

$\lambda=$ wave length,

$w=$ angular frequency of the motion, 


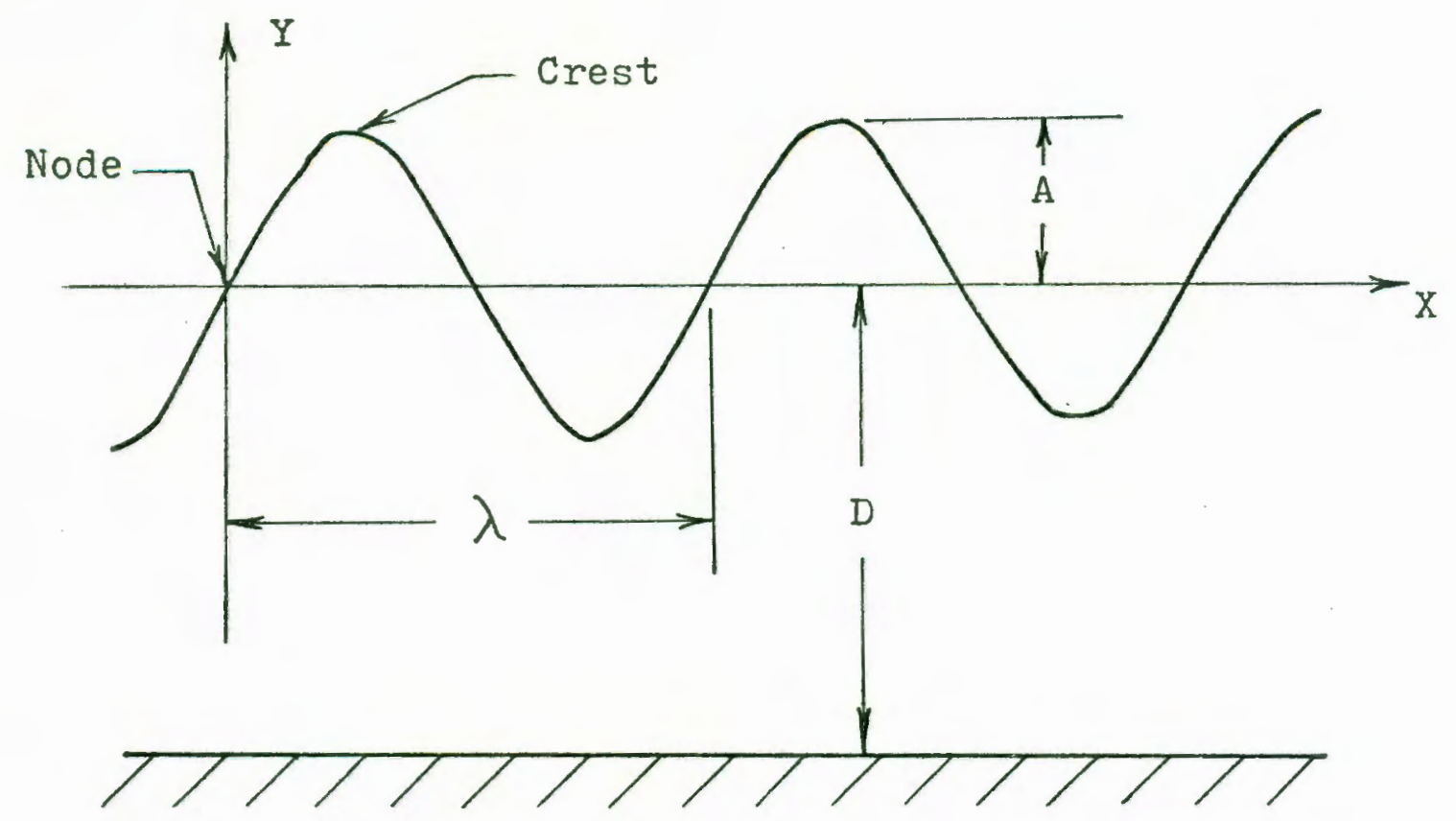

Figure 15. Simple oscillatory wave motion.

$t=$ time, and

$\mathrm{X}=$ length coordinate as shown on Figure 15 .

For simple harmonic motion, we know that:

$f=w /(2 \pi)$

$\mathrm{T}=1 / \mathrm{f}$

$\lambda=c T$

where $f, T$, and $c$ are the frequency, period, and celerity of the vave, respectively.

From the two dimensional theory of potential flow (27), the following equation is given for celerity as a function of the flow depth:

$$
c=[g \lambda \operatorname{Tanh}(6.28 \mathrm{D} / \lambda) / 6.28]^{\frac{1}{2}}
$$


where $g$ is the gravity constant. Since the depth $D$ of an oscillatory gravity wave is greater than one-half of the wave length;

$$
c \simeq(g \lambda / 6.28)^{\frac{1}{2}}
$$

and,

$$
\operatorname{Tanh}(6.28 \mathrm{D} / \lambda) \simeq 1
$$

From Equations $(A-4)$ and $(A-6)$ we get

$$
\begin{aligned}
& \lambda=5.12 \mathrm{~T}^{2} \\
& c=5.12 \mathrm{~T} \\
& \text { C.I. Bretschneider (?) proposed the following equa- }
\end{aligned}
$$
tions for the wave height and its period:

$$
\begin{aligned}
& \mathrm{H}_{1}=0.0555\left(\mathrm{~V}_{\mathrm{W}}^{2} \mathrm{~F}\right)^{\frac{1}{2}} \\
& \mathrm{~T}=\left[0.5\left(\mathrm{~V}_{\mathrm{W}}^{2} \mathrm{~F}\right)^{\frac{1}{2}}\right]^{\frac{1}{2}}
\end{aligned}
$$

where,

$\mathrm{H}_{1}$ = wave height, (it is equal to $2 \mathrm{~A}$, i.e. twice the wave amplitude),

$\mathrm{v}_{\mathrm{w}}=$ wind velocity in knots,

$F=$ fetch in nautical miles, and

$T=$ period in seconds.

From Equations $(A-9)$ and $(A-10)$ we have

$$
H_{1}=0.222 \mathrm{~T}^{2}
$$

The duration of the wind necessary for developing a such wave is given by

$$
t_{1}=F /(1.14 \mathrm{~T})
$$


where $t_{1}$ is the minimum wind duration in minutes.

\section{WATER PARTICLE DESCRIPTION}

Let us consider a water particle whose initial location is at the point $(X, Y)$ in Figure 16. In response to the imposed wave action, the particle moves in an elliptical orbit (27). The horizontal and vertical displacements of the particle from the point $(X, Y)$ are functions of the position and time as given by:

$$
\begin{aligned}
& \delta_{x}=\frac{A \operatorname{Cosh}(6.28(D+Y) / \lambda)}{\sinh (6.28 D / \lambda)} \cos (6.28 x / \lambda-w t) \\
& \delta_{y}=\frac{A \operatorname{Sinh}(6.28(D+Y) / \lambda)}{\sinh (6.28 D / \lambda)} \sin (6.28 X / \lambda-w t)
\end{aligned}
$$

Let,

$$
A_{2}=\frac{A \operatorname{Cosh}(6.28(D+Y) / \lambda)}{\operatorname{Sinh}(6.28 D / \lambda)}
$$

and

$$
B_{2}=\frac{A \sinh (6.28(D+Y) / \lambda)}{\sinh (6.28 D / \lambda)}
$$

Equations $(A-13)$ and $(A-14)$ become

$$
\delta_{x}=A_{2} \cos (6.28 \mathrm{x} / \lambda-w t)
$$

and,

$$
\delta_{y}=B_{2} \sin (6.28 x / \lambda-w t)
$$

From Equations $(A-17)$ and $(A-18)$ we can state that: 


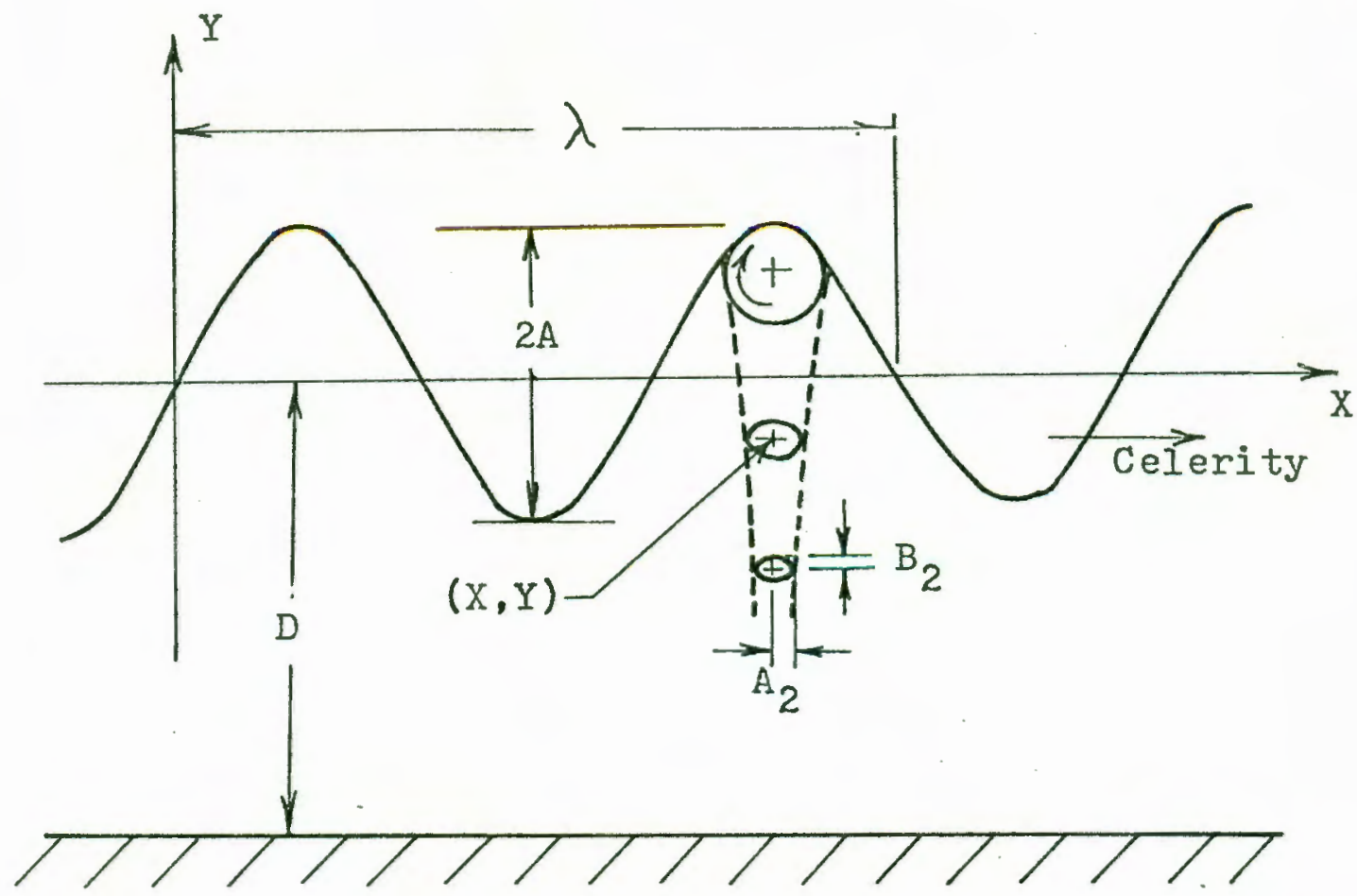

Figure 16. Water particle motion description.

1. $A_{2}$ and $B_{2}$ depend only on the depth $Y$ at which the particle is located.

2. For large values of $\mathrm{D}, \mathrm{A}_{2}$ will be equal to $\mathrm{B}_{2}$ and the orbits of the water particles become essentially circular.

The horizontal velocity component of a water particle in an oscillatory gravity wave can be obtained from Equation $(A-17)$ as

$$
a\left(S_{x}\right) / d t=v_{x}=A_{2} w \sin (6.28 x / \lambda-w t)
$$

Equation $(A-19)$ is used for finding the inertia and drag components of the in-line force as given by the Morison equation. 
APPENDIX B

STRUCTURAI MOMENT OF INERTIA

The equations related to the location of the center of gravity of the whole structure with respect to the reference water surface level and the structural moment of inertia are presented in this appendix.

\section{CENTER OF GRAVITY}

Figure 17 illustrates the geometrical characteristics of the floating structure. The symbols used in this figure correspond to the following descriptions:

$D=$ portion of the leg submerged in water,

$D_{1}=$ distance from the reference water surface level to the center of gravity of the whole structure,

$D_{2}=$ length of the platform legs.

$\mathrm{GC}=$ center of gravity of the whole structure,

$H$ = platform height,

I = platform length as given by the distance between the center line of the platform legs on the plane of motion (plane XZ),

$I_{1}=$ platform width as measured on the vertical plane normal to the plane of motion (plane YZ),

$I_{G C}=$ position of the center of gravity of each platform 


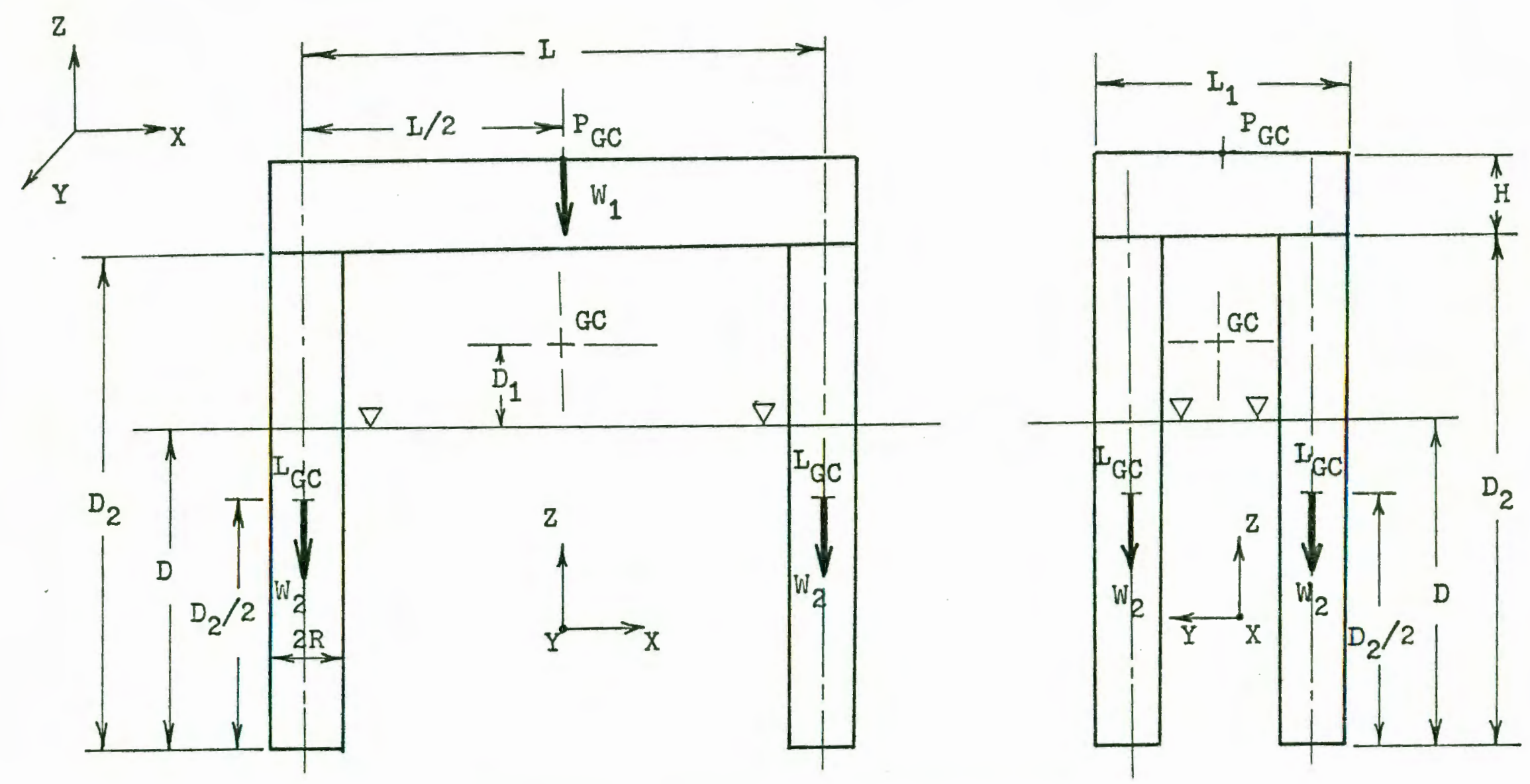

Figure 17. Characteristics of the structure. 
leg,

$P_{G C}=$ location of the center of gravity of the platform

(with loading),

$2 R$ = leg diameter,

$w_{1}=$ platform weight and load, and

$W_{2}=$ weight of each platform leg.

In order to find the distance $D_{1}$, let us take moments with respect to the point $G C$,

$$
W_{1}\left(D_{2}+H-D-D_{1}\right)-4 W_{2}\left(D-D_{2} / 2+D_{1}\right)=0
$$

So,

$$
D_{1}=\frac{W_{1}\left(D_{2}+H-D\right)-4 W_{2}\left(D-D_{2} / 2\right)}{W_{1}+4 W_{2}}
$$

II. MOMENT OF INERTIA

The moment of inertia of each leg about an axis parallel to the $Y$-axis through its center of gravity $I_{G C}$ is

$$
I_{I_{G C}}=W_{2} D_{2}^{2} /(12 \mathrm{~g})
$$

Applying the parallel axes theorem, the moment of inertia of each leg about a parallel axis to the Y-axis through the center of gravity of the whole structure can be expressed by,

$$
I_{G C}^{\prime}=I_{I_{G C}}+W_{2}\left(D+D_{1}-D_{2} / 2\right)^{2} / g
$$

The platform moment of inertia about an axis parallel 
to the Y-axis through its center of gravity is given by:

$$
I_{P_{G C}}=w_{1} I^{2} /(12 \mathrm{~g})
$$

The above expression is based on the assumption that the value of the moment of inertia about the centroidal axis of the platform in the XZ-plane is equal to the moment of inertia about an axis through $\mathrm{P}_{\mathrm{GC}}$. This assumption is permissible as the distribution of the load of the platform is taken into account. Applying the parallel axes theorem for finding the moment of inertia of the platform (with loading) about an axis through the center of gravity of the whole structure we can get

$$
I_{G C}^{\prime \prime}=I_{P_{G C}}+W_{1}\left(D_{2}+H-D_{1}\right) / g
$$

Therefore, the moment of inertia of the whole structure with loading is given by:

$$
I_{1}=I_{G C}+4 I_{G C}
$$

Equation $(B-7)$ is used for calculating the moment of inertia of the structure in the computer solution of the equation of motion. 


\section{APPENDIX C}

\section{NONENCIATURE}

This appendix deals with the definition of the symbols contained in the text and the symbols used in the computer programs.

\section{SYMBOLS IN THE TEXT}

A

$[\mathrm{A}]$

A

Amplitude of the oscillatory motion.

\section{]} Coefficient matrix. Area normal to the direction of flow of a moving body submerged in water. Value as given by Equation $(A-15)$. Value as given by Equation $(A-16)$.

c Wave celerity.

$\mathrm{C}_{1}$ Value as given by Equation $(2-31)$.

$\mathrm{C}_{2}$ $C_{1}$ after dividing by the moment of inertia. $\mathrm{C}_{\mathrm{d}}$ Drag coefficient in drag force component of the in-line force.

$\mathrm{C}_{\mathrm{D}}$ Euler's number. Value as given by Equation $(2-26)$. $C_{f I}$ Value as given by Equation (2-28). $\mathrm{C}_{\mathrm{m}}$ Inertia coefficient. $\delta_{x}, \delta_{y}$ values as given by Equations $(A-13)$ and 
$(A-14)$, respectively.

D

$D_{1}$

$\mathrm{D}_{2}$

$D_{i}$

$\mathrm{du} / \mathrm{dt}$

f

F

$F_{B L}, F_{B R}$

$F_{D}$

$F(t)$

$f(t)$

$f_{1}(t)$

y

GC

$\mathrm{H}$

$\mathrm{H}_{1}$

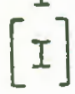

$I_{1}$

Portion of the leg submerged in the water.

Distance from the reference water surface

level to the center of gravity of the whole structure.

Length of the platform legs.

Displacement per leg as given by Equation $(2-14)$.

Horizontal component of the local acceleration of water particles at the platform leg. Wave frequency.

Fetch in nautical miles.

Buoyant force from the left and right legs of the platform, respectively.

Drag force as given by the Euler's number. Horizontal component of the in-line force per unit length of cylinder.

Time function as given by Equation (3-5). $f(t)$ after dividing by the moment of inertia. Specific weight of water.

Center of gravity of the whole structure. Distance between two water jet streams of each platform leg. Wave height (it is equal to $2 A$ ).

Identity matrix. Moment of inertia of the floating platform as 
given by Equation (B-7).

${ }^{I_{G C}}{ }_{G C} I_{G C} \quad$ Moment of inertia of each leg as given by Equations $(B-3)$ and $(B-4)$, respectively.

$I_{P_{G C}}$, I'GC Platform moment of inertia as given by Equations $(B-5)$ and $(B-6)$, respectively. Value as given by Equation (2-18). Wave length.

I Platform length as given by the distance between the center-line of the platform legs on the plane of motion.

$\mathrm{I}_{1}$ Platform width as measured on the vertical plane normal to the plane of motion. $\mathrm{I}_{\mathrm{GC}}$ Position of the center of gravity of each platform leg.

m Mass of water per jet stream.

$M_{B} \quad$ Buoyant moment.

${ }^{\mathrm{d}} \mathrm{d}$ Drag component of the in-line moment as given by Equation $(2-25)$.

$\mathrm{M}_{\mathrm{D}} \quad$ Drag moment.

$\mathrm{M}_{\text {i }}$ Inertia component of the in-Iine moment as given by Equation $(2-27)$.

$M_{\text {in }}$ In-line moment as given by Equation (2-22). im $\varnothing$ Control moment as given by Equation (3-1). $M \phi_{1}$ M after dividing by the moment of inertia. $\mathrm{N}$ Control variable as defined by Equation (3-2). 
Phase angle of the waves at the left platform legs.

$P_{G C}$<smiles>[CH-]</smiles>

$2 \mathrm{R}$

$t$

$\mathrm{T}$

$t_{1}$

$\mathrm{T}_{1}$

$\theta$

$\dot{\theta}, \ddot{\theta}$

$\theta_{r}$

$\dot{\theta}_{r}$

$\mathrm{U}$

$\dot{U}$

$\mathrm{U}(\mathrm{t})$

$\mathrm{V}$

$\mathrm{V}_{\mathrm{W}}$

W
Iocation of the center of gravity of the

platform (with loading) in Figure 17.

Density of water.

Diameter of the platform $1 \mathrm{eg}$.

Time.

Wave period.

Minimum wind duration (in minutes) as given by Equation (A-12) for generating an oscillatory gravity wave.

Sampling period.

Angle of pitching motion of the floating platform.

Angular velocity and acceleration of the floating platform, respectively.

Angle control criterion.

Velocity control criterion.

Horizontal component of the flow velocity at a platform leg.

Horizontal component of the local acceleration of water particles at a platform leg. Driving function as defined by Equation (4-4). Velocity of a water jet stream. Wind velocity in knots. Angular frequency of an oscillatory motion. 


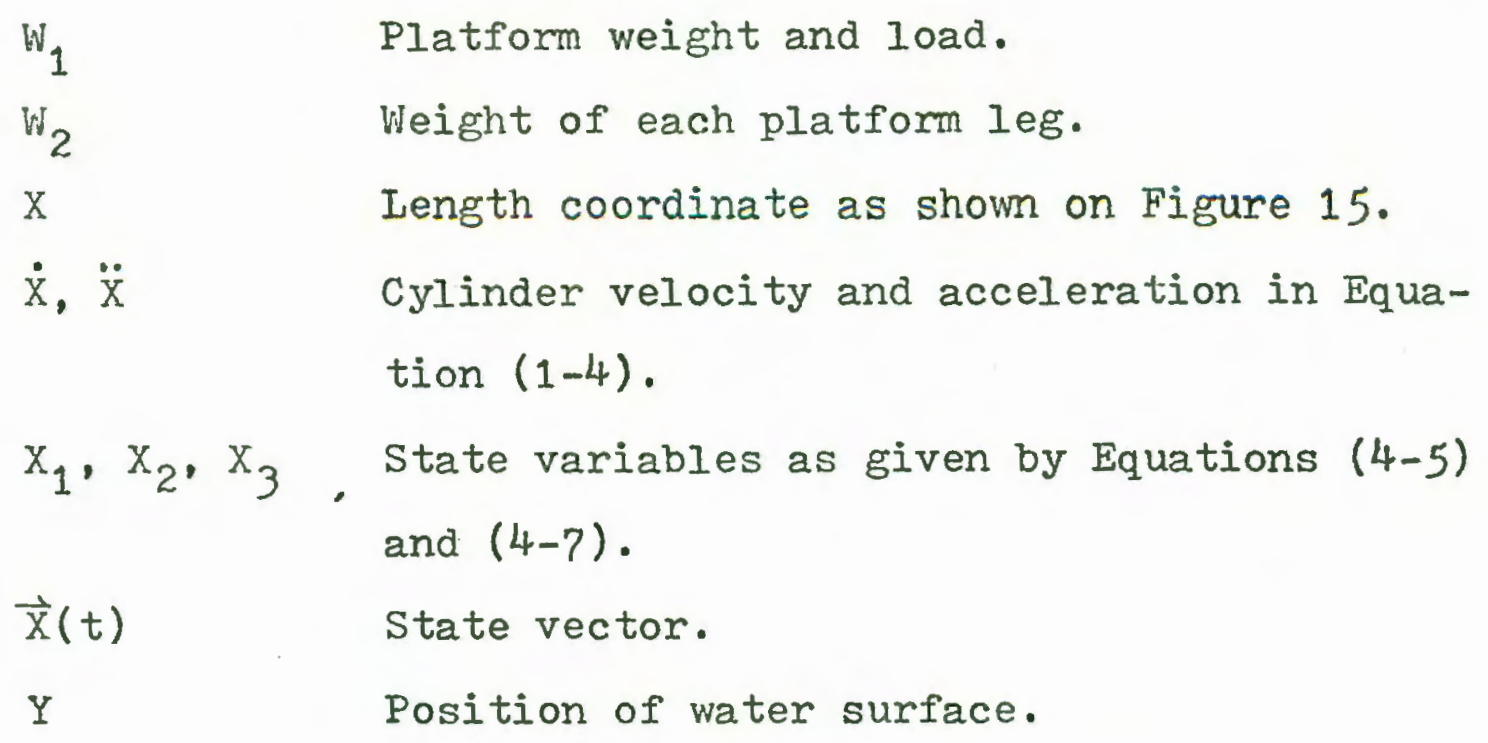

II. SYMBOLS IN THE COMPUTER PROGRAMS

AA Coefficient matrix as defined by Equation $(4-13)$.

AAT, AP1, AP2 Matrices used in the calculation.

AMP Wave amplitude.

AREA Area per jet stream required for providing FLOW.

BOYIP Buoyant moment after dividing by the moment of inertia of the whole structure.

CAMP Calculated amplitude of the waves. ( It is equivalent to AliP ).

C1 Dampening coefficient as given by Equations $(4-2 a)$ and $(2-31)$.

CHYDI COsh $(4 \pi$ (D+WAVEL)/XIAMD).

CHYDR COSh $(4 \pi(D+W A V E R) /$ XAIMD $)$.

CK2 Buoyancy coefficient as given by Equations 
$(4-2 a)$ and $(2-18)$.

Cino Control coefficient as given by Equations $(4-2 c)$ and $(3-1)$.

CONCR Control criterion given by the ratio of the control term (as given by Equation (3-1)) to the buoyancy coefficient (as given by Equation $(4-2))$.

CRTAN Angle control criterion as defined in Chapter III.

CRTVL

Maximum permissible value of the angular velocity $\dot{\theta}_{r}$ as defined in chapter III.

CWALE Calculated value of the leg length submerged in water.

D

Leg length submerged in water. (Equivalent to WALEG in the program PLATFORM PARAMETERS).

D1 Gravity center of the whole structure with respect to the water surface as given by Equation $(B-2)$ in Appendix $B$.

DIRAG, D2RAG Variables used in the calculation of terms in D3RAG, D4RAG Equation $(2-25)$ at the right legs. D5RAG, D6RAG

D5 Displacement per leg.

DIAM1 Nozzle diameter that gives a flow area equal to AREA.

DIAM2 Nozzle diameter that gives a flow area equal to $\mathrm{AREA} / 2$. 
DLEG

DRAG

DRAG1， DRAG2

DRAG3, DRAG4

DRAG5, DRAG6

ENTUM

EPS1

EPS2

EXBUF

F

FLOW

FMASS

$\mathrm{H}$
Leg diameter.

In-Iine moment component produced by the drag forces after dividing by the moment of inertia of the whole structure.

Variables used in the calculation of terms in Equation (2-25) at the left legs.

Momentum of the water immerging in a single direction from the legs of the platform. Reference value for considering a number larger than zero.

Convergent value of each term in the series for each element in matrices PHI and THETA. Extra buoyant force. (It is the result of the comparison between CWAIE and WALEG. By its definition, if this value is negative, it means that the buoyant force is Iarger than the required value and either WALEG should be reduced or the weight of the structure should be increased).

Fetch.

Flow corresponding to FMaSS.

Mass flow rate of water corresponding to ENTUM .

Vertical distance between two water jet streams that form the controlling couple. 


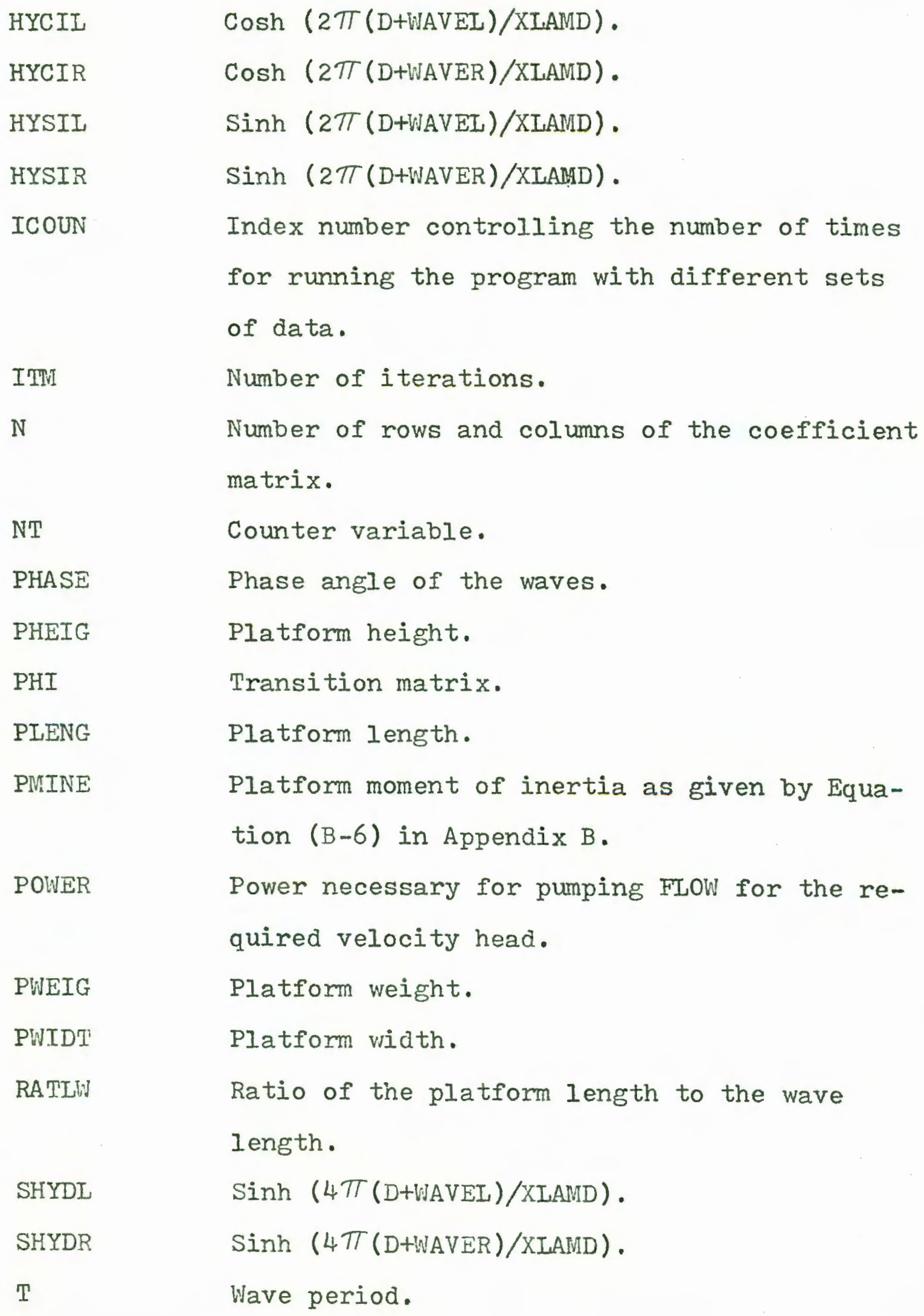


TAU

TEST

THEIN

THETA

THETX

TIMIP

TO

UNIT

VF

Vis

WAIEG

WAVFR

WAVEL,

WAVER

WCELE

XIINE, X 2INE

X3INE, X4INE

$\mathrm{XH}$
Sampling period.

Magnitude of angle selected for appiying the control criteria as explained in chapter III. Matrix (in Equation (4-21)) equal to

$$
\left(I \mathrm{~T}_{1}+\mathrm{AT}_{1}^{2} / 2 !+\ldots+\mathrm{A}^{\mathrm{m}-1} \mathrm{TT}_{\mathrm{T}} / \mathrm{m} !+\ldots\right) \overrightarrow{\mathrm{U}}\left(\mathrm{nT}_{1}\right)
$$

Integral of the transition matrix between zero and TAU.

Matrix used for calculating the matrix THETA. Value of function $f_{1}(t)$ defined by Equation (4-1).

Iteration number.

Matrix used for calculating the matrix PHI. Irmerging velocity of the water jet streams. wind velocity.

Length of the leg submerged in water. Wave frequency.

Wave position at the left legs of the platform.

Wave position at the right legs of the platform.

Wave celerity.

Variables used in calculating the terms in

Equation $(2-27)$ at the right legs.

Velocity of the state variables in Equation $(4-9)$. (In this way, the acceleration $\ddot{\theta}$ de- 
fined by Equation ( $4-5 c$ ) can be calculated).

IIEAD

XINE1, XINE2 Variables used in the calculation of terms in

XINE3, XINE4 Equation $(2-27)$ at the left legs.

$X I N E R$

XINPU

XIAMD

XIEGI

XIMIN

XINEI

$X M I N E$

$\mathrm{XK}$

$\mathrm{XN}$

XOLD

$\mathrm{XX}$

$X X(3,1)$

YY

In-line moment component due to the inertia force after dividing by the moment of inertia of the structure.

Time input vector $\vec{U}(t)$ as defined by Equation $(4-9)$.

Wave length.

Leg* length.

Leg moment of inertia as given by Equation $(B-5)$ in Appendix B. Weight of the platform leg. Moment of inertia of the whole structure as given by Equation (B-7) in Appendix B. Matrix used in the calculation of Equation (4-9).

Value of $\mathrm{N}$ in Equations (3-8) and (3-9) in the iteration ITO.

State vector at time (ITO - 1)TAU. State vector as defined by Equations (4-5) and $(4-7)$. (Its value is found by using Equation $(4-21))$.

Value defined by Equation (4-7). Matrix used in the calculation. (Equal to the 
product of $e^{A T_{1} \vec{X}}\left(n T_{1}\right)$ in Equation $\left.(4-21)\right)$.

YN Printing control reference. (Its value is given by XN in the iteration (ITO - 1)). Counter variable. 


\section{APPENDIX D}

\section{FIOW CHARTS}

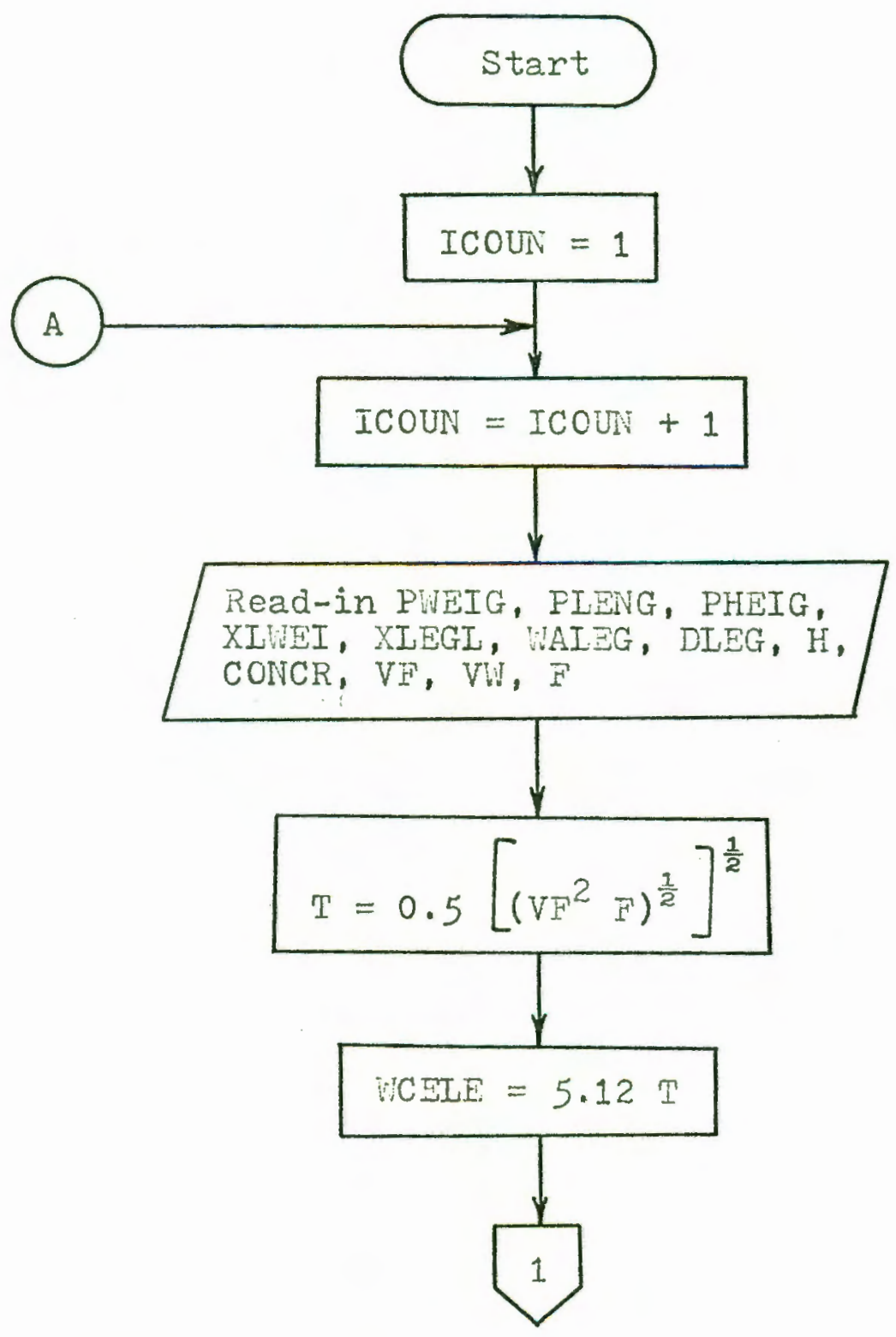

Figure 18. Flow chart for the program PLATFORI 


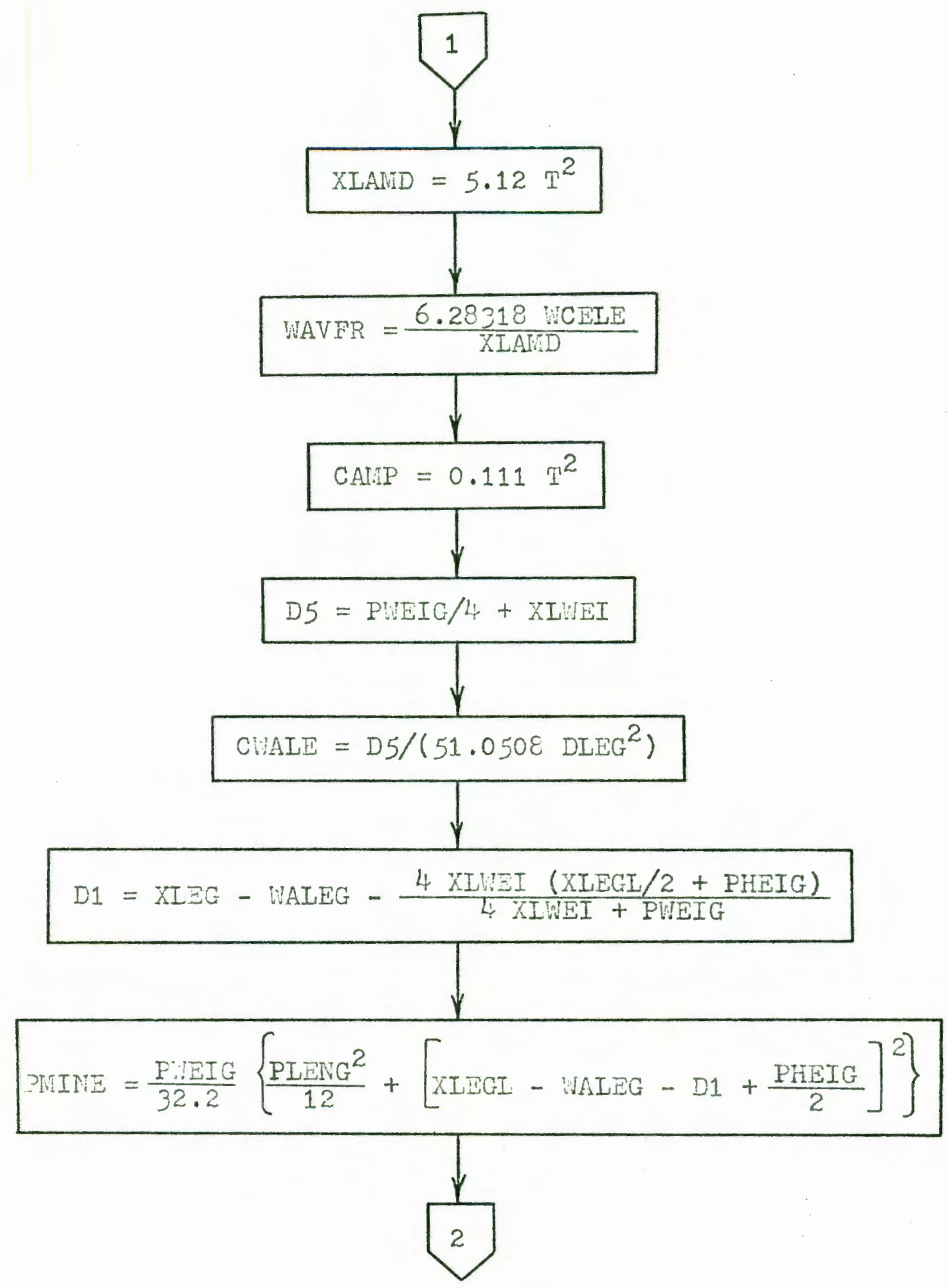

Figure 18. (Continued) 


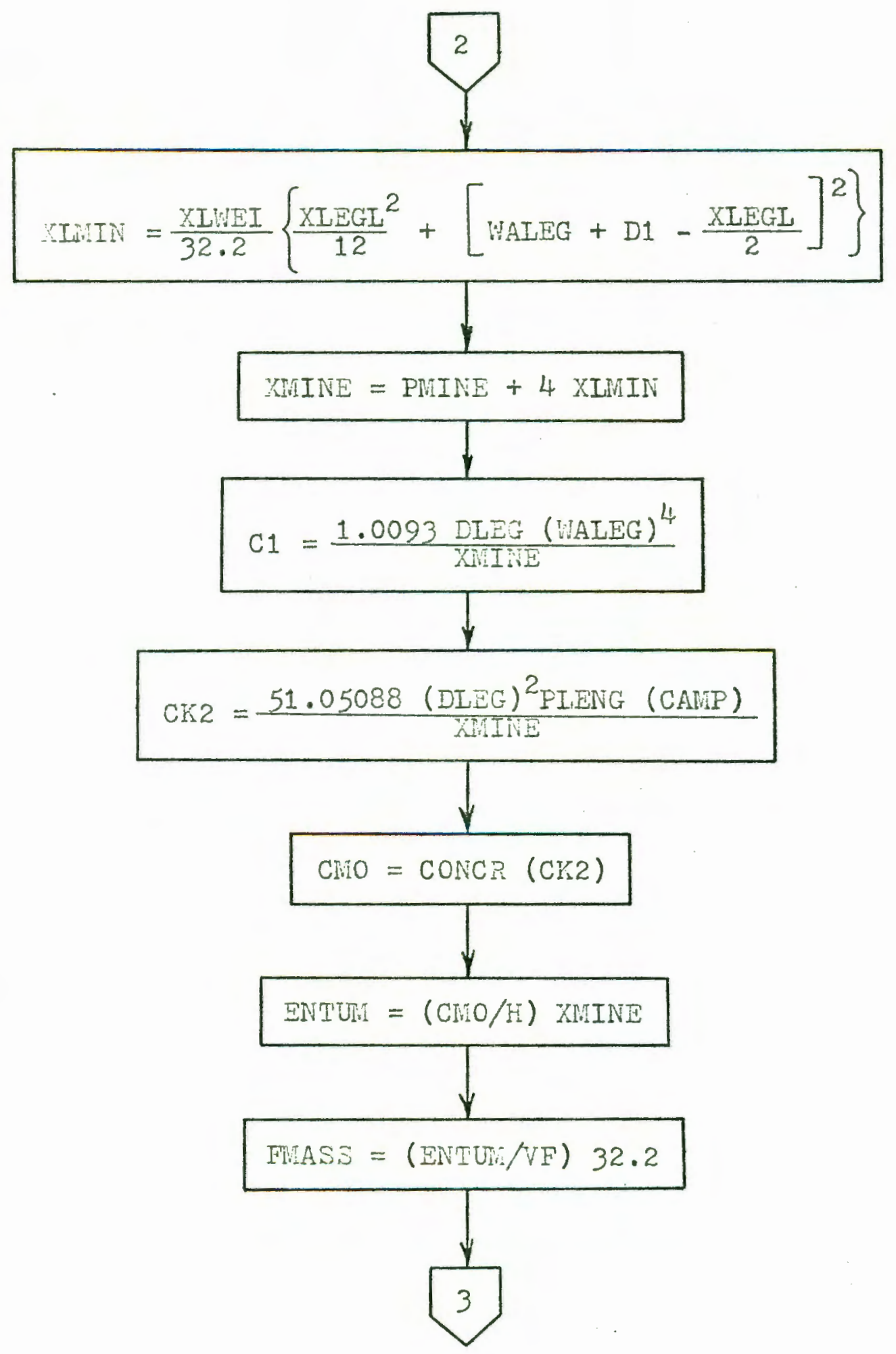

Figure 18. (Continued) 


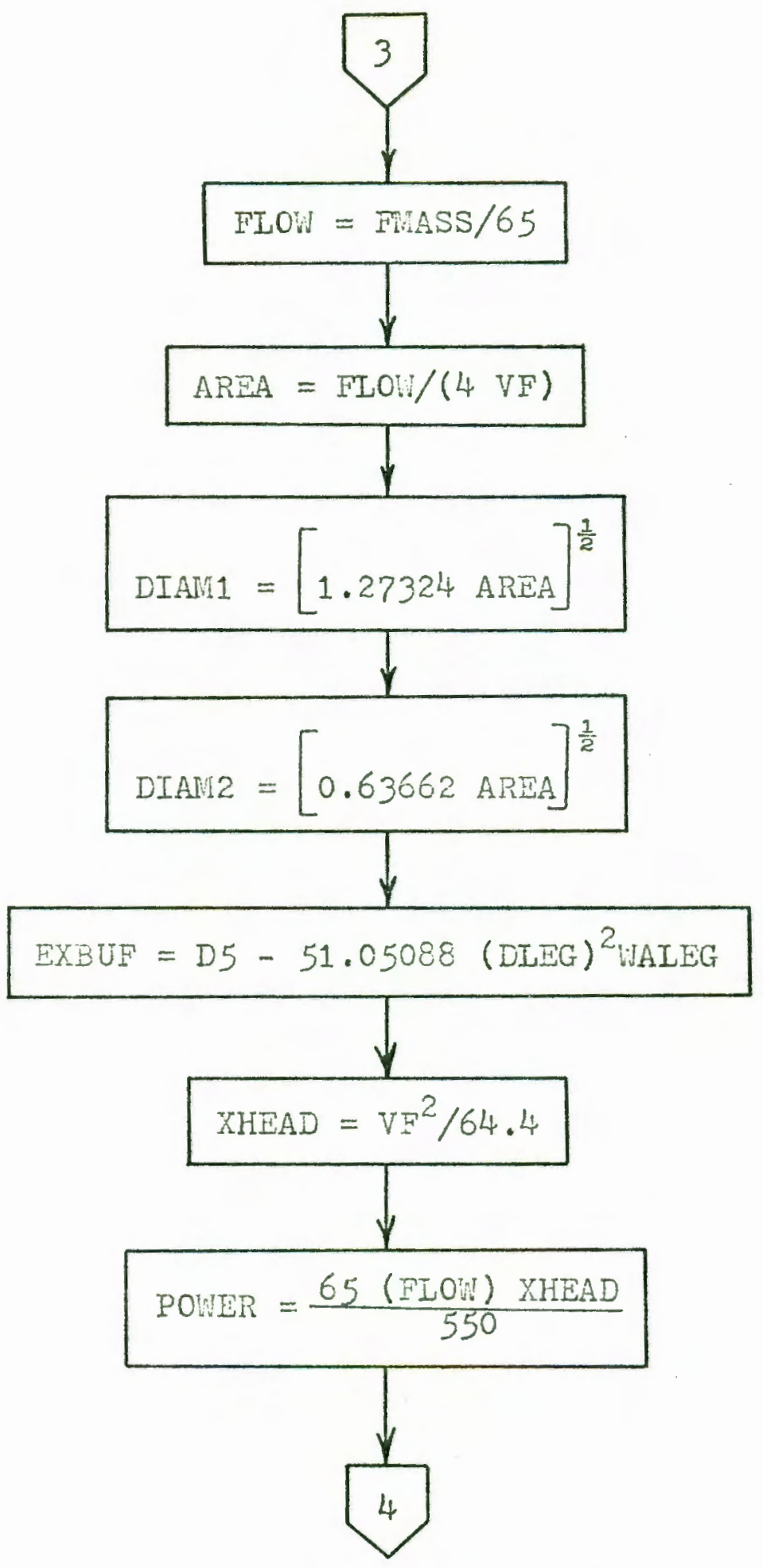

Figure 18. (Continued) 


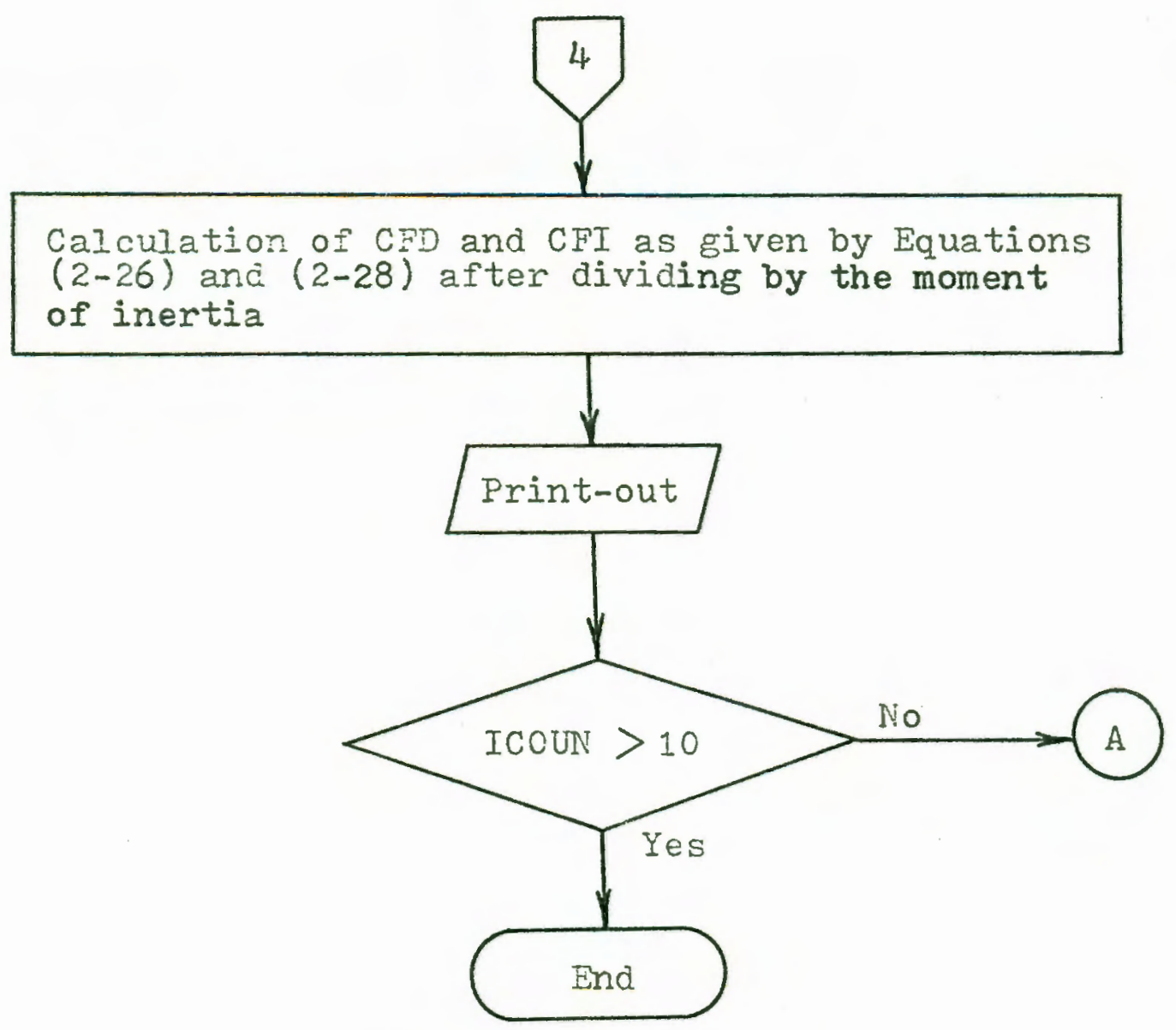

Pigure 18. (Continued) 


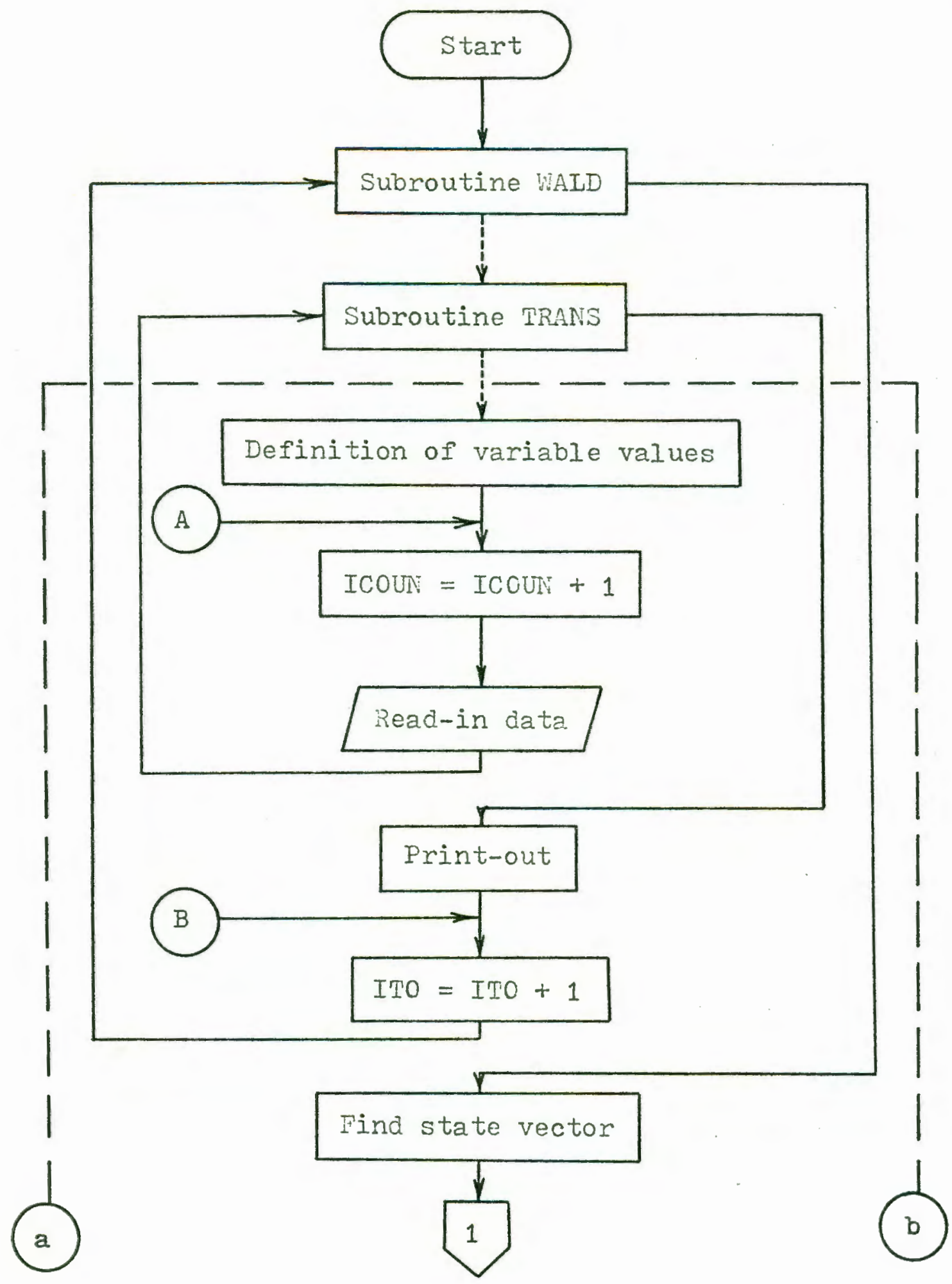

Pigure 19. Flow chart for the program Motion (the dashed lines enclose the subprogram PIATFORH). 


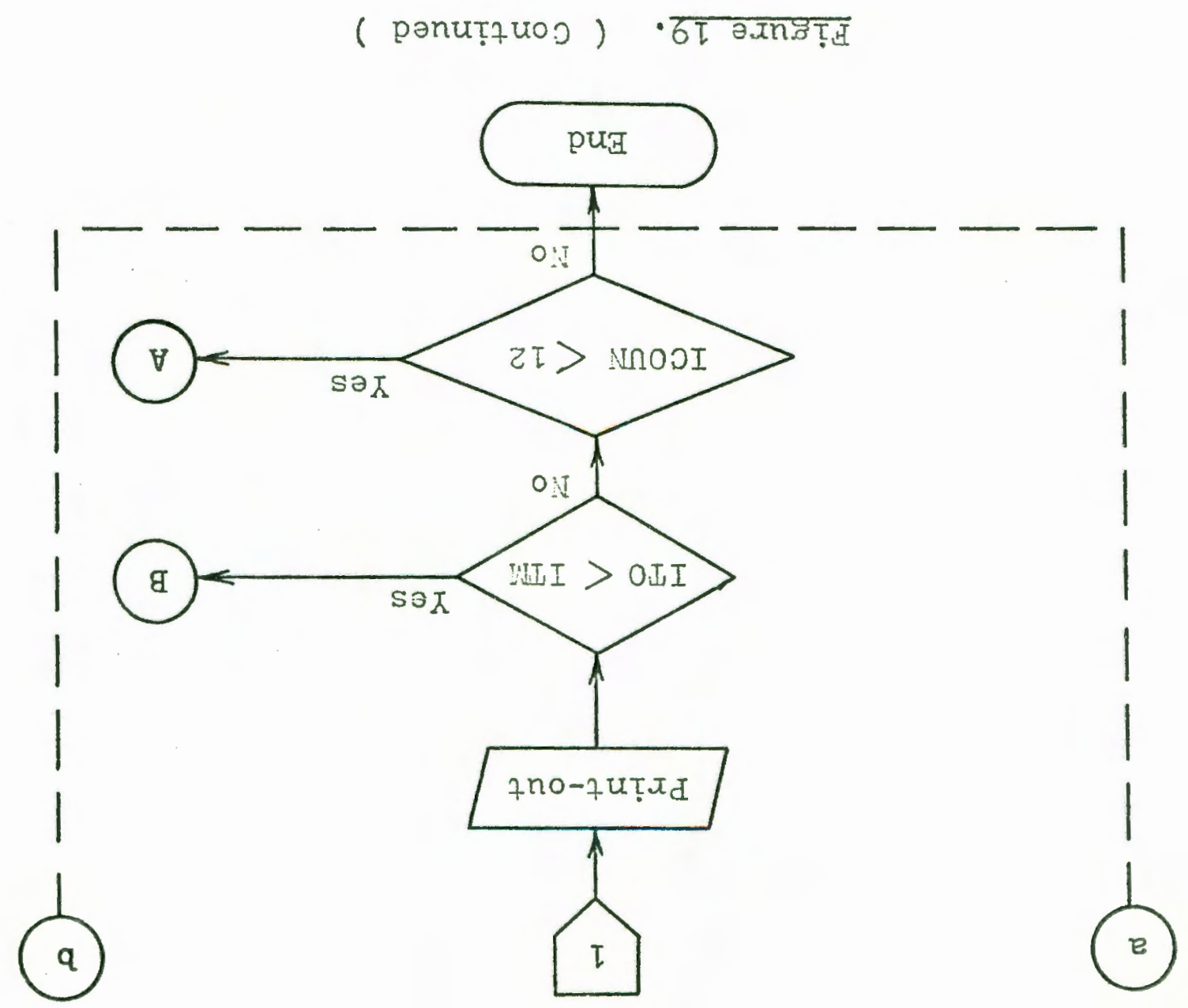




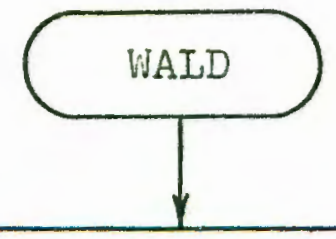

Buoyant moment after dividing by the moment of inertia

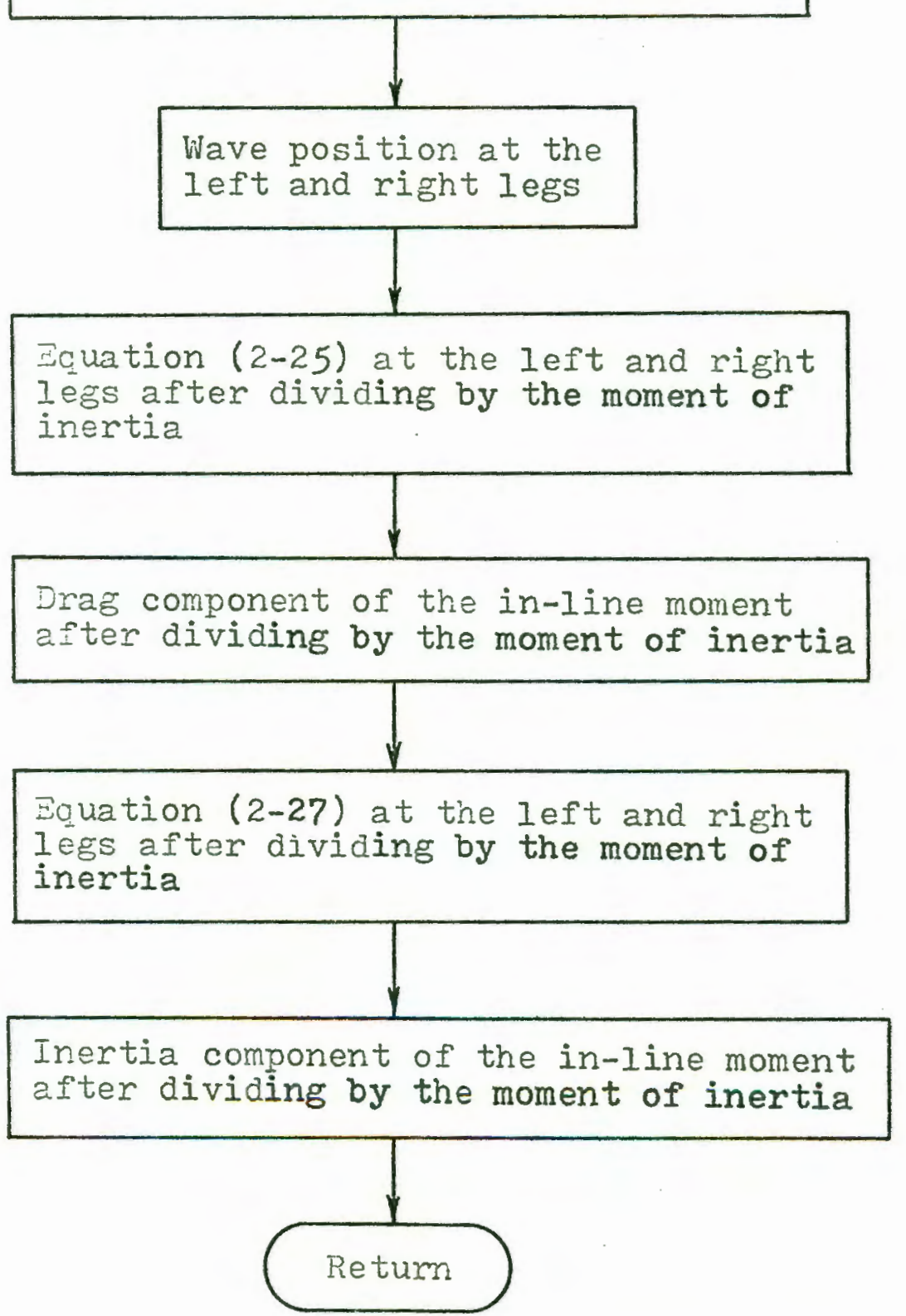

Disure 20. Flow chart for the subroutine WALD. 


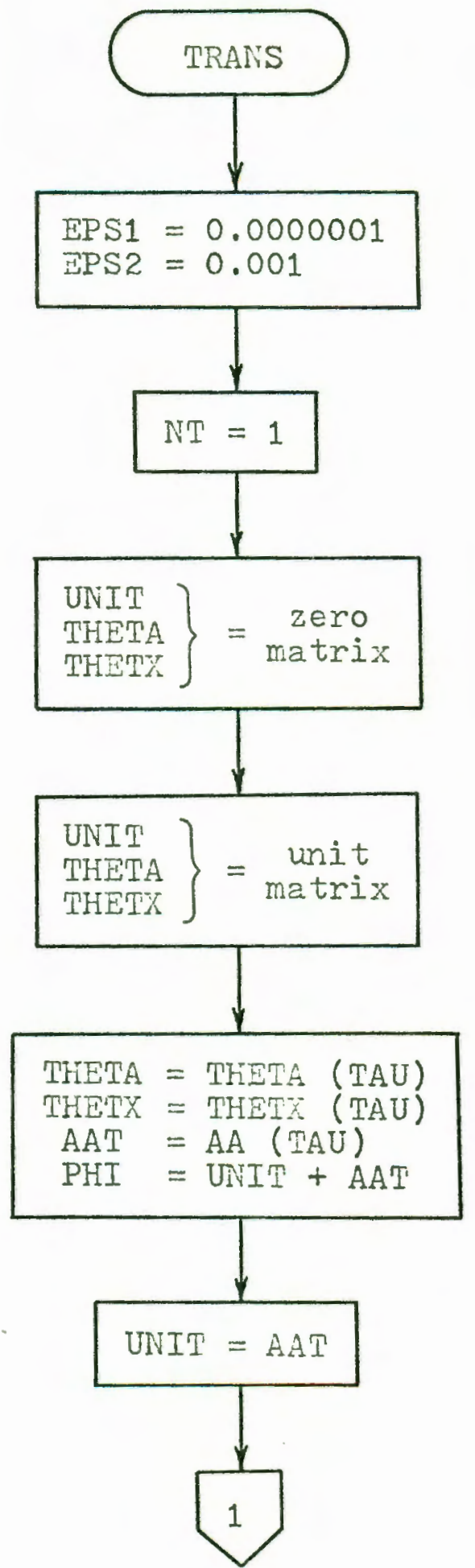

Figure 21. Flow chart for the subroutine TRANS 


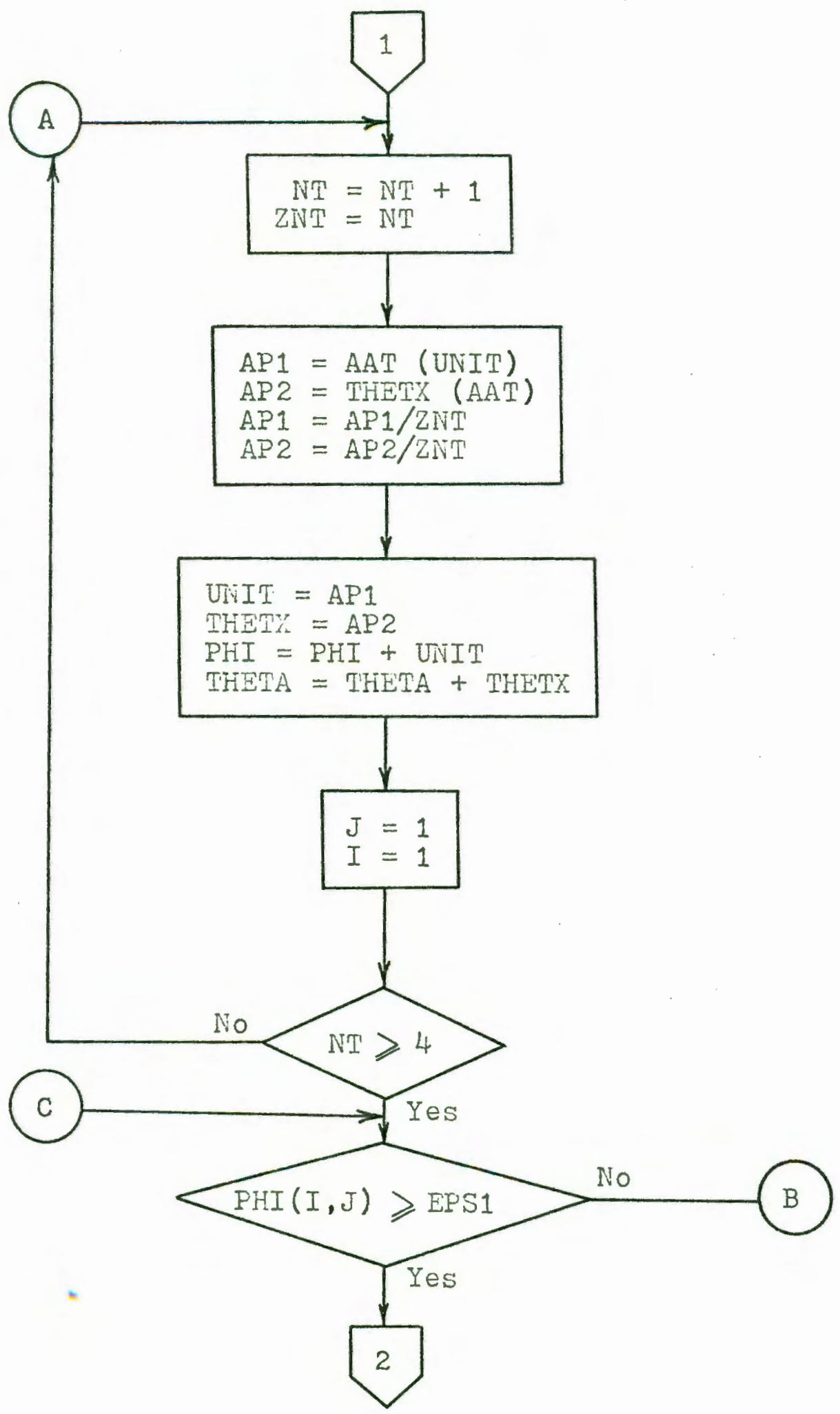

Figure 21. (Continued) 


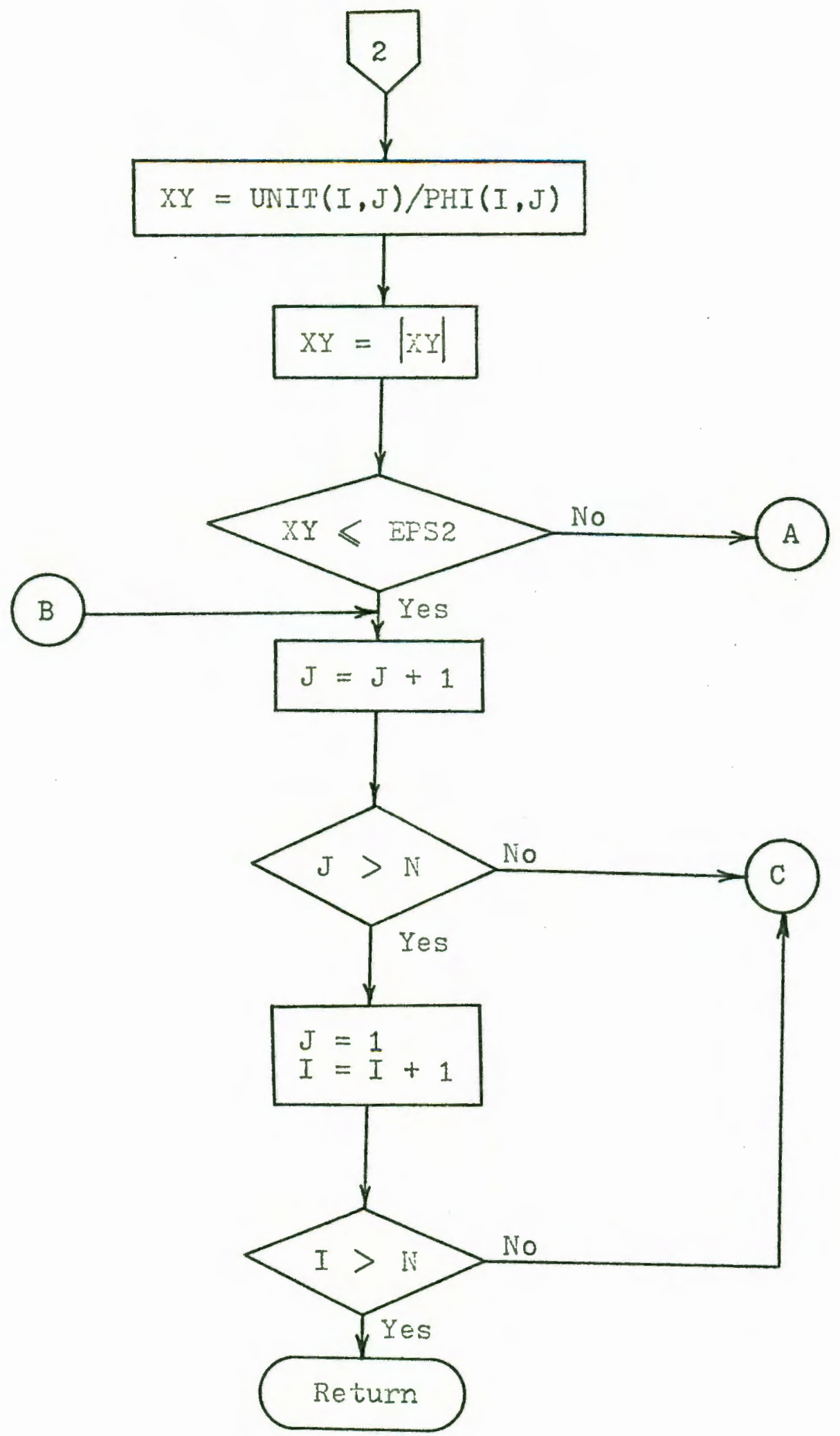

Figure 21. (Continued) 


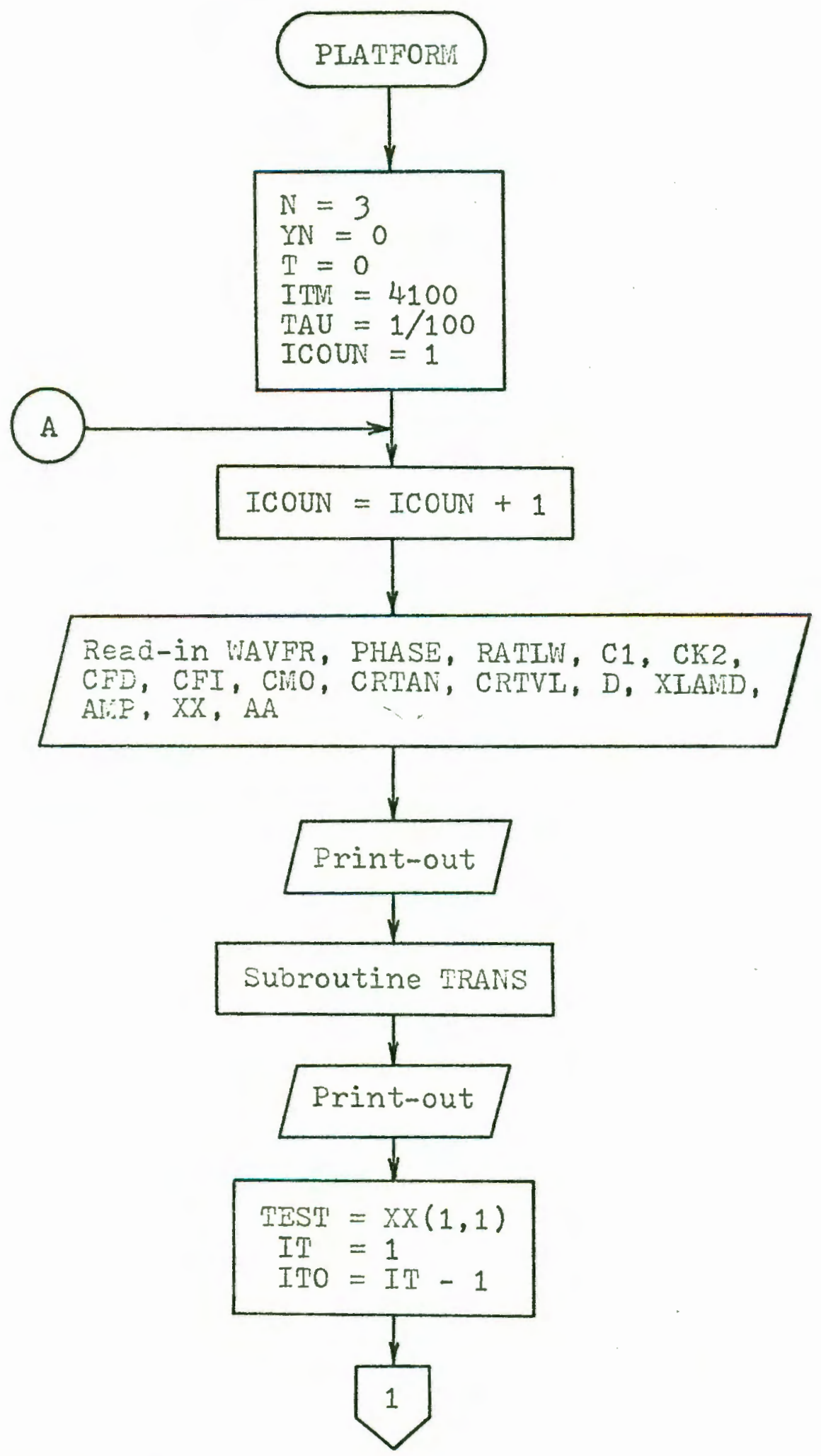

Pigure 22. Flow chart for the subprogram PLATFORn 


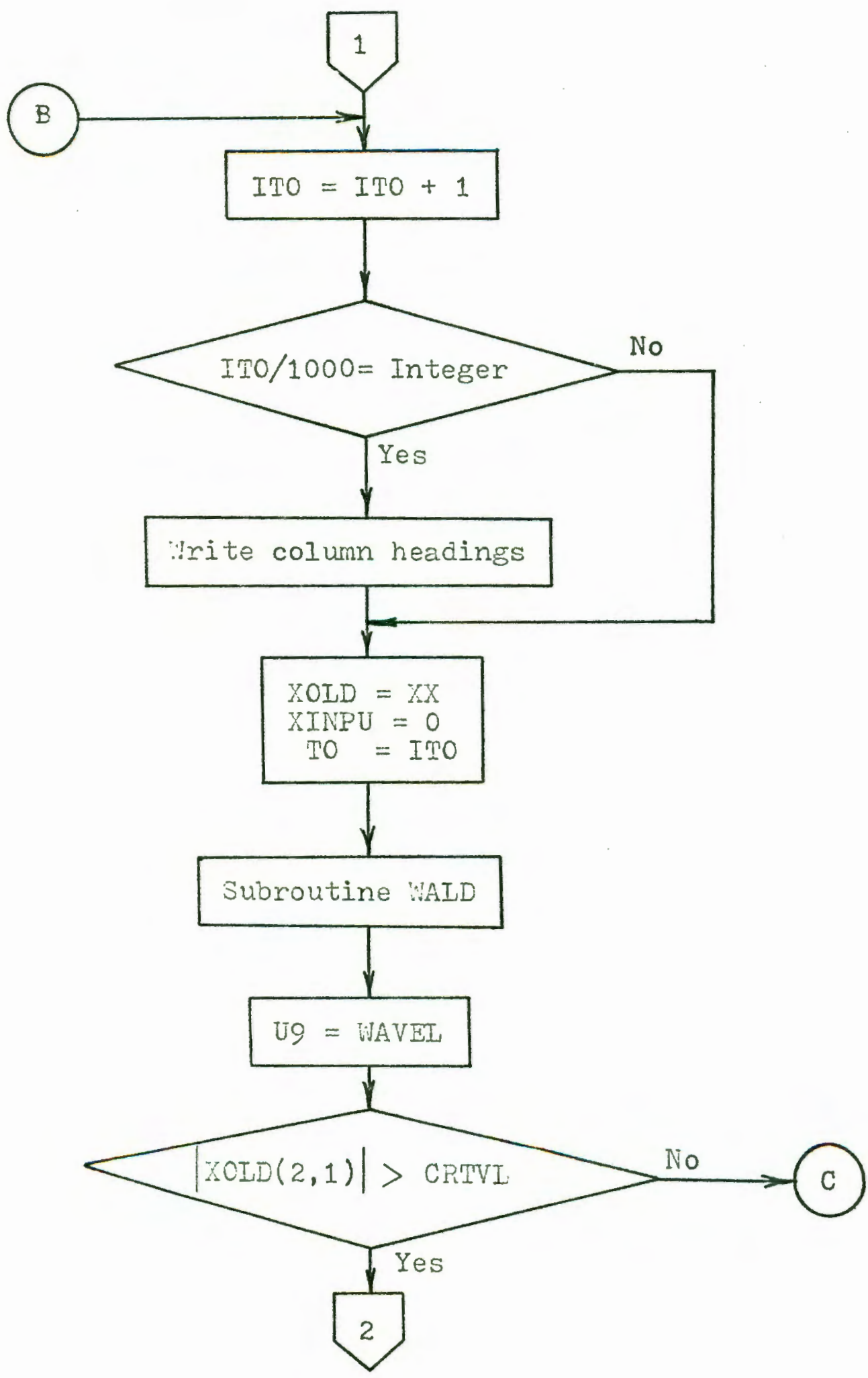

Eisure 22. (Continued) 


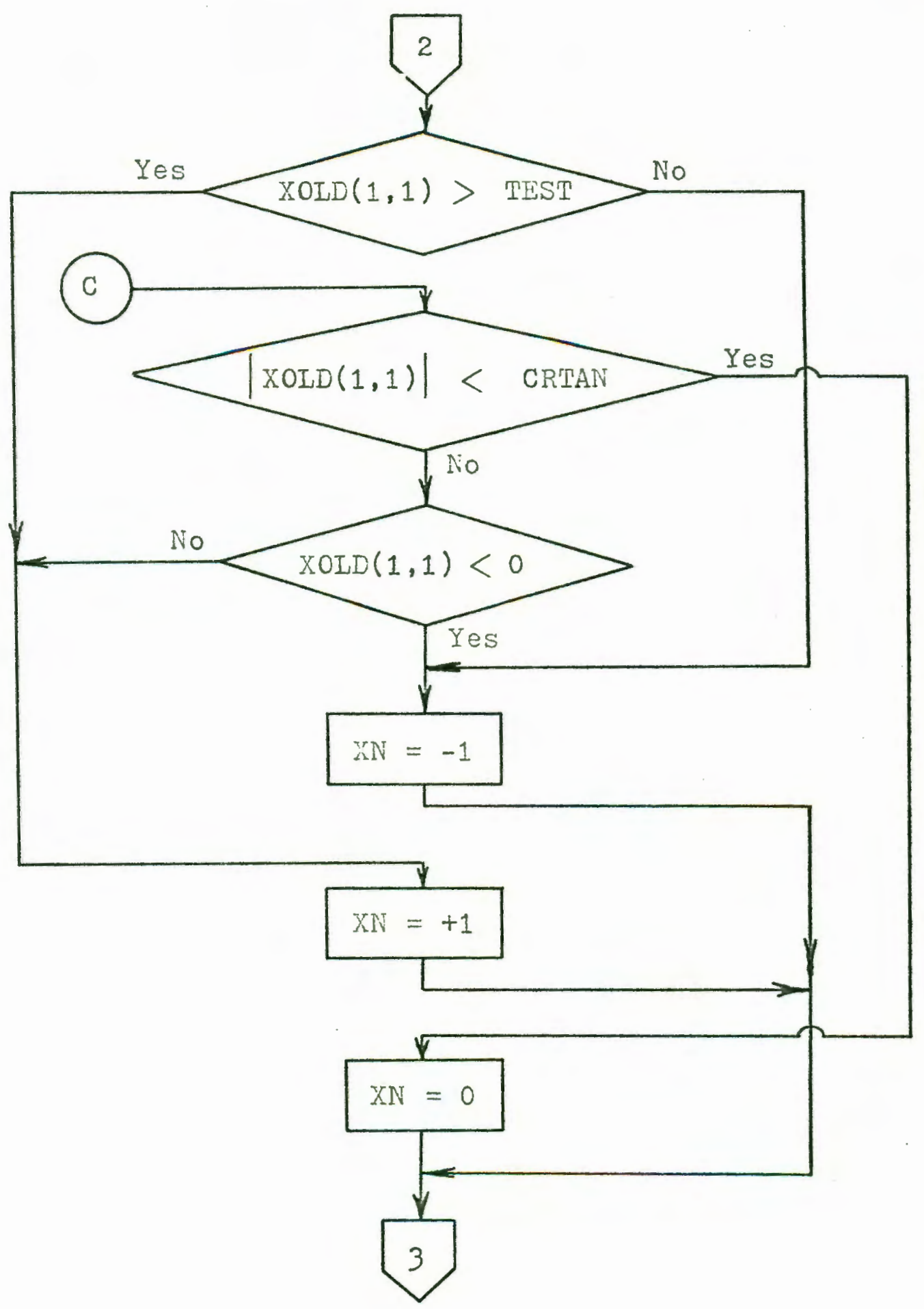

Figure 22. (Continued) 


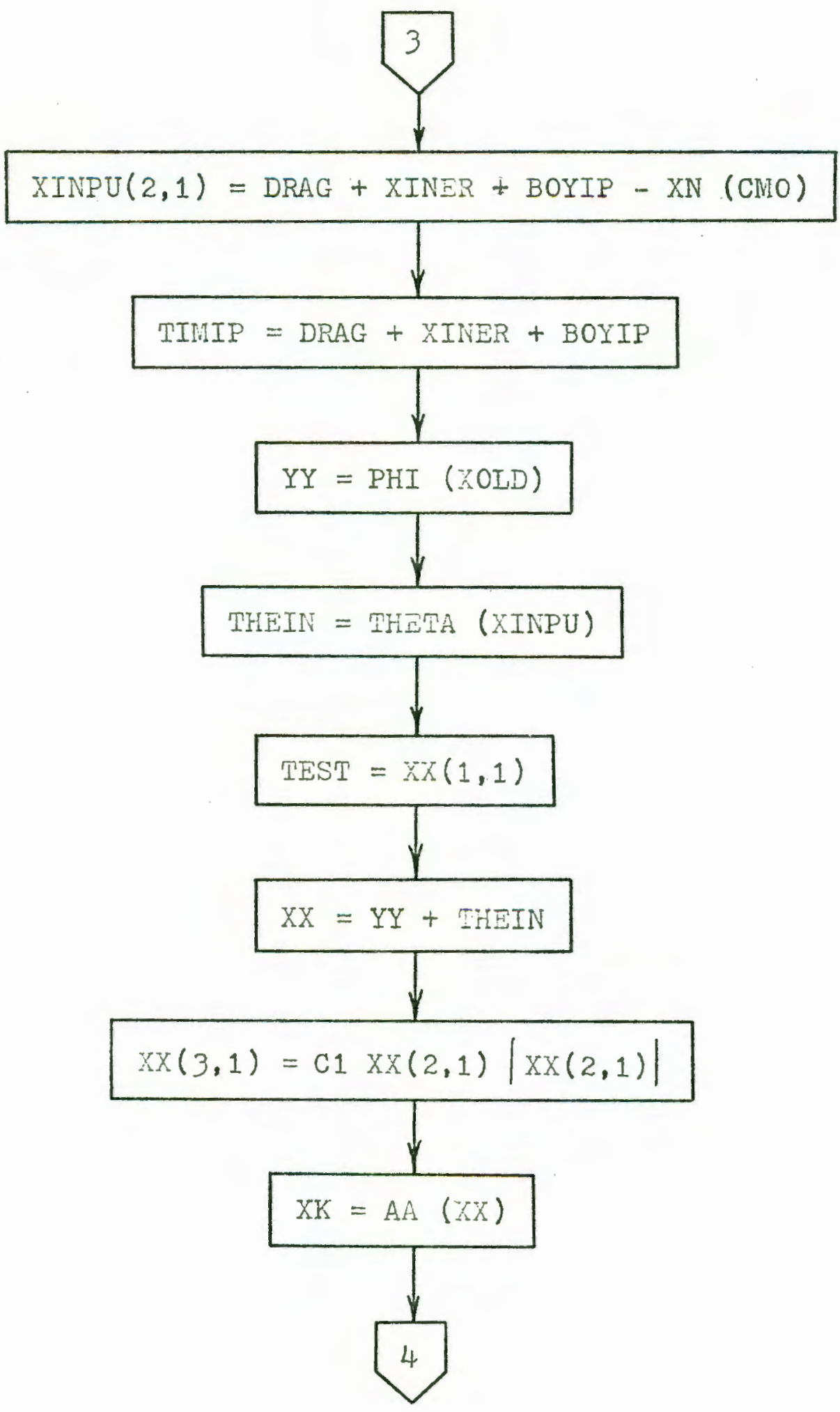

Figure 22. (Continued) 


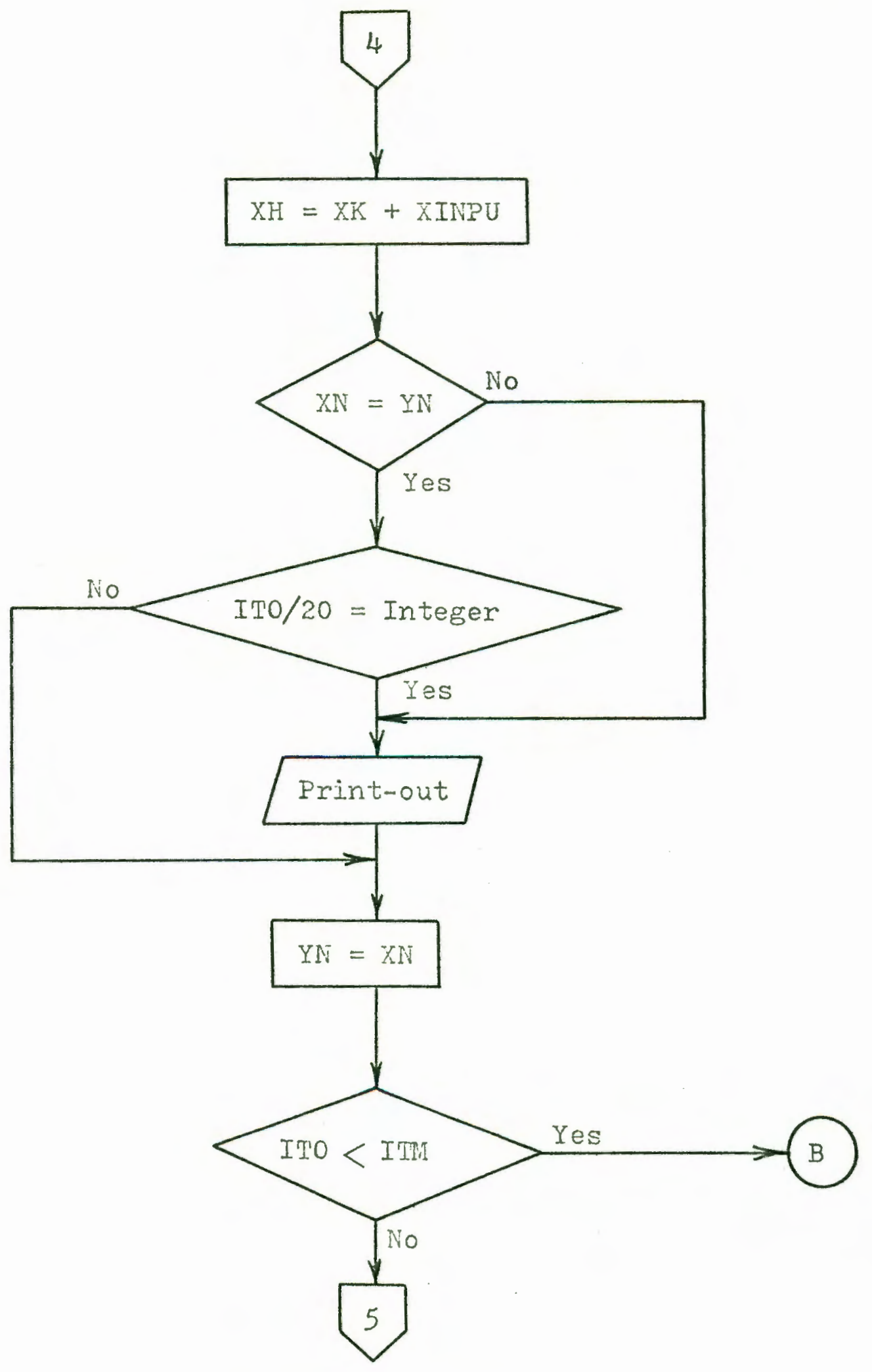

Figure 22. (Continued) 


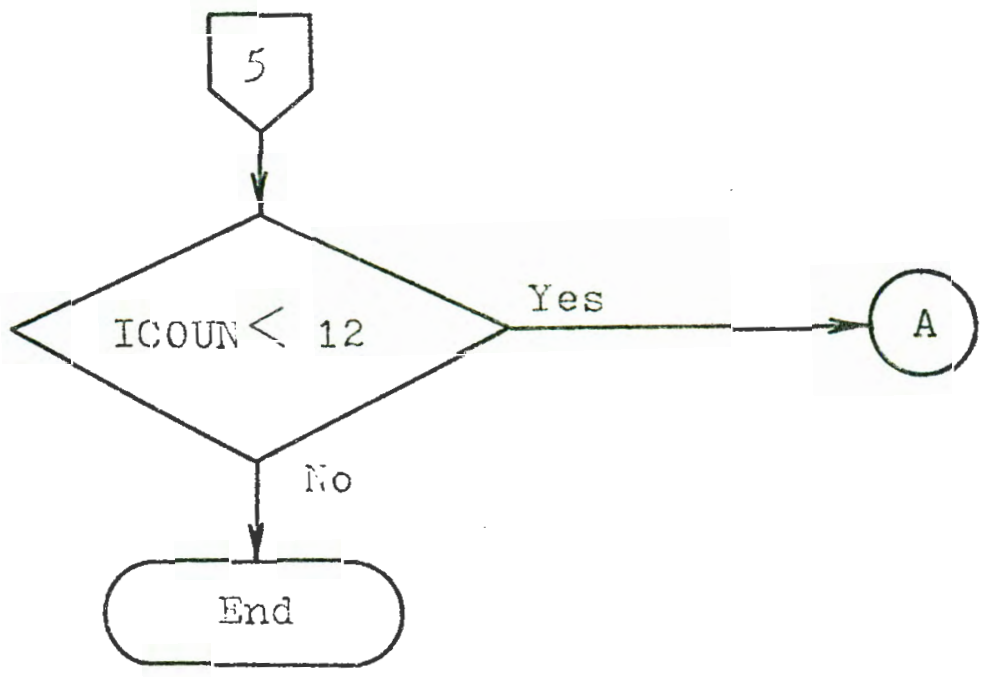

Iigure 22. (Continued) 


\section{APPENDIX E}

\section{COMPUTER PROGRAMS AND PRINTOUT}

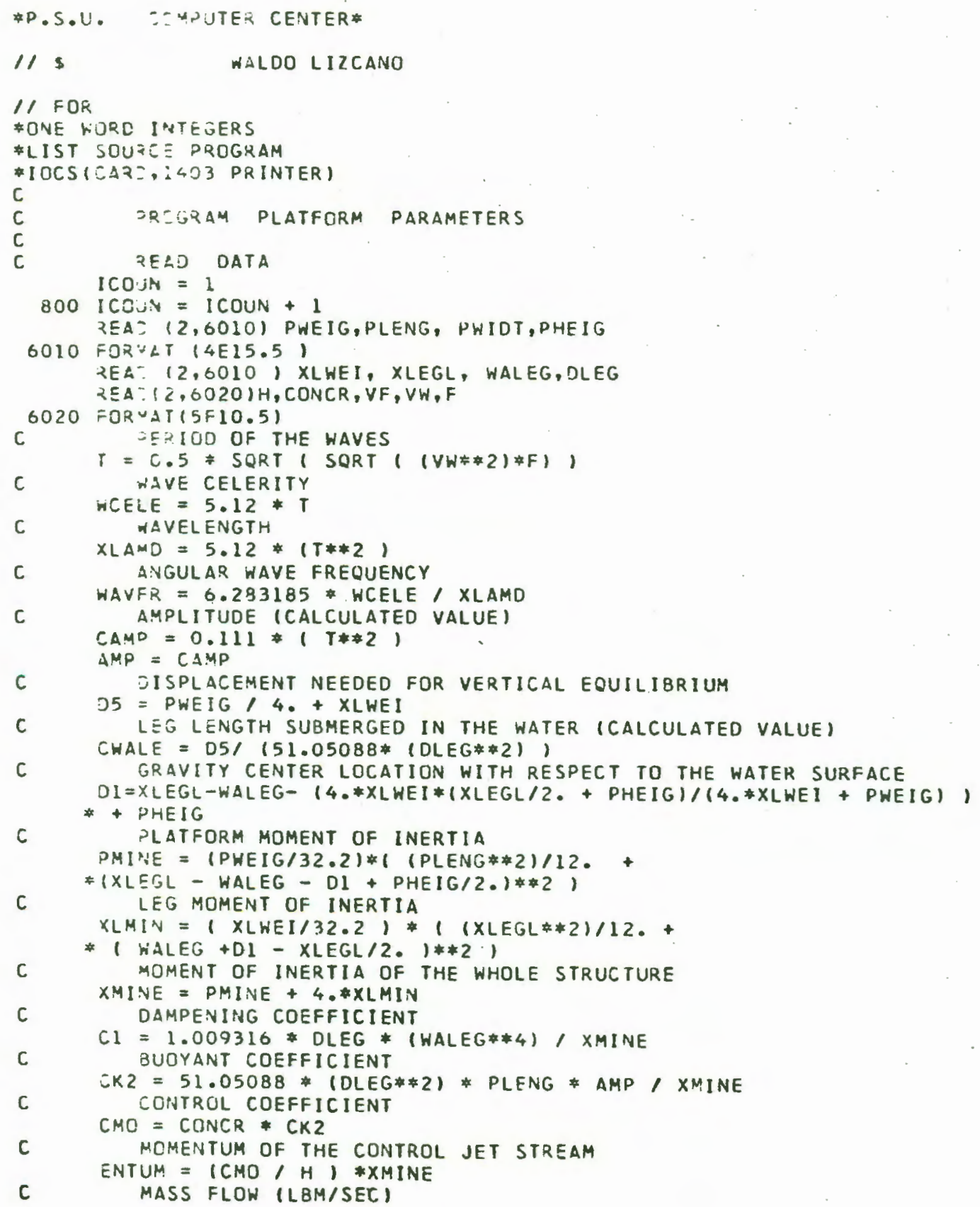




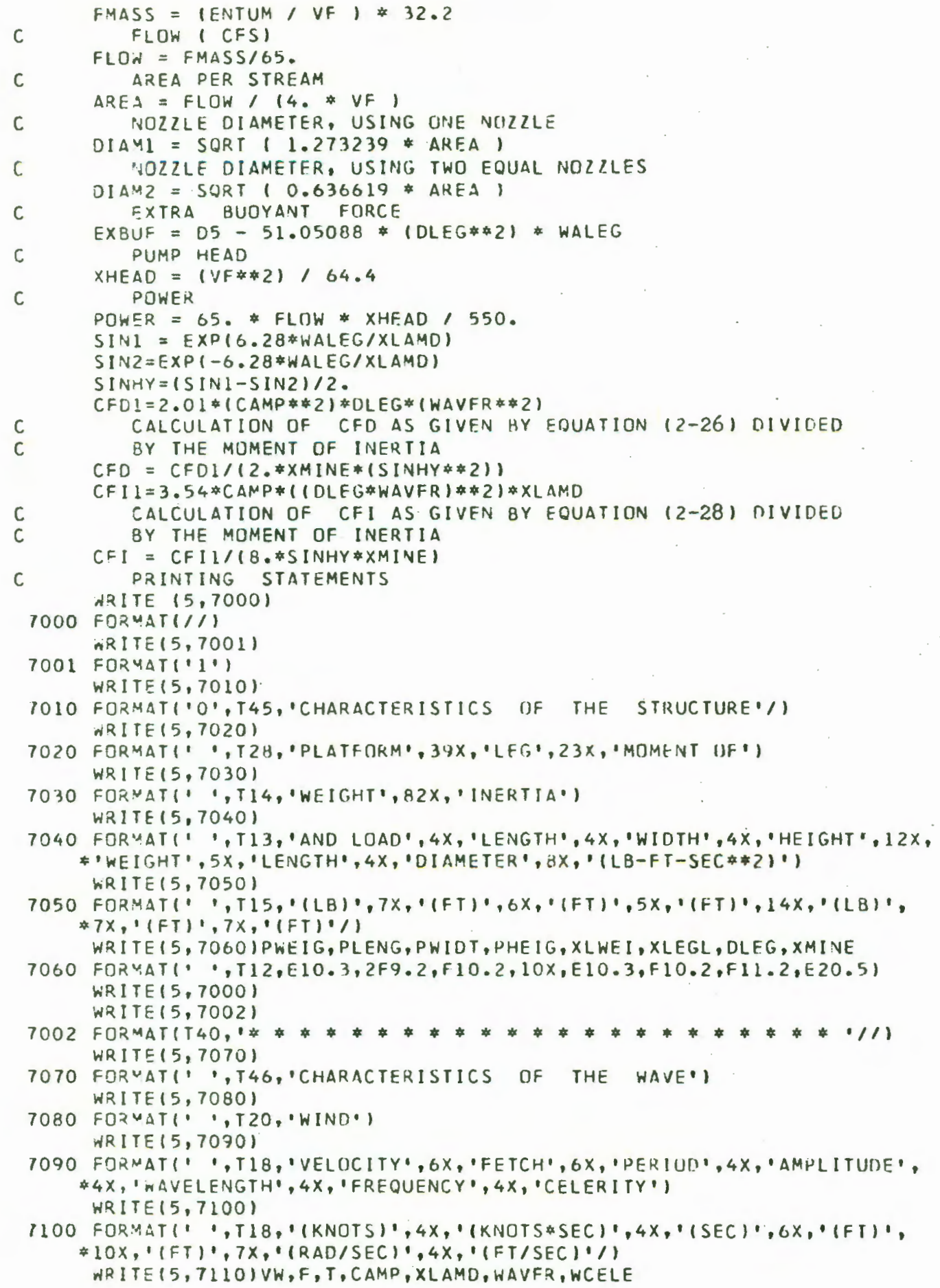


7110 FORMAT(F24,2,F13.2,F11.2,2F12,2,F14,4,F12.2)

WRITE $(5,7000)$

WRITE $(5,7002)$

WRITE $(5,712 \mathrm{U})$

7120 FORMATI" ",T38, 'COEFFICIEUTS OF THE EQUATION OF MOTION'/ WRITE $(5,7130)$

7130 FORMATI' ', T28, 'CL', I4X, 'CK2', 13X,'CFD', 13X, 'CF1', 12X, 'CMO'I WRITE $(5,7140)$

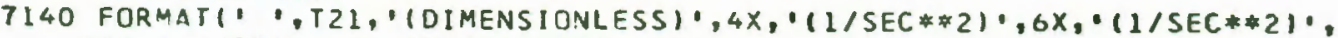
*6x, $(1 /$ SEC **2) $, 6 x, \cdot(1 /$ SEC**2) 1$)$

WRITE $(5,7150) \mathrm{C} 1, \mathrm{CK} 2, \mathrm{CFD}, \mathrm{CFI}, \mathrm{CMO}$

7150 FORMAT $(E 33.5, E 17.5,3 E 16.5)$

WRITE $(5,7000)$

WRITE $(5,7002)$

WRI TE $(5,7160)$

7160 FORMATI" 'T36. 'CHARACTERISTICS DF THE CONTROL REQUIREMENTS\% WRITE $(5,7170)$

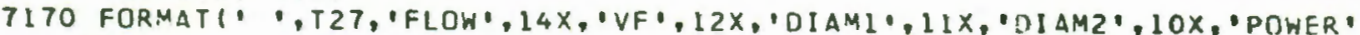
*)

WRITE $(5,7180)$

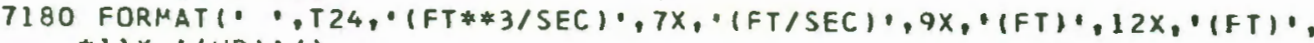
* $11 \times, \cdot(H P), 1)$

WRITE $(5,7190)$ FLOH, VF, DIAMI, OI AM2, POWER

7190 FORMAT (F32.2,F16.2,F15.3,F16.3,F17.2)

HRITE $(5,7000)$

WRITE $(5,7002)$

HRITE $(5,7200)$

7200 FORMATI" "T49, 'BUOYANCY REQUIREMENTS $/ / 1$

WRITE $(5,7210)$ EXBUF

7210 FORMATI' ', T50, 'EXBUF = ',EL2.5,' LB!/1

HRITE $(5,7220)$ CWALE

7220 FORMAT!" T50, 'CWALE $=0, F 8.2$, , FT, $^{\circ}$

WRITE $(5,7000)$

WRITE $(5,7001)$

910 CALL EXIT

IF IICOUN - $10,800,800,810$

END

FEATURES SUPPORTEO

ONE WORD INTEGERS

I OCS

CORE REQUIREHENTS FOR

$\begin{array}{lllll}\text { COMMON } & \text { O VARIABLES } & 96 & \text { PROGRAM } & 1260\end{array}$

END OF COMPILATION

II XEO 
CHARACTERISTICS OF THE STRUCTURE

\begin{tabular}{|c|c|c|c|c|c|c|c|}
\hline \multicolumn{4}{|c|}{ NLATFORM } & \multicolumn{3}{|c|}{ LEC } & \multirow{2}{*}{$\begin{array}{l}\text { MOMENT OF } \\
\text { INERIIA } \\
\text { 11B-FI-SEC* } * 2 \text {. }\end{array}$} \\
\hline $\begin{array}{l}A N 0 \text { LOAC } \\
\text { (LB) }\end{array}$ & $\begin{array}{l}\text { ZEQCET } \\
\text { (FT) }\end{array}$ & $\begin{array}{l}-10 T H \\
\text { IFT }\end{array}$ & $\begin{array}{l}\text { HE IGHT } \\
\text { (FT) }\end{array}$ & $\begin{array}{c}\text { WE IGHT } \\
\text { (LI) }\end{array}$ & $\begin{array}{l}\text { LENG IH } \\
\text { (FF) }\end{array}$ & $\begin{array}{c}\text { DIAMEIER } \\
\text { |f I I }\end{array}$ & \\
\hline
\end{tabular}

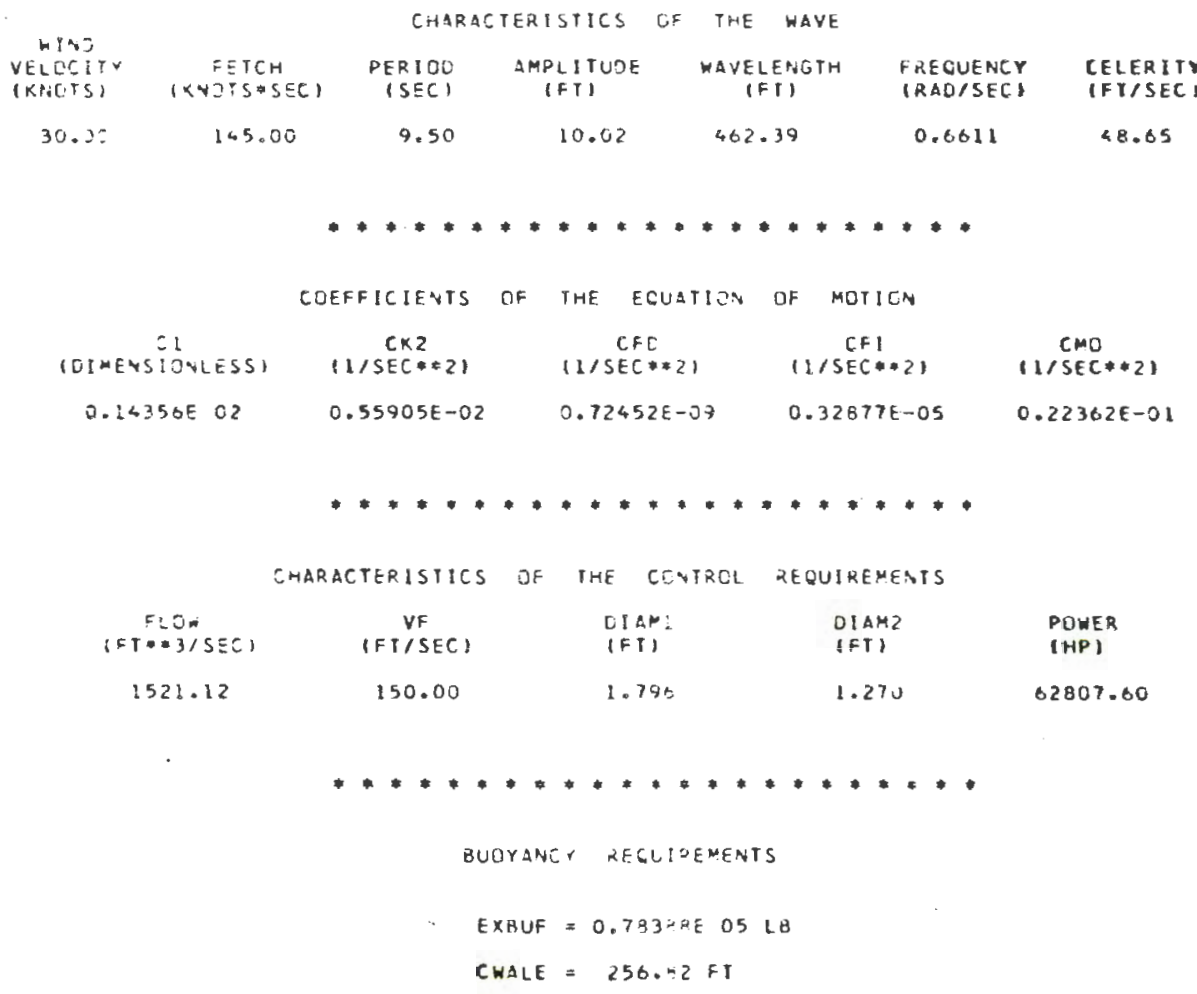




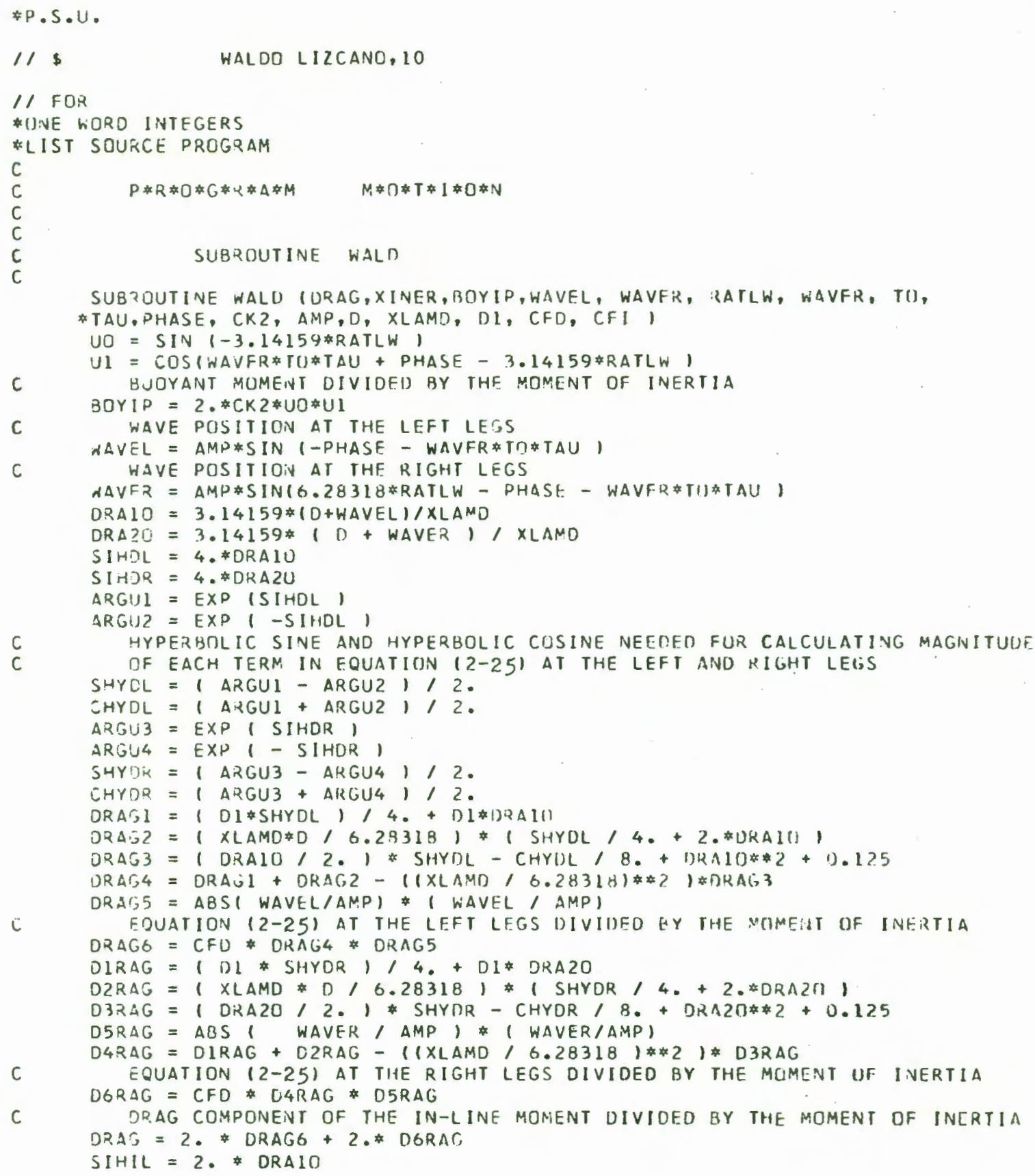




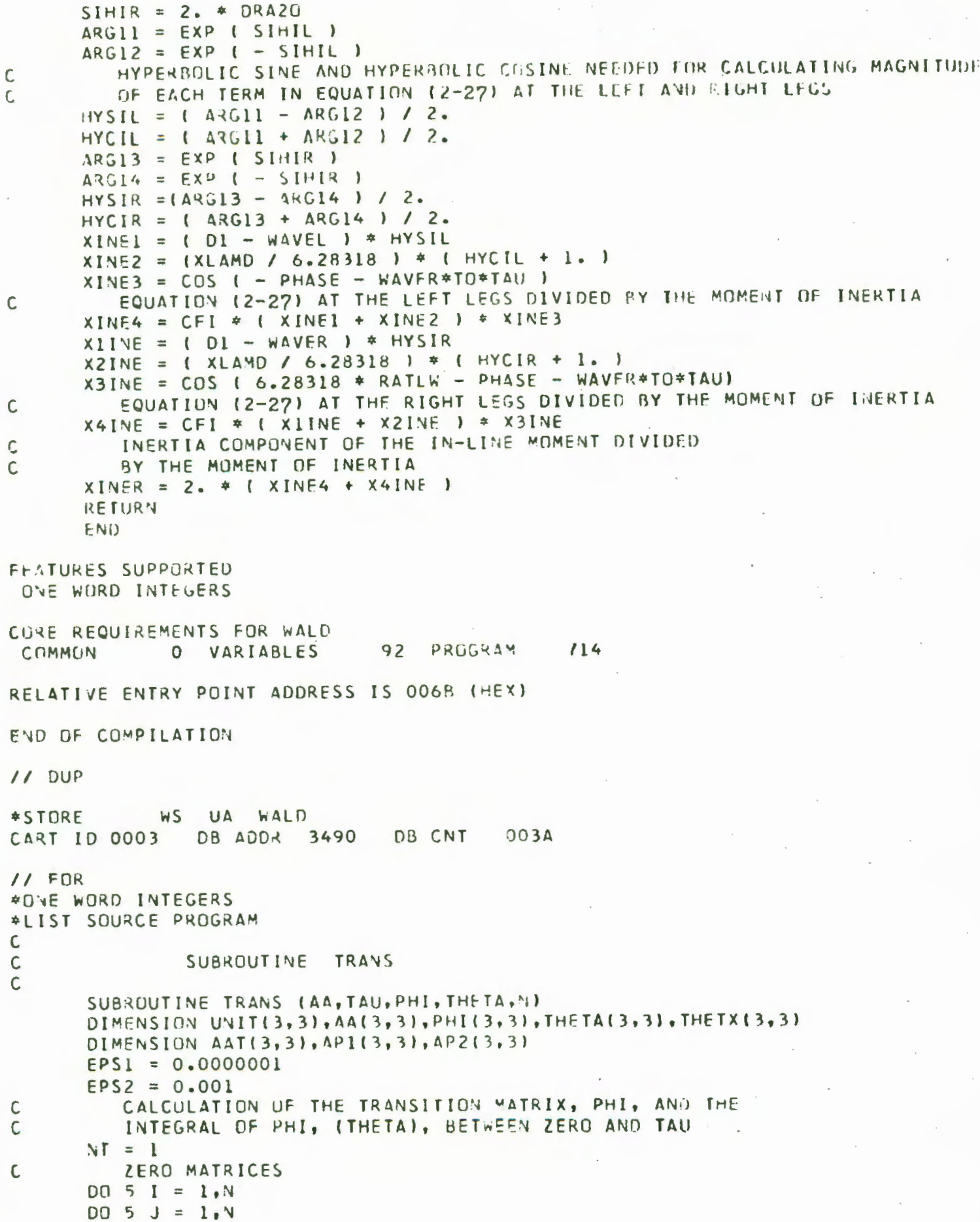




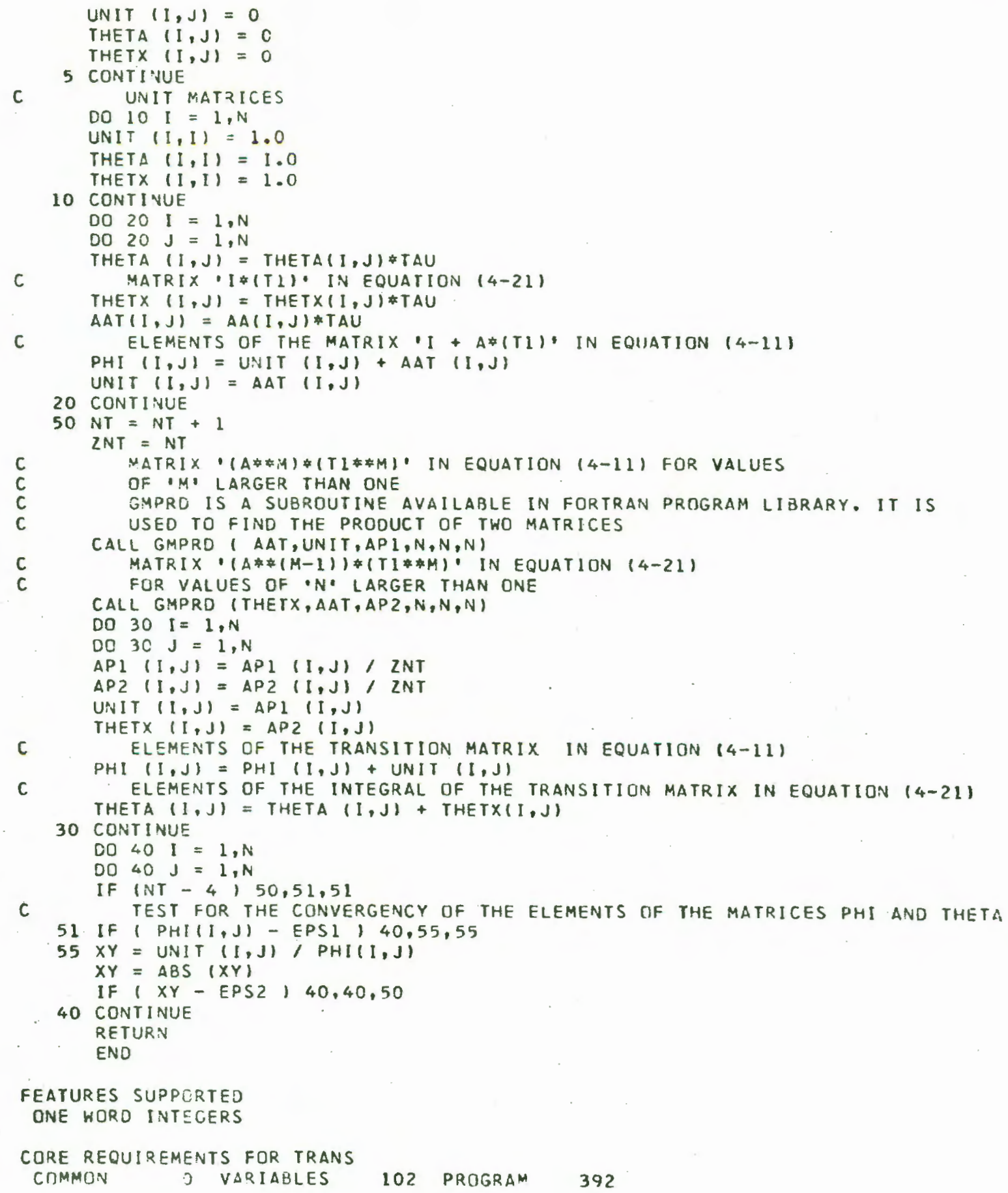


RELATIVE ENTRY POINT ADDRESS IS 006F (HEX)

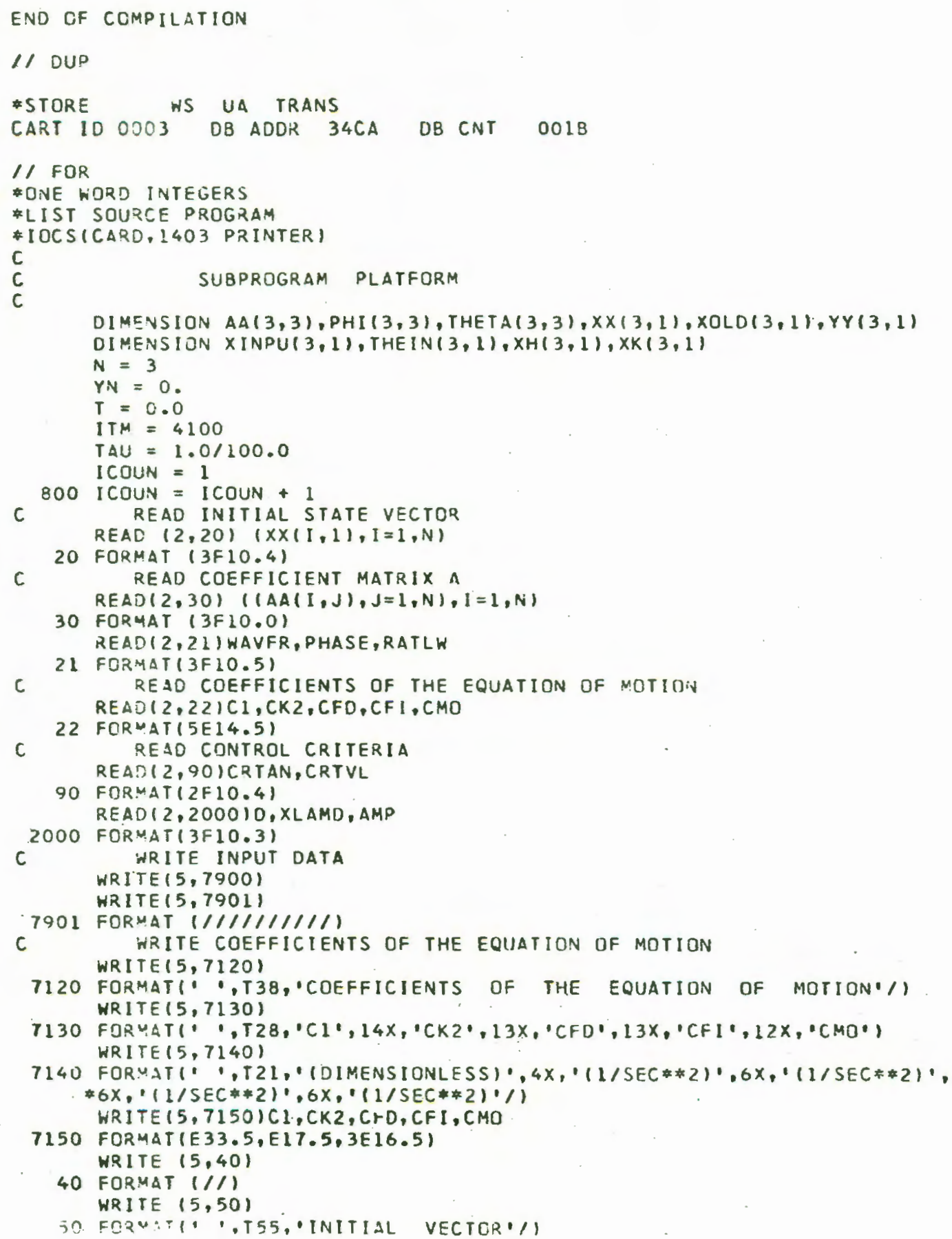


WRITE $(5,60)(x \times(I, 1), I=1, N)$

60 FORMAT(', T35, 3F 15.2$)$

WRITE $(5,40)$

WRITE $(5,70)$

70 FORMATI' 'T51, 'COEFFICIENT MATRIX'/!

WRITE $(5,65) \quad((A A(I, J), J=1, N), I=1, N)$

65 FORMAT $(\cdots$, T35,3F 15.5$)$

CALL TRANS (AA, TAU, PHI, THETA,N)

WRITE $(5,40)$

WR ITE $(5,75)$

75 FORMATI" ",T52, "TRANSITION MATRIX'/1

WRITE $(5,65)((P H I(I, J), J=1, N), I=1, N)$

WRITE $(5,40)$

WRITE $(5,85)$

85 FORMATI" ',T42,'INTEGRAL OF THE TRANSITION MATRIX*/1

WRITE $(5,65)((\operatorname{THETA}(I, J), J=l, N), I=1, N)$

WRITE $(5,7900)$

7900 FCRMAT $(11 \cdot)$

TEST $=X \times 11,11$

$I T=1$

C

$I T O=I T-I$

HRITE COLUMN HEADINGS

HRITE $(5,500)$

500 FORMAT' 'O', T3, 'TIME', 8X, 'ANGLE', 5X, 'VELOCITY', $8 X$, 'DAMPEN', $5 X$,

* 'aCCEleration', $7 x$, 'WAVE',9x, 'TIME INP',9x, "INPUT', $7 x$, 'CONTROL'/1

c CALCULATE THE INPUT DF THE PLATFORM

80 CONTINUE

ITO = ITO +1

$X I T O=I T O$

XITO $=$ XITO $/ 1000$.

MITO $=$ ITO $/ 1000$

YMITO = MITO

IF (XITO -YMITO) $1000,999,1000$

999 WRITE $(5,500)$

1000 D0 $95 \quad I=1, N$

$X O L D(I, I)=X X(I, 1)$

95 CONTINUE

DO $120 \quad 1=1,3$

XINPU $(1,1)=0$

120 CONTINUE

TO $=$ ITO

CALL WALD. $($ DRAG, XINER, BOYIP, WAVEL, WAVER, RATLW, HAVFR, TO,

* TAU, PHASE, CKZ, AMP,D, XLAMD, DI, CFD, CFI)

$U 9$ = WAVEL

C DEFINITION OF 'N. IN EQUATIONS $(3-8)$ AND
$C$

DEFINITION OF ' $N$ ' IN EOUATIONS $(3-8)$ AND $(3-9)$

IF ( $A B S$ (XOLD $(2,1)$ ) - CRTVL) $128,128,124$

124 IFI XOLDII, 1) $600,620,620$

600 IF $(X O L D(1,1)$ - TEST) $601,601,605$

$601 \times N=-1.0$

60 TO 150

$605 \times N=1.0$

GO TO 150

620 IF $(X O L D(1,1)$ - TEST $) 021,621,625$

$621 \times N=-1.0$

GO TO 150

$625 X N=1.0$

GO TO 150

TEST FOR THE ANGLE CONTROL CRITERION 


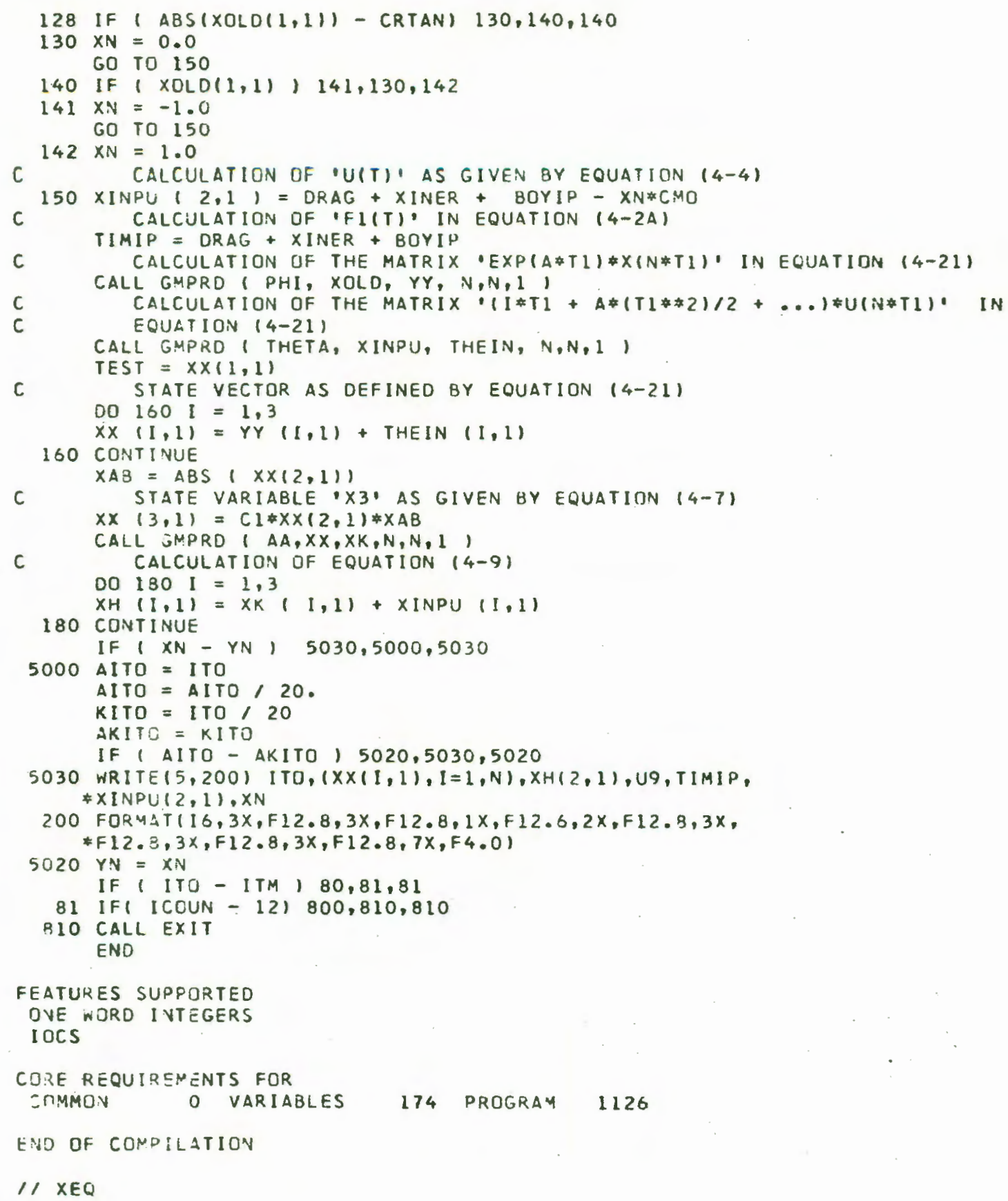




$\begin{array}{ccccc}\text { COEFFICIENTS } & \text { BF } & \text { THE EGUATION } & \text { OF MOTION } \\ \text { C1 } & \text { CK2 } & \text { CFD } & \text { CFI } & \text { CMO } \\ \text { (DIMENSIGNLESS) } & (1 / S E C * 21 & (1 / S E C * 2) & (1 / S E C * 2) & (1 / S E C * 2) \\ 0.14353 E ~ 02 & 0.55905 E-02 & 0.72452 E-09 & 0.32877 E-05 & 0.22362 E-01\end{array}$

INITIAL VECTER

$\begin{array}{lll}0.20 & 0.00 & 0.00\end{array}$

COEFFICIENT NATRIX

$\begin{array}{llr}0.00000 & 1.00000 & 0.00000 \\ 0.00000 & 0.00000 & -1.00000 \\ 0.00000 & 0.00000 & 0.00000\end{array}$

TRANSITION MATRIX

$\begin{array}{llr}1.00000 & 0.01000 & -0.00005 \\ 0.00000 & 1.00000 & -0.01000 \\ 0.00000 & 0.00000 & 1.00000\end{array}$

INTEGRAL OF THE TRANSITION MATRIX

$0.01000 \quad 0.00005 \quad-0.00000$

$\begin{array}{lll}0.00000 & 0.01000 & -0.00005\end{array}$

$0.00000 \quad 0.00000 \quad 0.01000$ 


\begin{tabular}{|c|c|c|c|c|c|c|c|c|}
\hline TIME & ANGLE & VELOCITY & DAMPEN & ACCELERATION & WAVE & TIME INP & INPUT & CONTRQL \\
\hline 1 & 0.14999936 & -0.00013012 & -0.000000 & -0.01301243 & 9.99981500 & 0.00934953 & -0.01301246 & b. \\
\hline 20 & $0.14+73582$ & -0.00265444 & -0.000010 & -0.01354734 & 9.92567255 & 0.00880454 & $-0.0135,745$ & \\
\hline 40 & 0.17472877 & -0.00543275 & -0.000042 & -0.01421630 & 9.70379259 & 0.00810332 & -0.01425867 & $i$ \\
\hline 60 & $0.1+155164$ & -0.00835533 & -0.000100 & -0.01498021 & 9.33766367 & 0.00728156 & -0.01508043 & i. \\
\hline 80 & 0.11457446 & -0.01143952 & $-0.00018 ?$ & -0.01582266 & 8.83272364 & 0.00635147 & -0.01601053 & $i$. \\
\hline 100 & $0.1+2.96267$ & -0.01469914 & -0.000310 & $=0.01672495$ & 8.19647600 & 0.00532685 & -0.01103514 & i. \\
\hline 120 & $0 . \ln 76, B O 51$ & -0.01814408 & -0.000472 & -0.01766640 & 7.43838978 & 0.00422298 & -0.01813901 & 1. \\
\hline 140 & 0.14569028 & -0.02177989 & -0.000680 & -0.01462467 & 6.56972695 & 0.00305632 & -0.01430567 & $i$. \\
\hline 160 & 0.180 .53309 & -0.02560757 & -0.000941 & -0.01757625 & 5.60340214 & 0.00184434 & -0.02051765 & 1. \\
\hline 180 & 0.17543283 & -0.02962334 & -0.001259 & -0.02049713 & 4.55377198 & 0.00060506 & -0.02175693 & i. \\
\hline 200 & 0.16709068 & -0.03381852 & 0.001641 & -0.02136319 & 3.43645477 & -0.00064307 & -0.02300507 & i. \\
\hline 220 & 0.10189262 & -0.03 1 7971 & 0.002092 & -0.02215087 & 2.26805353 & -0.00188153 & -0.02424353 & . \\
\hline 240 & 0.15380719 & -0.04268892 & 0.002616 & -0.02283773 & 1.06593680 & -0.00309190 & -0.02545389 & \\
\hline 260 & 0.14480098 & -0.04732385 & -0.003215 & -0.02340310 & -0.15203559 & -0.00425620 & -0.02661820 & . \\
\hline 273 & 0.13845756 & -0.04994443 & -0.003581 & $0.020+6291$ & -0.94363463 & -0.00498010 & 0.01738189 & \\
\hline 274 & .13775691 & -0.05018258 & -0.003615 & -0.02378129 & -1.00434136 & -0.00503455 & -0.02739655 & \\
\hline 275 & 0.13745604 & -0.04997368 & -0.003585 & 0.02085841 & -1.06501102 & -0.00508880 & 0.01727319 & i. \\
\hline 276 & 0.13695511 & -0.05021288 & -0.003619 & -0.02388525 & -1.12565040 & -0.00514288 & -0.02750488 & \\
\hline 277 & 0.13645398 & -0.05000502 & -0.003589 & 0.02075495 & -1.18623829 & -0.00519676 & 0.01716523 & \\
\hline 279 & .13545569 & -0.05003905 & -0.003594 & -0.02407133 & -1.30728936 & -0.00530394 & -0.02766594 & $i$. \\
\hline 280 & 13675630 & & -0.003565 & 0.02056983 & -1.36773824 & -0.00535723 & 0.01100476 & \\
\hline 281 & 13445669 & -0.05007512 & -0.003599 & -0.02417253 & -1.42013611 & -0.00541032 & -0.02777232 & \\
\hline 282 & & -0.04987012 & -0.003570 & 0.02046915 & -1.48849034 & -0.00546322 & 0.01689877 & \\
\hline 283 & 13345697 & -0.05011319 & -0.003605 & $=0.02427264$ & -1.54877972 & -0.00551591 & -0.02787791 & \\
\hline & 13295683 & -0.04990920 & -0.003575 & 0.02036957 & -1.60901241 & -0.00556839 & $0.01679360^{\circ}$ & \\
\hline 285 & 0.13245648 & -0.05015326 & -0.003611 & -0.02437164 & -1.66919279 & -0.00562067 & -0.02798267 & \\
\hline 286 & 0.13195592 & -0.04995025 & -0.003581 & 0.02027111 & -1.72930288 & -0.00567274 & 0.01608925 & \\
\hline 287 & 0.13145515 & -0.05019529 & -0.003617 & -0.02446950 & -1.78934812 & -0.00572460 & -0.02808660 & \\
\hline 288 & 0.13095417 & -0.04999326 & -0.003588 & 0.02017378 & -1.84932709 & -0.00577624 & 0.01658575 & \\
\hline 289 & 0.13045299 & -0.05023927 & -0.003623 & -0.02456624 & -1.90924668 & -0.00582768 & -0.02818968 & 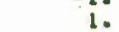 \\
\hline 290 & 0.12995156 & -0.05003819 & -0.003594 & 0.02007758 & -1.96908545 & -0.00587889 & 0.01648310 & \\
\hline 292 & 0.12895247 & -0.05008568 & -0.003601 & -0.02474135 & -2.08855105 & -0.00598067 & -0.02334266 & \\
\hline 293 & 0.12865259 & -0.04988636 & -0.0 & 0.01990348 & -2.14816380 & -0.00603122 & 0.01033077 & \\
\hline 294 & 0.1279524 & -0.050135 & -0.0 & -0.02483513 & -2.20769692 & -0.00608154 & -0.02364354 & \\
\hline 295 & 0.12745204 & -0.049936 & -0.0 & 0.01981025 & -2.26715612 & -0.00613165 & 0.01023034 & \\
\hline 296 & 0.12695142 & -0.05018629 & -0.0 & -0.02492 & -2.32652235 & -0.00618152 & $-0.02 \pm 54352$ & \\
\hline 297 & 0.1264505 & -0.04998 & -0.0 & 0.01971 & -2.38580179 & -0.00623117 & 0.01013082 & \\
\hline 298 & 0.1259493 & -0.05 & -0.0 & -0.02501914 & -2.44500208 & -0.00628059 & -0.02354259 & \\
\hline 299 & .125447 & -0.0 & -0.0 & & -2.50410 & -0.00632976 & 0.01603223 & \\
\hline 300 & 124948 & & $-0 . c$ & & -2.56310 & -0.00637871 & 0.01578 & - \\
\hline 301 & 0.124448 & & -0.0 & -0.02518 & -2.62202883 & -0.00642742 & -0.02978942 & \\
\hline 302 & 123948 & & -0.0 & 0.01946 & -2.68084335 & -0.00647589 & 0.01588610 & \\
\hline 303 & 0 & & -0.0 & -0.02527 & -2.73955727 & -0.00652411 & -0.02338611 & \\
\hline 304 & .122 & -0.0 & -0.003 & 0.01937 & -2.79816914 & -0.00657210 & 0.01578 & \\
\hline 305 & 0.12264673 & -0.0502 & -0.003620 & -0.02536157 & -2.85668612 & -0.00661984 & -0.02698184 & \\
\hline 306 & 0.12194550 & -0.050024 & -0.003592 & 0.01928713 & -2.91508770 & -0.00666733 & & \\
\hline 308 & 0.12094658 & -0.050087 & -0.003601 & -0.02552202 & -3.03157282 & -0.00676158 & -0.02712 & \\
\hline 309 & 0.12044665 & -0.04989583 & -0.003574 & 0.01912773 & -3.08964253 & -0.00 & 0.0155 & \\
\hline 310 & 0.11994637 & -0.05015225 & -0.003610 & -0.02560593 & -3.14759731 & -0.00685482 & -0.0272 & \\
\hline 311 & 0.11944578 & -0.04996152 & -0.003583 & 0.01904441 & -3.20544386 & -0.00690106 & 0.01546 & -1 . \\
\hline 312 & 0.11894486 & -0.05021877 & -0.003620 & -0.025688 & -3.26316214 & -0.00694704 & $-0.02+30$ & 1. \\
\hline 313 & 0.11844360 & & -0.003593 & 896237 & -3.32075930 & -0.00699276 & 0.0 & \\
\hline 315 & 0.11744454 & -0.05009847 & $\begin{array}{l}-0.00 \\
-0.00\end{array}$ & -0.0258422 & -3.43558932 & -0.00708343 & -0.02744543 & \\
\hline 316 & 0.11644405 & $\begin{array}{l}-0.04991009 \\
-0.05016967\end{array}$ & $\begin{array}{l}-0.003576 \\
-0.003613\end{array}$ & 0.0188097 & -3.44280930 & -0.00712837 & 0.01523362 & \\
\hline 317 & & -0.04998209 & $\begin{array}{l}-0.003613 \\
-0.003586\end{array}$ & -0.02592164 & -3.54990816 & & -0.0295 & \\
\hline 319 & 0.11544212 & -0.05024246 & $\begin{array}{l}-0.003586 \\
-0.003623\end{array}$ & $\begin{array}{r}0.01873097 \\
-0.02509909\end{array}$ & -3.60686636 & -0.00721745 & 0.01514454 & -1 \\
\hline & & & & & & -0.00726158 & -0.02902358 & \\
\hline
\end{tabular}

